\title{
Recent and prominent examples of nano- and microarchitectures as hemoglobin- based oxygen carriers
}

\author{
Jansman, Michelle M.T.; Hosta-Rigau, Leticia
}

Published in:

Advances in Colloid and Interface Science

Link to article, DOI:

10.1016/j.cis.2018.08.006

Publication date:

2018

Document Version

Peer reviewed version

Link back to DTU Orbit

Citation (APA):

Jansman, M. M. T., \& Hosta-Rigau, L. (2018). Recent and prominent examples of nano- and microarchitectures as hemoglobin-based oxygen carriers. Advances in Colloid and Interface Science, 260, 65-84.

https://doi.org/10.1016/j.cis.2018.08.006

\section{General rights}

Copyright and moral rights for the publications made accessible in the public portal are retained by the authors and/or other copyright owners and it is a condition of accessing publications that users recognise and abide by the legal requirements associated with these rights.

- Users may download and print one copy of any publication from the public portal for the purpose of private study or research.

- You may not further distribute the material or use it for any profit-making activity or commercial gain

- You may freely distribute the URL identifying the publication in the public portal

If you believe that this document breaches copyright please contact us providing details, and we will remove access to the work immediately and investigate your claim. 


\section{Accepted Manuscript}

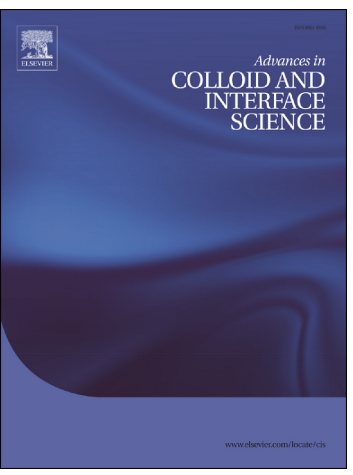

Recent and prominent examples of nano- and microarchitectures as hemoglobin-based oxygen carriers

Michelle M.T. Jansman, Leticia Hosta-Rigau

PII: $\quad$ S0001-8686(18)30206-9

DOI: $\quad$ doi:10.1016/j.cis.2018.08.006

Reference: $\quad$ CIS 1907

To appear in: $\quad$ Advances in Colloid and Interface Science

Please cite this article as: Michelle M.T. Jansman, Leticia Hosta-Rigau , Recent and prominent examples of nano- and microarchitectures as hemoglobin-based oxygen carriers. Cis (2018), doi:10.1016/j.cis.2018.08.006

This is a PDF file of an unedited manuscript that has been accepted for publication. As a service to our customers we are providing this early version of the manuscript. The manuscript will undergo copyediting, typesetting, and review of the resulting proof before it is published in its final form. Please note that during the production process errors may be discovered which could affect the content, and all legal disclaimers that apply to the journal pertain. 


\section{Recent and Prominent Examples of Nano- and}

\section{Microarchitectures as Hemoglobin-Based Oxygen}

\section{Carriers}

Michelle M. T. Jansman and Leticia Hosta-Rigau*

Department of Micro- and Nanotechnology, Centre for Nanomedicine and Theranostics, DTU

Nanotech, Technical University of Denmark, Building 423, 2800, Lyngby, Denmark 


\section{ABSTRACT}

Blood transfusions, which usually consist in the administration of isolated red blood cells (RBCs), are crucial in traumatic injuries, pre-surgical conditions and anemias. Although RBCs transfusion from donors is a safe procedure, donor RBCs can only be stored for a maximum of 42 days under refrigerated conditions and, therefore, stockpiles of RBCs for use in acute disasters do not exist. With a worldwide shortage of donor blood that is expected to increase over time, the creation of oxygen-carriers with long storage life and compatibility without typing and cross-matching, persists as one of the foremost important challenges in biomedicine.

However, research has so far failed to produce FDA approved RBCs substitutes (RBCSs) for human usage. As such, due to unacceptable toxicities, the first generation of oxygen-carriers has been withdrawn from the market. Being hemoglobin $(\mathrm{Hb})$ the main component of RBCs, a lot of effort is being devoted in assembling semi-synthetic RBCS utilizing $\mathrm{Hb}$ as the oxygen-carrier component, the so-called Hb-based oxygen carriers (HBOCs). However, a native RBC also contains a multi-enzyme system to prevent the conversion of $\mathrm{Hb}$ into non-functional methemoglobin (metHb). Thus, the challenge for the fabrication of next-generation HBOCs relies in creating a system that takes advantage of the excellent oxygen-carrying capabilities of $\mathrm{Hb}$, while preserving the redox environment of native $\mathrm{RBCs}$ that prevents or reverts the conversion of $\mathrm{Hb}$ into metHb. In this review, we feature the most recent advances in the assembly of the new generation of HBOCs with emphasis in two main approaches: the chemical modification of $\mathrm{Hb}$ either by cross-linking strategies or by conjugation to other polymers, and the $\mathrm{Hb}$ encapsulation strategies, usually in the form of lipidic or polymeric capsules. The applications of the aforementioned HBOCs as blood substitutes or for oxygen-delivery in tissue 
engineering are highlighted, followed by a discussion of successes, challenges and future trends in this field.

\section{KEYWORDS}

Encapsulation platforms; hemoglobin; hemoglobin-based oxygen carriers; red blood cells substitutes; oxygen delivery 


\section{INTRODUCTION}

Blood transfusions, which in most cases involve the administration of isolated red blood cells (RBCs), are crucial in several settings such as traumatic injuries (e.g., in accidents or natural disasters), in a pre-surgical context (e.g., transplants or trauma surgery) or for treatment of chronic and acute anemias.[1,2] Blood transfusion has been a routine and safe procedure over the last century since, under normal circumstances, donor blood is the best replacement for blood. However, blood transfusions from donors have some limitations and risks such as: a limited supply with a worldwide acute shortage that is expected to get worse due to an ageing population; [3] the need of typing and matching before RBCs can be transfused to patients due to the RBCs membranes blood group antigens, which can cause fatal delays in emergency situations; the short lifetime of RBCs by standard storage methods (one day stability when stored at room temperature and 42 days at $4^{\circ} \mathrm{C}$ ); or the fact that RBCs cannot be sterilized to remove infective agents such as hepatitis viruses, HIV and other potential emerging infective agents which could result in contaminated donor blood.[4]

The primary biological function of natural RBCs is to transport oxygen $\left(\mathrm{O}_{2}\right)$ from the $\mathrm{O}_{2}$-rich lungs to $\mathrm{O}_{2}$-poor tissues (Scheme 1Ai). Therefore, there is a significant clinical interest in creating synthetic analogues of RBCs, the so-called RBC substitutes (RBCSs), which can mimic the biological functions of natural RBCs while, simultaneously, overcoming some of its drawbacks. Unlike natural RBCs, RBCSs can be sterilized by pasteurization, ultrafiltration and other chemical means to remove microorganisms responsible for AIDS or hepatitis, amongst others, thus reducing biological risks. Furthermore, RBCSs do not possess RBC blood group antigens, eliminating the need for cross-matching or typing which saves time and facilities, a 
crucial factor in emergency situations. What is more, RBCSs can be readily lyophilized and stored for a long time in a dried powder form, which can be reconstituted with salt solution the moment is needed.[5,6] To this end, a large volume of research has been carried out in the area of synthetic RBCs.[1,7]

There are three main types of RBCSs that have undergone extensive preclinical and some clinical research, including perfluorocarbon (PFC)-based emulsions, iron $\left(\mathrm{Fe}^{2+}\right)$-containing porphyrins and hemoglobin (Hb)-based oxygen carriers (HBOCs). HBOCs make use of either bovine $\mathrm{Hb}$ or cell-free human $\mathrm{Hb}(\mathrm{hHb})$ from outdated blood. They take advantage of the excellent $\mathrm{O}_{2}$-carrying and releasing properties of $\mathrm{Hb}$ to create $\mathrm{RBCSs}$, and are the focus of this review. For a detailed overview of PFC-based emulsions and $\mathrm{Fe}^{2+}$-containing porphyrins, the reader is referred to excellent reviews on these fields.[1,8-10]

$\mathrm{Hb}$ is the main component of RBCs, but a RBC also contains a multi-enzyme system to prevent the conversion of $\mathrm{Hb}$ into non-functioning methemoglobin (metHb), as well as the allosteric effector 2,3-diphosphoglycerate (2,3-DPG), which promotes $\mathrm{O}_{2}$ release to the tissues.[4] Natural RBCs also carry out the important function of carbon dioxide $\left(\mathrm{CO}_{2}\right)$ transport from the tissues to the lungs for excretion. While around $20 \%$ of $\mathrm{CO}_{2}$ is carried by $\mathrm{Hb}$, the remaining $80 \%$ of $\mathrm{CO}_{2}$ is transported in the plasma as bicarbonate $\left(\mathrm{HCO}_{3}{ }^{-}\right)$. The conversion of $\mathrm{CO}_{2}$ into $\mathrm{HCO}_{3}{ }^{-}$is catalyzed in $\mathrm{RBCs}$ by the enzyme carbonic anhydrase (CA).[11]

$\mathrm{Hb}$ is a tetramer with two globular $\alpha$ and two globular $\beta$ polypeptide subunits $\left(\alpha_{1} \beta_{1} \alpha_{2} \beta_{2}\right)$, and each subunit contains a heme group consisting of a porphyrin ring structure with $\mathrm{Fe}^{2+}$ bound to the center (Scheme 1Aii). Each heme group is a single $\mathrm{O}_{2}$-binding site and, thus, each $\mathrm{Hb}$ molecule has the capacity to carry four $\mathrm{O}_{2}$ molecules. $\mathrm{Hb}$ is in the "oxy" state (oxy-Hb) when it carries $\mathrm{O}_{2}$, which is also known as the relaxed form of $\mathrm{Hb}$ (R-state), where it has a high $\mathrm{O}_{2}$ - 
affinity structure (Scheme 1Aiii). When $\mathrm{Hb}$ releases $\mathrm{O}_{2}$, it undergoes a conformational change to the "deoxy" state (deoxy-Hb), also known as the tense form of $\mathrm{Hb}$ (T-state), where the quaternary structure of $\mathrm{Hb}$ has low affinity towards $\mathrm{O}_{2}$ (Scheme 1Aiii). Diverse factors such as low $\mathrm{pH}$, high $\mathrm{CO}_{2}$ and high 2,3-DPG concentrations at the tissue level favor the T-state, which releases $\mathrm{O}_{2}$ into the tissues. Similarly, high $\mathrm{pH}$, low $\mathrm{CO}_{2}$ and low 2,3-DPG concentrations facilitate the R-state, where $\mathrm{Hb}$ prefers $\mathrm{O}_{2}$ binding. The amount of $\mathrm{O}_{2}$ bound to $\mathrm{Hb}$ at any time is related to the partial pressure of oxygen $\left(\mathrm{pO}_{2}\right)$ to which $\mathrm{Hb}$ is exposed. In the lungs, $\mathrm{pO}_{2}$ is typically high and $\mathrm{O}_{2}$ binds readily to $\mathrm{Hb}$ (R-state). As RBCs move to other body tissues with a lower $\mathrm{pO}_{2}, \mathrm{Hb}$ releases $\mathrm{O}_{2}$ into the tissue (T-state). The shape of the $\mathrm{O}_{2}$ dissociation curve (ODC) of $\mathrm{Hb}$ is sigmoidal (Scheme $1 \mathrm{~B}$ ), which results from the interaction of bound $\mathrm{O}_{2}$ with incoming $\mathrm{O}_{2}$ molecules. $\mathrm{Hb}$ 's affinity for $\mathrm{O}_{2}$ increases as successive molecules of $\mathrm{O}_{2}$ bind, due to an induced conformational change in its structure.[6] The p50 value refers to the $\mathrm{pO}_{2}$ at which $\mathrm{Hb}$ is $50 \%$ saturated with $\mathrm{O}_{2}\left(\mathrm{Hb}_{(\mathrm{p} 50)}=26.5 \mathrm{mmHg}\right)($ Scheme 1B).[12]

The transport of $\mathrm{O}_{2}$ requires $\mathrm{O}_{2}$ reversibly bound to ferrous $\mathrm{Hb}\left(\mathrm{Hb}\left(\mathrm{Fe}^{2+}\right)\right)$. Although oxy$\mathrm{Hb}\left(\mathrm{Fe}^{2+}\right)$ is a very stable molecule, it slowly auto-oxidizes to oxy- $\mathrm{Hb}\left(\mathrm{Fe}^{3+}\right)$, the so-called metHb,[13] which is unable to bind $\mathrm{O}_{2}$ and, furthermore, leads to dysregulated vascular tone and inflammatory reactions.[8] Thus, natural RBCs possess mechanisms to prevent or reverse the oxidative denaturation of $\mathrm{Hb}$ into metHb by making use of a multi-enzyme system that includes cytochrome- $b_{5}$ reductase, superoxide dismutase (SOD), glutathione peroxidase and catalase (CAT).[13-15]

Apart from the lack of an antioxidant multi-enzyme system and the allosteric effector 2,3DGP, $\mathrm{Hb}$ alone cannot be used for infusion in the body because, when outside the RBCs, the $\alpha_{1} \beta_{1} \alpha_{2} \beta_{2}$ tetramer breaks down into dimers $\left(\alpha_{1} \beta_{1}\right.$ and $\left.\alpha_{2} \beta_{2}\right)$ and monomers $\left(\alpha_{1}, \beta_{1}, \alpha_{2}, \beta_{2}\right)$ causing 
toxicity by means of several pathways (Scheme 1C).[4] One mechanism for the removal of extracellular oxy-Hb involves the plasma protein haptoglobin (Scheme 1C, 1).[16] Oxy-Hb dimers form complexes with haptoglobin which are subsequently recognized by the mononuclear phagocyte system (MPS), followed by macrophage endocytosis by the CD163 receptor and removal in the liver and spleen.[17] When large amounts of extracellular oxy-Hb are present, upon saturation of haptoglobin, the remaining oxy- $\mathrm{Hb}$ dimers and monomers get oxidized into metHb products (Scheme 1C, 2). This oxidation of oxy-Hb into metHb, a part of provoking the loss of the $\mathrm{O}_{2}$-carrying ability of $\mathrm{Hb}$, generates a series of free radicals and reactive oxygen species (ROS) such as superoxide radicals $\left(\mathrm{O}_{2}{ }^{\circ}\right)$ and hydrogen peroxide $\left(\mathrm{H}_{2} \mathrm{O}_{2}\right),[11,18-20]$ which subsequently react with nitric oxide (NO) converting it into nitrate $\left(\mathrm{NO}_{3}^{-}\right)$(Scheme $\left.1 \mathrm{C}, 3\right)$. Being NO a natural vasodilator, its depletion from the bloodstream generates vasoconstriction and the associated cardiovascular complications (e.g., myocardial infarction) and increased mortality.[21] Furthermore, $\mathrm{H}_{2} \mathrm{O}_{2}$ can oxidize both oxy- $\mathrm{Hb}$ and metHb into ferryl $\mathrm{Hb}\left(\mathrm{Hb}\left(\mathrm{Fe}^{4+}\right)\right)$ leading to the release of both the heme group and $\mathrm{Fe}^{4+}$ ions (Scheme 1C, 4).[20] While $\mathrm{Fe}^{4+}$ is sequestered by transferrin, the heme group binds to the plasma glycoprotein hemopexin (Scheme 1C, 5).[16,22] Next, the heme groups are released from hemopexin to be degraded in the liver while the hemopexin glycoprotein is recycled back.[22] When the plasma protein scavenging pathways are saturated, the oxy- $\mathrm{Hb}$ dimers and monomers will also start scavenging $\mathrm{NO}$ from the bloodstream, which will result in the formation of $\mathrm{NO}_{3}{ }^{-}$and the oxidized $\mathrm{Hb}$ products metHb and $\mathrm{Hb}\left(\mathrm{Fe}^{4+}\right)$ (Scheme 1C, 6). MetHb and $\mathrm{Hb}\left(\mathrm{Fe}^{4+}\right)$ will subsequently release the heme groups which will permeate into the endothelial cells lining the blood vessels generating an inflammatory response (Scheme 1C, 7).[23,24] Further accumulation of oxy-Hb in the bloodstream will be filtered out by the kidney glomeruli and reabsorbed by the tubules (Scheme 
1C, 8).[25] Overloading this system will result in oxidative damage and cell death within the kidneys. Additionally, upon dissociation of the oxy-Hb tetramer, the oxy-Hb dimers and monomers will be able to penetrate in between the endothelial cells lining the blood vessels due to their small size (Scheme 1C,9).[21,26] Following extravasation into the sub-endothelial layer, the oxy-Hb dimers and monomers can react again with $\mathrm{NO}$ present in the underlying smooth muscle cells which will result in conversion to metHb products together with $\mathrm{NO}_{3}^{-}$. This depletion of the NO present in the smooth muscle cells will cause endothelial dysfunction, irregular muscle functioning (e.g., vasoconstriction, contraction, and systemic hypertension) and intravascular platelet activation.[16,27] Platelet activation together with the vasoconstriction can, furthermore, cause blood clot formation.

Due to all the aforementioned toxic effects generated by the dissociation of $\mathrm{Hb}$ into dimers and monomers, the challenge when developing HBOCs lies in creating a system able to take advantage of the $\mathrm{Hb} \mathrm{O}_{2}$-carrying capabilities while avoiding dissociation of the $\mathrm{Hb}$ tetramer and preserving the redox environment of RBCs that minimizes the conversion of $\mathrm{Hb}$ into nonfunctional metHb and all the associated toxic effects. The research efforts to achieve this goal have so far gone through three different generations of HBOCs.[4,28] While the first generation focused on the polymerization or cross-linking of $\mathrm{Hb}$ to prevent tetramer dissociation and renal filtration, the second generation of HBOCs enhanced their functionality by incorporating antioxidant enzymes to minimize the conversion of $\mathrm{Hb}$ into non-functional metHb. While the first and second generations entail the Hb's chemical modification, the last or next generation of HBOCs involve the encapsulation of $\mathrm{Hb}$ within a synthetic membrane. In the next sections, we will review HBOCs with emphasis in recent examples from the last 2-3 years. The different approaches will be classified in the two main strategies that have been developed so far: the 
chemical modification of $\mathrm{Hb}$ (i.e., the first and second generation of HBOCs) or the encapsulation of $\mathrm{Hb}$ within a protective shell (i.e., the last generation of HBOCs) (Scheme 2). The different strategies will be further classified in nano or microarchitectures, depending on the size of the as-prepared HBOCs. It is important to note that, unless stated otherwise, the $\mathrm{Hb}$ employed to assemble the different HBOCs is from bovine descent.

\section{CHEMICAL MODIFICATIONS}

$\mathrm{Hb}$ cannot be administered alone due to its unacceptable short circulation times $(>6 \mathrm{~h})$ as well as to the associated toxicities due to the dissociation of the $\mathrm{Hb}$ tetramer. To overcome these drawbacks, several chemical modification approaches have been employed as a strategy.[1,4,21,29]

\subsection{Nanoarchitectures}

Mainly, three types of chemically modified $\mathrm{Hb}$ generating molecular structures in the nanorange have been developed to date: cross-linked $\mathrm{Hb}$, polymerized $\mathrm{Hb}$ and $\mathrm{Hb}$ conjugated to polymers (Table 1).

Intramolecular cross-linked $\mathrm{Hb}$ was the first approach to avoid dissociation of the tetramer by creating chemical cross-links between the $\alpha$ and $\beta$ chains of the tetramer, which gave rise to commercial products such as HemAssist (Baxter Healthcare Corporation, U.S.A.).[30] HemAssist, which consisted in diaspirin cross-linked $\mathrm{hHb}$, showed an increase in circulation time to up to $12 \mathrm{~h}$ (in contrast to $<6 \mathrm{~h}$ for native $\mathrm{Hb}$ ). [30] However, due to increased mortality rates in human patients as compared to the control group, all cross-linked Hb-based products have been discontinued.[10,31] 
Several bi-functional cross-linking reagents have also been used to polymerize $\mathrm{Hb}$. As such, glutaraldehyde (GA) and $o$-raffinose have been used to create different polyHb products. HemoPure (Biopure Corporation, U.S.A.), which consists ofHb polymerized by GA, is sold in South Africa to treat acute anemia and is the only FDA approved HBOC in the U.S.A. and Europe for veterinary use under the name of Oxyglobin (Biopure Corporation, U.S.A.).[32] Other polyHb products such as PolyHeme (hHb, Northfield Laboratories, Inc., U.S.A.)[33] or HemoLink (hHb, Hemosol BioPharma, Canada),[34] have been discontinued due to unacceptable toxicities.[10]

Finally, conjugation of $\mathrm{Hb}$ to other molecules has been considered as an approach to create HBOCs. As an example, $\mathrm{Hb}$ has been conjugated to polyethylene glycol (PEG) forming an $\mathrm{Hb}-$ polymer conjugate with reduced recognition by the MPS and with increased viscosity and osmotic pressure.[35] Some of the PEGylated products reached the market, such as Hemospan (hHb, Sangart, Inc., U.S.A.), Pyridoxalated Hemoglobin Polyoxyethylene (hHb, Apex Bioscience, U.S.A.), or PEG-Hb (Enzon, U.S.A.). However, these products have also demonstrated a statistical increase in the risk of death and myocardial infarction in the treatment groups,[36] and they have, therefore, been withdrawn from the market.[10]

Despite the disappointing outcomes of all these chemically modified $\mathrm{Hb}$ products, there are useful lessons to be learned from this first generation which can help to develop a safer HBOCs.[37] As an example, the vasoconstriction caused by the chemically modified Hb-based products has been partly attributed to the infiltration of modified $\mathrm{Hb}$ into the endothelium of blood vessels, probably due to incomplete cross-linking. This results in oxidative damage as well as in the scavenging of NO. Since NO is responsible for relaxation of the underlying smooth muscle,[25] NO removal causes potent microvascular vasoconstriction, which subsequently 
results in cardiovascular compromise (i.e., myocardial infarction) and increased mortality (Scheme 1C).[10,36,38-41]

It is also important to note that, despite having been withdrawn from the market, several polymerized $\mathrm{Hb}$ products (e.g., PolyHeme, Hemopure and Oxyglobin) induced limited NO sequestration as compared to unmodified $\mathrm{Hb}$. This fact is attributed to the increased particle size of polyHb, which limits its interaction with the vascular endothelium.[25] Similarly, polymerization of $\mathrm{Hb}$ with PEG (e.g., Hemospan) also produces larger particles as compared to cross-linked or free native $\mathrm{Hb}$ which, in turn, results in minimal vasoconstriction as well as longer circulatory half-lives.[10,42,43]

One of the current research directions towards the development of chemically modified HBOCs in the nano-range involves the conjugation of $\mathrm{Hb}$ with dextran (Dex). Since Dex is a natural, biocompatible, hydrophilic polymer which has the capacity to prevent thrombosis and shock, it is very attractive for the creation of HBOCs and has recently been employed for the fabrication of Hb-Dex conjugates.[44 46] Wang et al.[47] have recently developed an Hb-Dex conjugate of around $30 \mathrm{~nm}$ in diameter with lower oxidative toxicity as compared to other $\mathrm{Hb}$ polymer conjugates. Since one of the leading obstacles for the development of Hb-polymer conjugates is the fact that $\mathrm{Hb}$ can be easily oxidized to metHb, which results in oxidative stress and vasoconstriction, the authors prepared the Hb-Dex conjugate while protecting the critical moieties of the heme group. The rationale behind their approach lies in the fact that many of the reported Hb-polymer conjugates, including Hb-Dex but also hHb-PEG[48] and polyHb,[49] are prepared by modifying the thiol moiety of the amino acid residue Cys-93( $\beta$ ) which can unfavorably influence the heme pocket of the $\beta$ chain. This modification of the heme pocket increases the autoxidation rate, which subsequently increases the affinity towards $\mathrm{O}_{2}$ and 
significantly decreases the $\mathrm{p} 50$. Hb oxidation onto metHb causes a leftward shift in the ODC due to impaired metHb cooperativity.[50,51] Therefore, $\mathrm{Hb}$ was conjugated to Dex while protecting the Cys-93( $\beta$ ) residue. As expected, the Hb-Dex conjugates showed significantly higher hydrodynamic volume and higher viscosity than native $\mathrm{Hb}$. Furthermore, the authors could successfully demonstrate that protection of Cys-93( $\beta)$ played a critical role in decreasing the autoxidation rate of $\mathrm{Hb}$-Dex by comparing it to the autoxidation rate of the non-protected counterpart.

Also, making use of Dex to create Hb-polymer conjugates, Wei et al.[52] reported the synthesis of Dex-based nanogels. Nanogels are particularly well suited as $\mathrm{Hb}$ carriers their high water content which translates into high deformability, allows them to remain in circulation for extended amounts of time.[53] For the assembly of Hb-containing nanogels, the authors synthetized an amphiphilic graft co-polymer based on Dex, succinic anhydride (SA) and dopamine (DA) conjugated to $\mathrm{Hb}$ (Figure 1A). This Dex-SA-DA graft co-polymer could selfassemble into nanogels just by adjusting the $\mathrm{pH}$ to 2 . Next, the nanogels were cross-linked in situ employing sodium periodate to cross-link the DA moieties by oxidation. Finally, the Dex's moieties of the nanogels were functionalized with aldehyde groups to allow for Hb's conjugation via Schiff base reaction between the aldehydes of the functionalized Dex and the Hb's amino groups. Transmission electron microscopy (Figure 1B) and scanning electron microscopy (SEM) (Figure 1C) images showed that the Hb-nanogels (HbNGs) had a diameter of $260 \mathrm{~nm}$. It was possible to demonstrate the gas binding capacity of the HbNGs by UV-vis analysis (Figure 1D). The maximum absorption peak of HbNGs at different wavelengths when exposed to different gases, could shift reversibly. This fact demonstrates that the HbNGs are able to bind and release different gas ligands freely while retaining Hb's bioactivity. The $\mathrm{O}_{2}$ affinity of the HbNGs was 
assessed by an ODC and it revealed a p50 of about $14 \mathrm{mmHg}$, which indicates that the HbNGs exhibit a higher $\mathrm{O}_{2}$ affinity as compared to native $\mathrm{Hb}$ encapsulated within $\mathrm{RBCs}$ ( $\mathrm{p} 50=$ $26.5 \mathrm{mmHg}$ ). High $\mathrm{O}_{2}$ affinity (low p50) is an important feature for $\mathrm{HBOCs}$, since high $\mathrm{O}_{2}$ affinity avoids vasoconstriction caused by $\mathrm{O}_{2}$ oversupply in the precapillary arterioles. [54] Since $\mathrm{Hb}$ will slowly autoxidize into non-functional metHb, the authors also assessed the HbNGs halflife $\left(\mathrm{t}_{1 / 2}\right)$ (Figure 1E), showing that the HbNGs exhibited a similar $\mathrm{t}_{1 / 2}$ as native $\mathrm{Hb}$ at $37{ }^{\circ} \mathrm{C}$. In the same study, the authors also showed that the Dex-based HbNGs exhibited good biocompatibility as demonstrated by cell viability assays. It was also confirmed that the HbNGs do not interact with blood components and will, therefore, not cause a detrimental effect after being introduced in the bloodstream.

Dex has also been chosen as a component to create stimuli-responsive Hb-polymer conjugates by co-polymerizing it with poly( $N$-isopropylacrylamide) (PNIPAAm). PNIPAAm is one of the most prominent stimuli-responsive polymers reported to date since it displays a reversible phase transition with temperature in aqueous solution.[55,56] To create thermo-responsive Hb-polymer conjugates, Wang et al.[57] synthetized a Dex-graft-PNIPAAm (Dex-g-PNIPAAm) co-polymer that displayed a reversible change of solubility in response to temperature. Since above the lower critical solution temperature (LCST), which is $\sim 32{ }^{\circ} \mathrm{C}$, the PNIPAAm block experiences a transition from a hydrophilic to a hydrophobic conformation, the Dex-g-PNIPAAm co-polymer could self-assemble into stable micelles. The micelles, which were $\sim 100 \mathrm{~nm}$ in diameter, were composed of PNIPAAm as the hydrophobic core and Dex as the hydrophilic shell.[58] Incorporation of $\mathrm{Hb}$ into the co-polymer, which was conjugated to the Dex moieties of the copolymer, decreased the hydrodynamic diameter to $\sim 50 \mathrm{~nm}$. This fact could be attributed to the additional hydrogen-bonding interactions within the core. Interestingly, the authors demonstrated 
that, although at room temperature $(\mathrm{T}<\mathrm{LCST})$ the autoxidation rate of native $\mathrm{Hb}$ was much slower than the autoxidation rate of the Hb-Dex-g-PNIPAAm conjugates, when increasing the temperature to $\mathrm{T}>\mathrm{LCTS}$, the results were different. At $37^{\circ} \mathrm{C}(\mathrm{T}>\mathrm{LCTS})$, the autoxidation rate of native $\mathrm{Hb}$ was faster than the Hb-Dex-g-PNIPAAm conjugates. This result was explained by the authors by the fact that, when the polymer conjugates self-assembled into micelles, they provided a better protection to the oxy-Hb molecules, thus improving their stability in air.

On a very original study, $\mathrm{Bu}$ et al.[59] designed an $\mathrm{Hb}$-polymer conjugate functionalized with specific recognition moieties for cancer cells, which was designed for the treatment of hypoxia in tumors. The authors synthetized the amphiphilic block co-polymer poly[2-(methacrylamido) glucopyranose]-block-poly(methacrylic acid)-block-poly(butylmethacrylate) (PMAG-b-PMAAb-PBMA) where the first block consists of glucose units that are able to recognize cancer cells via the glucose transporter isoform 1 (GLUT1). Upon self-assembly of the amphiphilic polymer into micelles, $\mathrm{Hb}$ was conjugated to the PMAG- $b$-PMAA- $b$-PBMA polymer through a condensation reaction between the amino groups of $\mathrm{Hb}$ and the carboxyl groups of the PMAA block. The Hb-based micelles displayed a uniform size of $\sim 147 \mathrm{~nm}$. Importantly, the Hb-based micelles demonstrated excellent capacity for $\mathrm{O}_{2}$ binding, as shown by their UV-vis spectrum after being oxidized by $\mathrm{O}_{2}$ which displayed the characteristic oxy-Hb peak at $412 \mathrm{~nm}$, thus confirming the transformation of deoxy-Hb into oxy-Hb. Additionally, in vitro cell experiments showed high cell viability for both kidney cells (the control cell line) and cancer cells, therefore demonstrating the biocompatibility of the Hb-based micelles. In addition, the Hb-based micelles actively recognized cancer cells via GLUT1, as shown by the high cellular uptake of doxorubicin-loaded $\mathrm{Hb}$-based micelles by cancer cells as compared to kidney cells. These results demonstrate the potential of the Hb-based micelles in tumor therapy. 
Despite this progress in the development of $\mathrm{Hb}$-conjugates, all described products still lack the ability to regulate the autoxidation of oxy- $\mathrm{Hb}$. The oxidative state of the iron of the heme groups will unavoidably result in the irreversible conversion of oxy- $\mathrm{Hb}$ into metHb which, apart from not being able to deliver $\mathrm{O}_{2}$ at physiological $\mathrm{pO}_{2}$ tissue levels, also generates toxic free radicals.[10,20,60-62]

To prevent or reverse the conversion of oxy-Hb into metHb, natural RBCs contain antioxidant enzymes such as CAT and SOD. Thus, in an attempt to minimize metHb conversion, these enzymes have been cross-linked to polyHb to form polyHb-SOD-CAT conjugates.[63,64] The as-prepared conjugate was able to reduce the oxidative stress produced by ROS, thus demonstrating its potential in reducing oxidative damage in injured and ischemic tissues. $[8,65,66]$

Based on the previous approach and with the aim to create a RBCS with three augmented RBCs functions, namely $\mathrm{O}_{2}$ transport, $\mathrm{ROS}$ removal, and elimination of $\mathrm{CO}_{2}$, Bian et al.[67] employed polyHb where the $\mathrm{Hb}$ molecule was cross-linked to the antioxidant enzymes SOD and CAT, and also to the CA enzyme, which is responsible for the conversion of $\sim 80 \%$ of the $\mathrm{CO}_{2}$ into $\mathrm{H}_{2} \mathrm{O}$ and $\mathrm{HCO}_{3}{ }^{-}$. The polyHb-SOD-CAT-CA conjugate was synthetized by cross-linking SOD, CAT and CA to polyHb employing GA (Figure 2A). The authors chose to work with a derivative of polyHb since it has been previously shown that polyHb can delay the need for blood transfusion for up to 12 hours.[39] Furthermore, although polyHb has only been authorized for routine use in countries such as South Africa, where the side effects caused by polyHb are not considered as serious as compared to having HIV-contaminated donor blood or to not having donor blood at all, so far, polyHb is the only approved HBOC.[1,68] The authors conducted an in vivo study with a severe hemorrhagic shock rat model to which two thirds of the 
blood volume had been removed generating a mean arterial blood pressure (MAP) of only 30 mmHg. This was followed by the reinfusion of polymerized stroma-free hemolysate (polySFHb), polySFHb-SOD-CAT-CA, and several control solutions (sham control, blood, lactated Ringer's solution, polyHb, and polyHb-SOD-CAT) for 60 minutes (Figure 2B). The results demonstrated that the MAP decreased after reinfusion with the lactated Ringer's solution (ii, $43.3 \pm 2.8$ $\mathrm{mmHg}$ ), while was maintained after reinfusion with blood (iii, $91.3 \pm 3.6 \mathrm{mmHg}$ ), polyHb (iv, $82.6 \pm 3.5 \mathrm{mmHg}$ ), polySFHb (v, $85.0 \pm 2.5 \mathrm{mmHg}$ ), polyHb-SOD-CAT (vi, $86.0 \pm 4.6 \mathrm{mmHg}$ ), and polySFHb-SOD-CAT-CA (vii, $87.5 \pm 5 \mathrm{mmHg}$ ). Although there were no significant differences in the MAP when injecting polySFHb-SOD-CAT-CA, polyHb-SOD-CAT, polySFHb or polyHb, the authors also measured the partial pressure of $\mathrm{CO}_{2}\left(\mathrm{pCO}_{2}\right)$ upon applying the different resuscitation fluids (Figure 2C). The relevance of $\mathrm{pCO}_{2}$ has been demonstrated, since increasing levels of intracellular $\mathrm{pCO}_{2}$ are associated to a more severe myocardial ischemia[69] as well as to higher mortality rates.[70] Interestingly, the results showed that polySFHb-SOD-CAT-CA was able to reduce tissue $\mathrm{pCO}_{2}$ from $98.0 \pm 4.5 \mathrm{mmHg}$ to $68.6 \pm 3.0 \mathrm{mmHg}$ (Figure 2Cvii), demonstrating that polySFHb-SOD-CAT-CA was significantly more effective in reducing the $\mathrm{pCO}_{2}$ levels than all the other resuscitation fluids (lactated Ringer's solution (ii, $98.0 \pm 4.5 \mathrm{mmHg}$ ), blood (iii, $79.1 \pm 4.7 \mathrm{mmHg}$ ), polyHb (iv, $90.1 \pm 4.0$ $\mathrm{mmHg}$ ), polySFHb $(\mathrm{v}, 77.0 \pm 5.0 \mathrm{mmHg}$ ) and polyHb-SOD-CAT (vi, $90.9 \pm 1.4 \mathrm{mmHg})$ ). The authors also demonstrated that polySFHb-SOD-CAT-CA could be freeze-dried, pasteurized and stored for 320 days at room temperature, all of them crucial parameters to create successful RBCSs.

Another strategy employing enzymes to minimize oxidative stress and, therefore, the metHb conversion, was employed by Hathazi et al.[71] The authors conjugated $\mathrm{Hb}$ to the non-heme 
peroxidase rubrerythrin (Rbr), which is an enzyme with the ability to reduce $\mathrm{H}_{2} \mathrm{O}_{2}$ to $\mathrm{H}_{2} \mathrm{O}$ without involving free radicals or ferryl iron, which is usually formed in peroxidase and catalase reactions. Thus, with the aim of using a safer enzyme than heme-based peroxidases or catalases, the authors polymerized $\mathrm{Hb}$ with Rbr using GA to form polyHb-Rbr. UV-vis characterization showed that polyHb-Rbr accumulated significantly less $\mathrm{Fe}^{4+}$ than polyHb, thus demonstrating the ability of Rbr to protect against oxidative stress, which may result in reduced toxicity in vivo. Furthermore, cell viability studies using endothelial cells revealed slightly better performance of polyHb-Rbr as compared to polyHb, showing the potential for a better protective effect towards $\mathrm{Hb}$ autoxidation in vivo.

A different approach to avoid the toxic effects of polyHb was developed by Simoni et al. $[72,73]$ The authors reported a product named HemoTech, where $\mathrm{Hb}$ had been cross-linked intramolecular by adenosine-5'-triphosphate (ATP), intermolecular by adenosine and further combined with reduced glutathione (GSH). With this composition, ATP prevented $\mathrm{Hb}$ dimerization while regulating the vascular tone through purinergic receptors; adenosine promoted the polymerization of $\mathrm{Hb}$ while simultaneously counteracting the vasoconstrictive and pro-inflammatory properties of $\mathrm{Hb}$ by stimulating the adenosine receptors; and GSH shielded the heme group from NO and ROS while blocking Hb's extravasation and glomerular filtration by lowering its isoelectric point. Preclinical studies and an older clinical proof-of-concept study have already been performed, and the results suggest that HemoTech can work as an effective HBOC able to treat several conditions such as blood loss, anemia or ischemic vascular conditions.[72]

A very creative approach to minimize the conversion of oxy- $\mathrm{Hb}$ into metHb was developed by Tomita et al.[74] The authors employed a previously reported core-shell structure where $\mathrm{Hb}$ was 
located at the core and conjugated to human serum albumin (HSA) which was located in the periphery (Figure 3A1-2). The assembly was conducted by cross-linking the amino groups of the lysines on the Hb's surface to the free cysteines of HSA. The heterobifunctional cross-linker $N$ succinimidyl 4-( $N$-maleimidomethyl) cyclohexane-1-carboxylate was employed to conduct the reaction and three HSA molecules were conjugated to each Hb.[74] These Hb-(HSA) 3 nanoclusters are envisaged to have low risks of rapid clearance and extravasation, since HSA shows low permeability in the vasculature walls due to the electrostatic repulsion between the negatively charged HSA's surface and the negatively charged membrane of the endothelial cells.[75] An important consideration for this system is that flavin derivatives can bind strongly to the exterior of the HSA units of the core-shell structure (Figure 3Ai). The relevance of flavin derivatives lies in that they are electron mediators in biological systems and, upon being reduced by the co-factor nicotinamide adenine dinucleotide (NADH), they can act as reducing agents and convert metHb back to oxy-Hb (Figure 3B). The authors showed the reduction of metHb after addition of NADH using the flavin derivatives lumiflavin (LF) and flavin monocleotide (FMN) (Figure 3C). LF, which is smaller and more hydrophobic than FMN, binds more tightly into the HSA pocket and showed increased metHb reduction rates as compared to FMN. Another modification of these $\mathrm{Hb}-(\mathrm{HSA})_{3}$ core-shell nanoclusters where platinum nanoparticles (PtNPs) were embedded into the HSA pockets was also reported (Figure 3Aii).[76] PtNPs can perform SOD and CAT activities, since they can convert $\mathrm{O}_{2}{ }^{-}$into $\mathrm{H}_{2} \mathrm{O}_{2}$ plus $\mathrm{O}_{2}$, and $\mathrm{H}_{2} \mathrm{O}_{2}$ into $\mathrm{O}_{2}$ plus $\mathrm{H}_{2} \mathrm{O}$ and, as such, they have the ability to minimize the autoxidation of $\mathrm{Hb}$ to metHb. The results demonstrated higher CAT activities for the HSA-PtNP complexes as compared to the free PtNPs, marking the importance of the PtNP-protein complexes. Furthermore, metHb levels were measured for different $\mathrm{Hb}-(\mathrm{HSA})_{3}$ cluster combinations in aqueous $\mathrm{H}_{2} \mathrm{O}_{2}$ solutions (Figure 3D). 
Incorporation of PtNPs into the $\mathrm{Hb}-(\mathrm{HSA})_{3}$ nanoclusters showed good protection towards the oxidation of $\mathrm{Hb}$ as compared to the different controls. In a different study, the authors evaluated the potential of $\mathrm{Hb}-(\mathrm{HSA})_{3}$ nanoclusters as an $\mathrm{HBOC}$ in vivo.[77] The hemodynamic and pharmacokinetic properties were analyzed and compared to that of cross-linked $\mathrm{Hb}$ (XLHb). The authors first demonstrated that there was no unfavorable interaction between the $\mathrm{Hb}-(\mathrm{HSA})_{3}$ nanoclusters and the different blood components. Next, the potential of the $\mathrm{Hb}-(\mathrm{HSA})_{3}$ nanoclusters as HBOCs was investigated by analyzing the MAP after their injection in rats (Figure 3E). The results show that the injection of $\mathrm{Hb}-(\mathrm{HSA})_{3}$ nanoclusters displayed the same response as an HSA injection, which had a non-vasopressor effect, showing only slight MAP alternation after injection. In contrast, upon injection of XLHb an immediate increase in MAP was observed followed by urinary excretion only 10 minutes after injection. The circulation $\mathrm{t}_{1 / 2}$ was also investigated using iodine-125 labeling (Figure 3F). While XLHb had a $\mathrm{t}_{1 / 2}$ of only 0.53 hours, HSA had a $t_{1 / 2}$ of 11.0 hours, while $\mathrm{Hb}-(\mathrm{HSA})_{3}$ had a $\mathrm{t}_{1 / 2}$ of 18.5 hours. This increase in circulation time was ascribed to the increased size and negative surface charge of the $\mathrm{Hb}-(\mathrm{HSA})_{3}$ nanoclusters as compared to bare HSA. The in vivo studies also demonstrated that there were no negative side effects or toxic reactions in the major organs after injection. Other articles published using the same Hb-albumin core structure, but employing serum albumins from feline and canine origin, showed the potential of this HBOCs product for veterinary use.[78,79]

Despite the toxicities displayed by many of the chemically modified nano-sized HBOCs, which has resulted in the withdrawal from clinical trials and/or the market of most of the products, chemically modified HBOCs have been thoroughly studied and, as a result, we have learned several lessons from their shortcomings, which are now being addressed in the most recent studies. Promising results arise from the strategies that aim at limiting the autoxidation of 
$\mathrm{Hb}$ into metHb, thus decreasing the toxicity caused by ROS. However, although most of this new generation of chemically modified $\mathrm{HBOCs}$ with $\mathrm{Hb}$ protection towards oxidation have been extensively evaluated for their $\mathrm{O}_{2}$-binding capacity, redox properties and in vitro stability, rigorous in vivo studies are still needed in order to establish their in vivo applicability.

\subsection{Microarchitectures}

Parameters such as the shape, stiffness and surface chemistry strongly influence the particles circulation time.[80] For example, elongated or disc-shaped particles have shown to have longer circulation times as compared to their spherical counterparts, $[81,82]$ and carriers with high deformability which allows them to flow through small vesicles have also shown extended circulation times. $[83,84]$ However, the chemical modification of $\mathrm{Hb}$ renders spherical particles. When considering the size for spherical carriers it is noted that, while particles larger than $5 \mu \mathrm{m}$ can block the circulation at high concentrations, particles in the range of 1-3 $\mu \mathrm{m}$ can be strongly phagocytosed.[85,86] Therefore, for spherical HBOCs that are expected to be injected intravenously sizes in the submicron range are the preferred ones. Nonetheless, micron-sized particles can have applications in other fields that do not require intravenous administration such as tissue engineering (Table 1).[87,88]

Despite the fact that $\mathrm{Hb}$-based biomaterials are expected to have great potential in both in vitro tissue engineering and wound healing applications, the field is still in its infancy with few reports having been published to date. For in vitro tissue engineering, $\mathrm{O}_{2}$ delivery is a crucial parameter specially for the fabrication of large tissue analogues due to the "size-barrier effect", which hinders the transport of nutrients.[89] For in vivo wound closures, lowering the $\mathrm{O}_{2}$ tension during the regeneration process is a critical phenomenon affecting both the final architecture, as well as the functionality of the restored part. Therefore, the presence of a scaffold that releases $\mathrm{O}_{2}$ 
locally during a wound healing process would help to maintain suitable levels of tissue oxygenation.[90]

One of the most recent examples of chemically modified micron-sized HBOCs for tissue engineering applications was reported by Paciello et al.[91] The authors conjugated hHb to the surface of biocompatible and biodegradable gelatin microparticles (GM) with a size in the range of $75-150 \mu \mathrm{m}$, with the aim of producing an $\mathrm{Hb}$-based $\mathrm{O}_{2}$ depot (GM-Hb). For the GM-Hb preparation, two different conjugation strategies were employed to link the $\mathrm{Hb}$ molecules to the surface of the GMs (Figure 4A). The authors demonstrated that the conjugation strategy employed affected the adsorption and release of $\mathrm{O}_{2}$. When employing the first strategy (strategy 1, GM-Hb-1), $\mathrm{Hb}$ was conjugated to GM by means of the formation of a polyurethane linker while, when making use of the second strategy (strategy 2, GM-Hb-2), the conjugation took place via amide bond formation. To form the polyurethane linker in strategy GM-Hb-1, urethane functions through the use of $N, N^{\prime}$-disuccinimidyl carbonate (DSC) activation were employed,[92,93] since DSC is highly reactive toward primary amines and hydroxyls.[94] By using this method, $\mathrm{Hb}$ was conjugated to the surface of GMs without compromising the Hb's secondary structure. In contrast, to conduct strategy GM-Hb-2, 1-ethyl-3-(3dimethylaminopropyl)carbodiimide (EDC) chemistry was employed. EDC chemistry is known to induce the auto cross-linking of Hbs through amide bonds which, in turn, induces the formation of large Hb clusters.[95-97] Those large clusters affect the equilibrium between the R- and Tstate of the quaternary structure of $\mathrm{Hb}$. $[98,99]$ As a consequence the $\mathrm{O}_{2}$-binding and release properties, which are mediated by the structural changes of $\mathrm{Hb}$, could be compromised.

The functionality of GM-Hb-1 and GM-Hb-2 was evaluated by conducting $\mathrm{O}_{2}$-uptake/release experiments. For the $\mathrm{O}_{2}$ uptake experiments, the cell medium was oxygenated (initial $\mathrm{pO}_{2}=$ 
$100 \%, 0.21 \mathrm{~atm})$ and nitrogen $\left(\mathrm{N}_{2}\right)$-treated samples were loaded into the medium. The decay of the solution's $\mathrm{pO}_{2}$ was measured over time to analyze the $\mathrm{O}_{2}$ uptake by both GM-Hb-1 and GMHb-2 (Figure 4B). Even though GM-Hb-2 displayed a higher $\mathrm{Hb}$ content, the results demonstrated lower $\mathrm{O}_{2}$-absorption capacity for this strategy, a fact that could be explained by the steric hindrance for the $\mathrm{Hb}$ inner units due to the $\mathrm{Hb}$-cluster formation and the cross-links among the $\mathrm{Hb}$ subunits. Next, the solutions were treated with $\mathrm{N}_{2}$ (initial $\mathrm{pO}_{2}=0 \%$ ) and the $\mathrm{O}_{2}$ release from GM-Hb-1 and GM-Hb-2 was measured over time (Figure 4C). The results showed different release kinetics for the two different strategies, with $67 \%$ and $100 \% \mathrm{O}_{2}$ release with respect to the loaded $\mathrm{O}_{2}$ for GM-Hb-1 and GM-Hb-2, respectively (Figure 4B, 24 hours). Interestingly, the authors also demonstrated that GM-Hb-1 were able to work under repeated charge and discharge cycles. To assess the functionality of the GM-Hb-1 in a cellular context, the GM-Hb-1 were embedded within a disk-shaped collagen $3 \mathrm{D}$ cell culture. The setup allowed nutrients and $\mathrm{O}_{2}$ transport along the disk thickness $(2 \mathrm{~mm})$. After 48 hours of incubation, the 3D cell cultures were transversally cut and the cell viability was assessed by live/dead fluorescence staining (Figure 4D). Fluorescence microscopy images showed the living cells (green) and dead cells (red) throughout the cut section, demonstrating increased cell viability and proliferation rate in the cell culture loaded with GM-Hb-1 as compared to the control (spheres also showed in green). The cell viability fraction (Figure 4E) confirmed these findings, since GM-Hb-1 displayed good cell viability throughout the $3 \mathrm{D}$ cell culture after 48 hours. These results demonstrate the potential of the system to work as an $\mathrm{O}_{2}$ reservoir in $3 \mathrm{D}$ cell cultures to overcome the critical issue of the high $\mathrm{O}_{2}$ demand in the early stages of the fabrication of tissue analogues in vitro.[100]

Knirsch et al. also assembled Hb-loaded GM.[101,102] Although an application for such microparticles still remains to be identified, the authors managed to incorporate polyHb, which 
had been previously cross-linked making use of PEG bis( $N$-succynimidil succinate), into 1.37 $\mu \mathrm{m}$ gelatin microcapsules.

\section{ENCAPSULATION STRATEGIES}

In the body, native $\mathrm{Hb}$ is protected by the membrane of RBCs. This encapsulation strategy allows to entrap a multi-enzyme system able to avoid or reverse the conversion of $\mathrm{Hb}$ into metHb

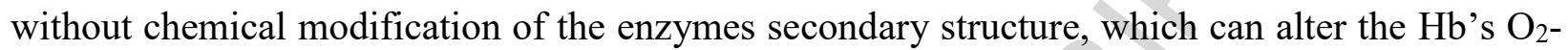
binding and releasing properties. Additionally, by enclosing $\mathrm{Hb}$ within a protective shell, $\mathrm{Hb}$ is prevented from both its rapid removal from circulation and from extravasation through the vessel walls. Encapsulation also reduces Hb's high viscosity and high colloidal osmotic pressure while protecting it from direct contact with surrounding tissues and blood components.[2,103] Therefore, due to the aforementioned advantages, several approaches have been investigated to encapsulate $\mathrm{Hb}$ within synthetic carriers.[10]

\subsection{Nanoarchitectures}

The advent of nanoparticle technologies has revolutionized the field of drug delivery by entrapping all kinds of active compounds within delivery vehicles, thus protecting the compounds from plasma-induced effects, increasing their circulation time and, furthermore, allowing for their sustained delivery to cells, tissues and organs. Naturally, the concept of encapsulation within nano-sized architectures has also been adapted to create HBOCs entrapping Hb within biomaterials-based carrier vehicles (Table 2).[8]

The concept of $\mathrm{Hb}$ encapsulation was first introduced by the Chang group[38,104] a few decades ago by making use of a double-emulsion-solvent evaporation technique, where Hb was entrapped within poly(lactic acid) (PLA), poly(lactic acid-co-glycolide) (PLGA), PLA-PEG, and 
poly(isobutyl cyanoacrylate) as matrix polymers. Essential enzymes that avoid the conversion of $\mathrm{Hb}$ into $\mathrm{MetHb}$, and $\mathrm{CA}$, which allows for $\mathrm{CO}_{2}$ transport, could also be entrapped within the polymeric shell.[38] Furthermore, the as-prepared polymeric particles had diameters that made them suitable for intravenous delivery $(70-200 \mathrm{~nm})$. However, they suffered from low encapsulation efficiency, a parameter that was later on improved by Meng et al.[105] by making use of a w/o/w double-emulsion-solvent-diffusion process, which yielded a $90 \% \mathrm{Hb}$ encapsulation efficiency.

In the following years, the concept of $\mathrm{Hb}$ encapsulation employing polymeric nanoparticles has been expanded to a wide range of polymer systems which usually involve the use of amphiphilic co-polymers such as poly( $\varepsilon$-caprolactone)-PLA (PCL-PLA), PCL-PEG, PEG-PLAPEG or PLGA-PEG co-polymers that self-assemble to form the so-called polymersomes.[106109] Polymersomes are considered as the synthetic analogues of liposomes, but with improved chemical and mechanical stability, since their membranes are significantly thicker than those of liposomes. Importantly, polymersomes offer more flexibility in the choice of several parameters such as the vesicle size, membrane thickness or drug-encapsulation efficiency. These parameters can be tuned by the right choice of the constituting polymers and a proper selection and adjustment of the polymers molecular weight and concentration. Furthermore, polymersomes can be designed to be both biocompatible and biodegradable.[110] The polymersomes surfaces can be functionalized with targeting moieties and they can also be composed of PEG polymers to further improve their in vitro stability, increase their in vivo bioavailability and prolong their circulation in blood.[110,111] The field of $\mathrm{Hb}$ encapsulation within polymeric vehicles has been continuously growing and, herein, we will illustrate the most up to date and appealing examples. 
$\mathrm{Lu}$ et al.[112] were the first to conduct in vivo $\mathrm{O}_{2}$ delivery of $\mathrm{Hb}$ encapsulated within a polymer shell. They fabricated nanoparticles made of PLGA-PEG. PEG was chosen as a copolymer due to its low fouling properties, which may create particles that evade the MPS system thus exhibiting longer circulation times, while PLGA was chosen due to its elastic modulus (which plays an important role in RBCs mimicking),[84] biodegradability, and biocompatibility.[113] The Hb-loaded PLGA-PEG nanoparticles were prepared by the double emulsion method. The authors conducted a thorough investigation of the composition of the organic solvent, the emulsifier and the ratio between co-polymer and $\mathrm{Hb}$ to optimize the system. The authors were then able to report Hb-loaded PLGA-PEG nanoparticles displaying sufficient and effective capacity for $\mathrm{O}_{2}$ supply, negligible leakage, blood compatibility, and a viscosity comparable to that of whole blood. What is more, the Hb-loaded PLGA-PEG nanoparticles were also evaluated in vivo and, by means of a controlled hemorrhage mice model, the authors demonstrated their efficiency in in vivo oxygenation. These results highlight the potential of the Hb-loaded PLGA-PEG nanoparticles in the biomedical field.

Hb-loaded polymer nanoparticles have also been employed to explore their potential in the treatment of ischemic tissue reperfusion in hemorrhagic shock. Li et al.[114] fabricated nanoparticles consisting of a hetero triblock co-polymer containing a hydrophilic PEG chain and hydrophobic biodegradable PCL and PLA chains. The authors synthetized a series of PEG-PCLPLA-PEG co-polymers by varying their molecular weights, followed by optimization of the polymer/Hb ratio. The as-prepared nanoparticles where $\sim 800 \mathrm{~nm}$ in size and had an $\mathrm{Hb}$ content comprising above $60 \%$ of the total dehydrated nanoparticles weight. Although the Hb dry weight content in natural RBCs is substantially higher $(\sim 90 \%)$, the Hb-loaded nanoparticles demonstrated undamaged $\mathrm{O}_{2}$-binding capacity and $\mathrm{O}_{2}$ affinity $(\mathrm{p} 50=21.6 \mathrm{mmHg}$ ). Furthermore, 
the authors explored the potential of this system in vivo to evaluate its efficacy on ischemia reperfusion injury by injecting the $\mathrm{Hb}$-loaded polymer nanoparticles into an acute anemia rat model. The results demonstrated that $\mathrm{Hb}$-loaded polymer nanoparticles were efficient in mitigating the lethal shock symptom and were also able to reduce short-term mortality.

Recent studies involving $\mathrm{Hb}$ encapsulation within polymeric nanoparticles include the work by Li et al.[115] With the aim to correlate the polymer composition with important parameters of HBOCs such as morphology, encapsulation efficiency, non-specific protein adsorption, $\mathrm{Hb}$ leakage or hemocompatibility, the authors conducted a study where $\mathrm{Hb}$ was loaded within polymer shells of three different compositions. In particular, PCL, PEG-block-poly(allyl glycidyl ether) (functionalized with mercaptopropionic acid)-block-PCL (PEG-PAGE(MPA)-PCL) and the blend of the two polymers, was studied. The results demonstrated that the amphiphilic PEGPAGE(MPA)-PCL co-polymers showed higher stability in blood and no interference with blood components as compared to the hydrophobic PCL. Both properties are a central prerequisite to avoid premature recognition by the MPS system. The authors also conducted a thorough study to identify the emulsification parameters that allow to maintain the bioactivity of $\mathrm{Hb}$, since it is well known that Hb's functionality can be damaged by mechanical forces, or by the existence of an oil/water interface.[116] The authors demonstrated that both a reduced emulsification speed together with a suitable organic solvent such as ethyl acetate, could maintain the quaternary structure and subsequent functionality of the encapsulated $\mathrm{Hb}$.

On a very creative work, Wang et al.[117] encapsulated $\mathrm{Hb}$ within a polydopamine (PDA) shell. DA polymerizes at basic conditions $(\mathrm{pH}>7.5)$ and in the presence of $\mathrm{O}_{2}$ to form PDA, which can deposit onto virtually any substrate independent of size and shape.[118] The structure of PDA consists of a mixture of DA and indole units at various oxidation states.[119] However, 
the bulk of the PDA structure consist of indole units, since ring closure of the aminoethyl chain takes place upon oxidation. The DA and indole units polymerize at their benzo moiety into PDA oligomers, which are subsequently stacked using hydrogen bonds, $\pi-\pi$ stacking and charge transfer.[119,120] Unlike the previously reported chemically-modified strategies, PDA has barely any chemical reaction with functional groups of $\mathrm{Hb}$, thus preserving $\mathrm{Hb}$ 's structure and activity.[117,118] PDA holds great promise in biomedical applications due to its excellent hemoand biocompatibility since, PDA coatings, have demonstrated to preserve the viability or proliferation of many kinds of mammalian cells, and have also shown to not promote tissue damage, inflammation or fibrosis.[121-123] Furthermore, PDA also holds a redox character by means of its quinone groups due to the release of electrons during the spontaneous oxidation process of the different PDA constituting oligomers.[118] By coating Hb with a PDA shell, the authors aimed to endorse $\mathrm{Hb}$ with oxidative protection towards the conversion of $\mathrm{Hb}$ into nonfunctional metHb (Figure 5A). Using a $\mathrm{Fe}^{3+}$ reducing antioxidant power assay, it was shown that PDA-Hb has the ability to reduce $\mathrm{Fe}^{3+}$ into $\mathrm{Fe}^{2+}$ (absorbance at $598 \mathrm{~nm}$ ), while $\mathrm{Hb}$ does not have this ability (Figure 5B). The authors also showed that PDA-Hb nanoparticles were efficient in scavenging 2,2-azino-bis(3-ethylbenzthiazoline-6-sulfonic acid) (ABTS ${ }^{+}$) and 2,2-diphenyl-1picrylhydrazyl (DPPH) radicals, as shown by their respective radical-scavenging assays. The amount of $\mathrm{ABTS}^{+}$radicals (absorbance at $734 \mathrm{~nm}$ ) decreased in presence of Hb-PDA (Figure 5C). Similarly, a decrease in absorbance at $520 \mathrm{~nm}$, which is the characteristic wavelength of the DPPH radical, was shown in the presence of Hb-PDA (Figure 5D). No decrease in absorbance at $520 \mathrm{~nm}$ is observed for DPPH radical incubated with $\mathrm{Hb}$ only, thus demonstrating the capabilities of PDA to scavenge radicals. The authors also demonstrated exceptional ROS scavenging properties in vitro by $\mathrm{Hb}-\mathrm{PDA}$, a very important feature since, ROS such as $\mathrm{H}_{2} \mathrm{O}_{2}$, 
would be generated by $\mathrm{Hb}$ during its autoxidation to metHb.[20] Cardiomyoblasts were prematurely damaged with $\mathrm{H}_{2} \mathrm{O}_{2}$ to generate intracellular ROS, after which the cells were incubated with PDA-Hb particles. The fluorescent probe dichlorofluorescein-diacetate, which is able to permeate through the cells and is subsequently converted into the fluorescent dichlorofluorescein product (DCF) by ROS-mediated oxidation, was monitored by fluorescence microscopy and flow cytometry (Figure 5E). Cells treated with PDA-Hb showed weaker fluorescent intensity signal, demonstrating their ability to suppress the intracellular $\mathrm{H}_{2} \mathrm{O}_{2}$ induced ROS. In a follow-up study,[124] the authors employed the PDA coating to diminish the effect of $\mathrm{H}_{2} \mathrm{O}_{2}$-induced apoptosis. By monitoring fluorescence intensity readings the authors demonstrated the suppressive effect of $\mathrm{Hb}$-PDA on $\mathrm{H}_{2} \mathrm{O}_{2}$-induced apoptosis, which had been previously induced through changes in the membrane potential of mitochondria. Furthermore, the authors were also able to show that the PDA layer thickness did not affect the $\mathrm{O}_{2}$-release capacity. Lastly, Wang et al. demonstrated that the PDA-Hb particles had a high $\mathrm{O}_{2}$ affinity (p50 $=13.86 \mathrm{mmHg}$ ), low interaction with blood components and low cytotoxicity, thus making them good candidates as HBOCs.

While in the previous examples the Hb-loaded polymer nanoparticles have been prepared by the self-assembly of amphiphilic co-polymers (except for the PDA-coated $\mathrm{Hb}$ ), the Layer-byLayer (LbL) assembly technique, which consists on the deposition of alternating interacting polymers onto a (sacrificial) template, allows for the fabrication of hollow capsules or core-shell particles with specific shapes, sizes, material compositions and functionality.[125-128] As such, this technique has also been employed to prepare Hb-based hollow capsules and particles. One of the most recent examples was reported by Chen et al.[129] who created Hb- and CAT-loaded nanotubes to combat oxidative stress. The authors claimed advantages of using nanotubes as 
compared to nanospheres. For instance, by making use of nanotubes several functionalities can be introduced independently by functionalizing the inner and the outer surface,[130] while the open-end terminals allow for quick loading. Furthermore, nanotubes have a longer circulating time than spherical particles in the bloodstream.[81,131] The Hb-based nanotubes were prepared by the alternating deposition of $\mathrm{Hb}$ and dialdehyde heparin (DHP), which interact by covalent binding, onto a polycarbonate (PC) membrane which was removed at the end of the assembly to render hollow nanotubes. After removal of the PC membrane, the CAT enzyme was introduced by using DHP as the cross-linker to covalently attach the enzyme (Figure 6A).[129] CAT was attached to the inner part of the nanotubes in order to be protected from the external environment, and ( $\mathrm{Hb} / \mathrm{DHP})_{5}-\mathrm{CAT}$ nanotubes were obtained. Interestingly, $\mathrm{Hb}$ was not used to transport $\mathrm{O}_{2}$, but to scavenge radicals instead. It has also been demonstrated that $\mathrm{Hb}$ overexpression suppresses oxidative stress in pathological cells due to the Hb's ability to attenuate $\mathrm{H}_{2} \mathrm{O}_{2}$-induced oxidative stress by acting as an antioxidative peroxidase.[132] Additionally, the $(\mathrm{Hb} / \mathrm{DHP})_{5}-\mathrm{CAT}$ nanotubes displayed autofluorescence capacity after excitation at 405 and $488 \mathrm{~nm}$, where the nanotubes showed fluorescence at 460-490 nm (Figure 6B), at $510-540 \mathrm{~nm}$ (Figure 6C), and at 570-600 nm (Figure 6D), thus allowing them to be detected and tracked without having to conjugate them to any external fluorophore. This autofluorescence was attributed to the $\mathrm{n}-\pi^{*}$ transition of $\mathrm{C}=\mathrm{N}$ bonds between the amino groups of $\mathrm{Hb}$ and the aldehyde groups of DHP. The authors evaluated the ability of (Hb/DHP) ${ }_{5}$-CAT nanotubes to remove $\mathrm{H}_{2} \mathrm{O}_{2}$ in vitro by assessing the cell viability under oxidative stress. Liver cells were cultured in the presence of different concentrations of $\mathrm{H}_{2} \mathrm{O}_{2}$, with or without $(\mathrm{Hb} / \mathrm{DHP})_{5}$-CAT nanotubes, and the results demonstrated a higher cell viability for the cells cultured in the presence of the nanotubes (Figure 6E). 
Lastly, efforts have also been made to encapsulate $\mathrm{hHb}$ within lipidic vesicles ( $\mathrm{HbV})$, commonly known as liposomes, which already started being investigated in the 1980s.[133-135] hHb-loaded liposomes have shown longer circulation times ( $\sim 24$ hours) than free $\mathrm{Hb}(>6$ hours).[136,137] This circulation time can be further dramatically increased by PEGylating their surface (up to 65.2 hours and up to 72 hours in rabbits and monkeys, respectively).[138-140] Surface functionalization with PEG further augments the liposomes hemodynamic properties as well as their biocompatibility.[139,141-143] Liposomes have shown to be able to encapsulate $\mathrm{Hb}$ with almost the same $\mathrm{O}_{2}$ affinity as native $\mathrm{RBCs}(\mathrm{p} 50=28 \mathrm{mmHg})$, a fact that can be attributed to the liposomes biomimetic phospholipid bilayer membrane which resembles natural RBCs membranes.[144] Also, Hb entrapment within liposomes reduces the NO scavenging, thus diminishing the vasoconstriction effects and it also prevents glomerular clearance of $\mathrm{Hb}$, subsequently reducing renal toxicity.[2,136] Additionally, liposomes can have shelf-storage lives of two to three years in liquid state (under $\mathrm{N}_{2}$ ) and even longer when freeze-dried.[1,144] Since the early days in the 1980s, Hb-loaded liposomes have undergone considerable research in preclinical animal models for potential use as RBCSs in several fields, including transfusion and resuscitative approaches in perioperative settings, hemorrhagic shock and hemodilution incidents, oxygenation of ischemic tissues and in transplantation of tissues and organs.[2,10,136,139,141,145] The current optimized $\mathrm{HbV}$ product, aside from having an $\mathrm{O}_{2}$ affinity similar to that of $\mathrm{Hb}$ in $\mathrm{RBCs}$, has an extremely high $\mathrm{Hb}$ concentration $\left(\mathrm{hHb}=10 \mathrm{~g} \mathrm{dL} \mathrm{L}^{-1}\right.$, lipids $\left.=6 \mathrm{~g} \mathrm{dL}^{-1}\right)$ which is similar to the $\mathrm{Hb}$ concentration in native RBCs $\left(14 \mathrm{~g} \mathrm{dL}^{-1}\right) \cdot[2,136]$ HbVs contain about $30000 \mathrm{Hb}$ molecules encapsulated within one PEGylated liposomal vesicle of $\sim 250 \mathrm{~nm}$ in diameter (RBCs contain 250 million Hb molecules).[2,136] Research is currently being conducted towards improving Hb-loaded liposomes for potential clinical 
translation.[2,146-148] Recent advances in the development of Hb-loaded liposomes include the usage of a non-phospholipidic anionic lipid to increase the $\mathrm{Hb}$ encapsulation efficiency and to reduce the host immune response to liposomes containing anionic phospholipids.[149] Utilizing the novel non-phospholipid amphiphilic hexadecylcarbamoyl-methylhexadecanoate-conjugated PEG of 2000 Da to further improve the liposomes tolerance against host immune response, has also been explored.[150-153] A very recent example of HbVs development was reported by Yadav et al., who prepared $\mathrm{HbVs}$ constituted by dipalmitoylphosphatidylcholine (DPPC), anionic $N_{1}$-(2-aminoethyl)- $N_{4}$-hexadecyl-2-tetradecyl succinamide (HDAS), cholesterol, vitamin E, and HDAS-PEG (2000 Da).[152-154] The vesicles were $215 \mathrm{~nm}$ in size (Figure 7A), contained $7.2 \mathrm{~g} \mathrm{dL}^{-1}$ of $\mathrm{hHb}$ and displayed a p50 of $31.9 \mathrm{mmHg}$. The authors induced a hemorrhagic shock into rats by removing $45 \%$ of their blood volume and measured different parameters before shock (baseline), immediately after inducing the hemorrhagic shock, after 6 hours of hemorrhagic shock (HS) and after resuscitation with saline or the as-prepared HbVs. While the heart rate, MAP, and corticosterone (a stress indicator) levels showed no significant difference between saline and $\mathrm{HbVs}$ resuscitation, a difference in tissue inflammation and toxicity could be observed for the different resuscitation fluids. Cardiac dysfunction was measured using cardiac troponin, a specific marker for cardiac injury; skeletal muscle metabolism was measured by an isoform of troponin, which is only generated by skeletal muscle injury; renal insufficiency was measured by creatinine, which is normally removed by glomerular filtration; and lastly, liver injury was investigated using the plasma levels of alanine transaminase (ALT), which is a marker for hepatic parenchyma injury, and the scavenger receptor CD163, indicating the activation of the Kupffer cells in the MPS. For the cardiac and muscle dysfunction, both saline and $\mathrm{HbV}$ resuscitation fluids could reduce the troponin 
concentrations to similar concentrations as before inducing hemorrhagic shock (control) (Figure 7B-C). In contrast, for the renal insufficiency, $\mathrm{HbV}$ resuscitation could reduce the creatinine levels, while the saline solution still had a significant difference with the HS (Figure 7D). Additionally, a significant decrease in both ALT and CD163 was observed when administering HbVs as compared to the saline control (Figure 7E-F). Thus, these results demonstrate both lower renal insufficiency and liver injury when $\mathrm{HbVs}$ were employed as resuscitation fluids as compared to the saline control, demonstrating the potential of $\mathrm{HbVs}$ acting as an $\mathrm{O}_{2}$ carrier able to prevent tissue inflammation and toxicity.

Although these studies have shown significant potential for $\mathrm{HbVs}$ working as RBCSs, liposomes still present several shortcomings such as a broad size distribution, variations in $\mathrm{Hb}$ encapsulation efficiencies, variable pharmacokinetics, and variable clearance profiles by the MPS.[1,2,147,148,155] Other important drawbacks of liposomes as RBCSs include the fact that phospholipids are expensive and, furthermore, they may induce peroxidation in ischemia reperfusion injuries. Additionally, the lipid bilayer membrane is impermeable to some reducing agents present in the circulating blood that are crucial to avoid or minimize the conversion of $\mathrm{Hb}$ into metHb.[38,103,156]

\subsection{Microarchitectures}

The concept of encapsulating $\mathrm{Hb}$ within a microparticle was presented as early as the 1960s and 1970s by the Chang group.[157-159] The authors encapsulated not only Hb, but also relevant enzymes present in native RBCs such as CAT or CA, within a polymeric microparticle which was first made of collodion (cellulose nitrate) and later changed to PEG-PLA.[157] These Hb-loaded microcapsules showed a similar ODC as $\mathrm{Hb}$ enclosed within native RBCs and also retained the enzymatic activity of the entrapped enzymes.[157,158] However, one of the main 
shortcomings of these microarchitectures was their rapid removal from blood circulation by the MPS.[8]

Recent examples to construct micron-sized architectures encapsulating $\mathrm{Hb}$ involve the fabrication of hollow microcapsules employing the LbL technique which include the alternate deposition of $\mathrm{Hb}$ and GA, which interact through covalent interactions, onto PLGA particles or polystyrene microparticles.[84,103] In another study, Hb-based microcapsules were prepared by the deposition onto sacrificial manganese carbonate templates of alternating layers of $\mathrm{Hb}$ and DHP which interact covalently.[160] In this work, DHP was used both as one of the wall components but also as a cross-linker to avoid the use of the toxic GA cross-linker. Similarly to the $(\mathrm{Hb} / \mathrm{DHP})_{5}$-CAT nanotubes described in section 3.1, these Hb/DHP capsules where also fluorescent, a feature attributed to the $n-\pi^{*}$ transition of $C=N$ bonds due to the Schiff base reaction between the Hb/DHP multilayers.[161] This property could be very favorable to track and monitor the Hb-capsules without the need to attach foreign fluorochromes.

So far, all the previously reported $\mathrm{Hb}$ encapsulating systems display a spherical morphology, however, it is noted that native RBCs possess a biconcave discoid morphology, with a diameter of $\sim 7 \mu \mathrm{m}$ and a thickness of $\sim 2 \mu \mathrm{m}$, and are also highly flexible (with a Young's modulus of $\sim 26$ $\mathrm{kPa}$ ).[162,163] These properties allow RBCs to change both their shape and morphology when passing through the microvascular circulation.[164,165] Oxy-Hb renders RBCs significantly more deformable than deoxy-Hb, a fact that enables RBCs to pass through the microvasculature transporting $\mathrm{O}_{2}$. Also, the size, shape and deformability of RBCs are known to influence their hemodynamic distribution in the blood flow. While in mid to large vessels the RBCs flow in the center of the parabolic flow field, in small vessels and capillaries RBCs are distributed throughout the vessels for efficient $\mathrm{O}_{2}$ exchange.[8,166,167] Thus, in recent years a substantial 
amount of effort has been devoted in mimicking not only the functionality but also the structure of native RBCs, since both parameters are highly interconnected.

First attempts in mimicking the biconcave RBC-shaped structure of native RBCs were conducted by Doshi et al.,[84] who made use of templates with a biconcave RBC-shaped structure. In particular, the authors employed PLGA particles of $\sim 1 \mu \mathrm{m}$ diameter and $400 \mathrm{~nm}$ of shell thickness, which were subsequently collapsed into biconcave spheres with a diameter of $\sim 7$ $\mu \mathrm{m}$. The authors coated the PLGA templates by the alternating deposition of $\mathrm{hHb}$ and bovine serum albumin (BSA), which interact via electrostatics. After PLGA core removal, RBC-shaped, Hb-based capsules were obtained.

Alternatively, Yu et al.[168] prepared RBCs-shaped microparticles by co-precipitation of Dex together with $\mathrm{Hb}$ and calcium hydroxide $\left(\mathrm{Ca}(\mathrm{OH})_{2}\right)$, followed by GA cross-linking (Figure 8A). The as-prepared microparticles exhibited a biconcave discoidal morphology and a size of $\sim 6.5$ $\mu \mathrm{m}$. SEM images show pure $\mathrm{Ca}(\mathrm{OH})_{2}$ particles are hexagonal prismatic crystals in shape (Figure 8B), while upon addition of Dex and $\mathrm{Hb}$ during the reaction process, particles with a biconcave discoidal morphology are obtained (Figure 8C). The $\mathrm{Hb}$ content in the microparticles corresponded to the $68 \%$ of the $\mathrm{Hb}$ content in native $\mathrm{RBCs}$. The carrying-releasing $\mathrm{O}_{2}$ properties of the microparticles were studied employing UV-vis absorption and electrochemical techniques. The UV-vis absorbance spectrum (Figure 8D) of the as-prepared $\mathrm{Ca}(\mathrm{OH})_{2}-\mathrm{Hb}$ microparticles treated with $\mathrm{O}_{2}$ displayed the three characteristic peaks of oxy-Hb, namely, at $406 \mathrm{~nm}$ (the Soret peak) and at $540 \mathrm{~nm}$ and $578 \mathrm{~nm}$. After $\mathrm{N}_{2}$ treatment, as expected, the Soret peak shifted to 429 $\mathrm{nm}$ and a single peak appeared at $558 \mathrm{~nm}$, which corresponds to the characteristic deoxy-Hb peaks. The $\mathrm{O}_{2}$ uptake and release by $\mathrm{Ca}(\mathrm{OH})_{2}-\mathrm{Hb}$ was further investigated using differential pulse voltammetry (DPV) and cyclic voltammetry. The DPV results (Figure 8E) show 
microparticles carrying and releasing $\mathrm{O}_{2}$ for five consecutive cycles. The values were normalized (normalized ratio $=$ DPV peak current of $\mathrm{N}_{2}$ or $\mathrm{O}_{2}$ treatment / DPV peak current of initial $\mathrm{N}_{2}$ saturation treatment) and showed that the microparticles displayed a better $\mathrm{O}_{2}$-binding reversibility as compared to free $\mathrm{Hb}$ which, the authors speculate, could be due to the high $\mathrm{Hb}$ encapsulation efficiency within the microparticles. Furthermore, even though a slight decrease in $\mathrm{O}_{2}$ uptake was observed throughout the cycles, the $\mathrm{Ca}(\mathrm{OH})_{2}-\mathrm{Hb}$ microparticles showed 7 times higher values of $\mathrm{O}_{2}$ uptake as compared to free $\mathrm{Hb}$ after the five cycles. Additionally, the authors demonstrated that the $\mathrm{O}_{2}$-binding and releasing properties were maintained at different temperatures, ranging from $5{ }^{\circ} \mathrm{C}$ to $50{ }^{\circ} \mathrm{C}$.

Worth mentioning in this context is the work by Duan et al.[169] who fabricated Hb-based microparticles for a different purpose than the synthesis of RBCSs. Their study was aimed at removing uranyl ions $\left(\mathrm{UO}_{2}{ }^{2+}\right)$, an important radionuclide, from radiation-contaminated blood. The contamination of blood by $\mathrm{UO}_{2}{ }^{2+}$ is attributed to the high binding coordination as well as to the electrostatic interactions of $\mathrm{Hb}$ with $\mathrm{UO}_{2}{ }^{2+}$. With the aim to eliminate $\mathrm{UO}_{2}{ }^{2+}$ from blood, the authors fabricated magnetic $\mathrm{Hb}$ microparticles employing iron oxide $\left(\mathrm{Fe}_{3} \mathrm{O}_{4}\right)$-loaded porous calcium carbonate $\left(\mathrm{CaCO}_{3}\right)$ particles. The particles were subsequently coated by the LbL technique with alternating layers of $\mathrm{Hb}$ and dialdehyde PEG which interact covalently to create $\mathrm{CaCO}_{3}-(\mathrm{Hb} / \mathrm{PEG})_{5}$ microparticles (Figure 9A).[169] The magnetic properties of $\mathrm{Fe}_{3} \mathrm{O}_{4}$ facilitated the trapping of the Hb-based microparticles from blood with the help of a magnet (Figure 9B). The $\mathrm{Hb} / \mathrm{PEG}$ layers increased the capacity of $\mathrm{UO}_{2}{ }^{2+}$ loading as compared to bare $\mathrm{Fe}_{3} \mathrm{O}_{4}$-loaded particles from $5 \%$ to up to $90 \%$ (Figure 9C), which showed that the capacity to adsorb $\mathrm{UO}_{2}{ }^{2+}$ is mainly due to the $\mathrm{Hb}$ coating, demonstrating the high affinity of $\mathrm{Hb}$ towards $\mathrm{UO}_{2}{ }^{2+}$. 
Another recently adopted approach to prepare polymeric HBOCs is the Shirasu porous glass (SPG) membrane emulsification technique.[170,171] Lai et al.[172] were the first to employ the SPG technique to prepare emulsion droplets containing bovine $\mathrm{Hb}$ and BSA, which were crosslinked by GA. The authors employed the SPG technique since, by means of the narrow pore-size distribution of the SPG membrane, it enables the preparation of monodispersed and sizecontrolled emulsions that can be obtained in $1 \mu \mathrm{m}$ increments.[170,173] The microparticles had a diameter of 4-5 $\mu \mathrm{m}$ and showed to be biocompatible, as demonstrated by a cell viability assay with a liver cancer cell line. Furthermore, the authors conducted an ODC of the Hb-based microparticles which was left shifted as compared to the ODC of native $\mathrm{Hb}$, thus indicating an increase in $\mathrm{O}_{2}$ affinity for the SPG microparticles.

Since one of the main challenges in tissue engineering is to achieve sufficient $\mathrm{O}_{2}$ supply for regeneration of a compelling amount of tissue,[174] the authors also evaluated the potential of the as-prepared $\mathrm{Hb}$-BSA microparticles for tissue engineering applications.[175] Employing HBOCs for tissue engineering purposes is of special relevance for liver cells, since they have a high demand for $\mathrm{O}_{2},[176-179]$ and it has been previously demonstrated that supplementing the circulating cell culture with HBOCs enhances the hepatocytes metabolism.[180] Thus, taking advantage of the precise control of the microparticles size enabled by the SPG technique, the optimum size of the Hb-BSA microparticles to perform as HBOCs in tissue engineering applications was evaluated. The study involved the preparation of Hb-BSA microparticles with varying diameters ranging from 1.2 to $18.3 \mu \mathrm{m}$, which were evaluated with macrophage, liver cancer, and endothelial cell lines to assess the optimum size of the $\mathrm{O}_{2}$ depot. The authors demonstrated that cell uptake of the microparticles was only observed for macrophages exposed to $\mathrm{Hb}$-BSA microparticles of diameters below $5 \mu \mathrm{m}$ while uptake of the microparticles by liver 
cancer and endothelial cells was not observed for any of the studied diameters. The authors put special emphasis in evaluating the biocompatibility of Hb-BSA microparticles of varying diameters since, good biocompatibility is a crucial factor for the applicability of any HBOCs. The results demonstrated that the biocompatibility of the Hb-BSA microparticles increased with decreasing microparticle diameter for the three studied cell lines.

\section{CONCLUSIONS}

In this review, we have featured the most recent advances in the design and assembly of HBOCs, which can be classified in two different groups. The first group involves chemically modified HBOCs, where $\mathrm{Hb}$ has been modified either by cross-linking its four sub-units, by polymerizing it with other $\mathrm{Hb}$ molecules, or by conjugating $\mathrm{Hb}$ to a different polymer. These systems comprise the first and second generation of HBOCs and, as such, they have been studied most extensively and have provided important lessons to implement for the upcoming generations of HBOCs. Furthermore, chemically modified HBOCs are mainly constituted by $\mathrm{Hb}$, and possible copolymerized enzymes, thus rendering high $\mathrm{Hb}$ encapsulation per particle. However, covalent modification of $\mathrm{Hb}$ affecting its secondary structure, could also result in the loss of functionality. The second group comprises the so called third generation of HBOCs and entails the encapsulation of $\mathrm{Hb}$ within a protective shell that can be either of lipidic (i.e., liposomes encapsulating $\mathrm{Hb}$ ) or polymeric nature. The latter mainly involving the encapsulation of $\mathrm{Hb}$ within carrier shells composed of amphiphilic polymers (i.e., polymersomes encapsulating $\mathrm{Hb}$ ), or polymer shells assembled by the $\mathrm{LbL}$ technique, where $\mathrm{Hb}$ is either entrapped in the capsules core or is a component of the polymeric wall. The main advantage of using an encapsulating platform as opposed to chemically modifying $\mathrm{Hb}$ relies in the preservation of $\mathrm{Hb}$ 's secondary structure and, in turn, its functionality. Such an approach, furthermore, offers a broad 
variety of possible particle structures - ranging from spherical assemblies to nanotubes - each one with its own tailored properties. However, this custom-made encapsulating platforms entail that each system has to be optimized individually. Another drawback is that encapsulation platforms often afford low encapsulation efficiencies as compared to the chemically-modifying strategies. Furthermore, the encapsulating protective shell can hinder the $\mathrm{O}_{2}$ diffusion from the $\mathrm{Hb}$ to the tissue. As such, prior to clinical trials, encapsulation strategies require a more exhaustive characterization as compared to the approaches involving $\mathrm{Hb}$ 's chemical modification.

The academic developments highlighted throughout the review are highly successful and include examples where the $\mathrm{HBOCs}$ display $\mathrm{O}_{2}$-binding and releasing properties very close to the ones of $\mathrm{Hb}$ encapsulated within natural $\mathrm{RBCs}$, high $\mathrm{Hb}$ loading efficiency, incorporation of a reducing system that minimizes the conversion of $\mathrm{Hb}$ into metHb, minimization of $\mathrm{NO}$ scavenging by $\mathrm{Hb}$, thus diminishing the associated vascular and toxic side effects, or the extremely long storage shelf-lives achieved by some HBOCs products. However, although each of this single achievements is of utmost importance in its own rights, none of the HBOCs reported to date has been able to address all the aforementioned challenges. Additionally, despite the multiple and diverse strategies that have been developed, and the increasing efforts that have been undertaken in the field, which is shown by the increasing number of scientific publications in recent years, several challenges still remain to be solved towards a translation into the clinic.

While is noted that most of the reported HBOCs systems have been thoroughly characterized either in test tub or in vitro examples employing small animal models remain scarce. Thus, the first challenge relies in obtaining HBOCs exhibiting a precise and durable functionality in vivo, not only in the context of the specific functions of RBCs, but also regarding their potential side 
effects and immune response. Thus, it is important to take into account that, when making use of foreign materials such as polymers, they will need to be removed from the body once they have conducted their required function for the desired time-period. The clinical usefulness of the HBOCs will be limited if their constituting materials remain in the body for a long time after administration, potentially causing long-term toxicity and immunogenicity, which may limit their potential clinical applications. It is also of utmost importance to evaluate the immunological response (e.g., MPS clearance) that HBOCs will encounter upon intravenous administration, which may involve a more advanced design of the HBOCs to achieve the desired physicochemical properties, especially since reasonably long circulation times are required. Recent studies have demonstrated the impact of physicochemical parameters such as shape, size, surface charge or mechanical modulus towards influencing the biodistribution and function of RBCs.[181,182] Only robust research of the HBOCs in standardized preclinical animal models, followed by a rigorous clinical evaluation of these systems, can lead to fully RBCs substitutes for blood transfusion applications in the future. The clinical translation of these HBOCs will only occur with the collaborative efforts of chemists, materials scientists, and blood biology experts together with trauma clinicians.

\section{AUTHOR INFORMATION}

\section{Corresponding Author}

*E-mail: leri@nanotech.dtu.dk

\section{ACKNOWLEDGMENT}

This work was supported by the Danish Council for Independent Research [Grant No. 611100298B]. 


\section{REFERENCES}

[1] Modery-Pawlowski CL, Tian LL, Pan V, Sen Gupta A. Synthetic approaches to RBC mimicry and oxygen carrier systems. Biomacromolecules 2013;14:939-48. doi:10.1021/bm400074t.

[2] Sakai H, Sou K, Horinouchi H, Kobayashi K, Tsuchida E. Review of hemoglobin-vesicles as artificial oxygen carriers. Artif Organs 2009;33:139-45. doi:10.1111/j.15251594.2008.00698.x.

[3] http://www.euro.who.int/en/health-topics/Health-systems/blood-safety/data-and-statistics n.d.

[4] Chang TMS. Blood substitutes based on nanobiotechnology. Trends Biotechnol 2006;24:372-7. doi:10.1016/j.tibtech.2006.06.005.

[5] Zuck TF, Bensinger TA, Peck CC, Chillar RK, Beutler E, Button LN, et al. The in vivo survival of red blood cells stored in modified CPD with adenine: Report of a multi-institutional cooperative effort. Transfusion 1977;17:374-82. doi:10.1046/j.15372995.1977.17477216866.x.

[6] Riess JG. Oxygen carriers ("blood substitutes") - Raison d'etre, chemistry, and some physiology. Chem Rev 2001;101:2797-920. doi:10.1021/cr970143c.

[7] Chang TMS. Blood substitutes: Principles, methods, products, and clinical trials. vol. 1. S. KargerAG; 1997.

[8] Sen Gupta A. Bio-inspired nanomedicine strategies for artificial blood components. Wiley Interdiscip Rev: Nanomed Nanobiotechnol 2017;9:e1464. doi:10.1002/wnan.1464.

[9] Castro CI, Briceno JC. Perfluorocarbon-based oxygen carriers: Review of products and 
trials. Artif Organs 2010;34:622-34. doi:10.1111/j.1525-1594.2009.00944.x.

[10] Tao Z, Ghoroghchian PP. Microparticle, nanoparticle, and stem cell-based oxygen carriers as advanced blood substitutes. Trends Biotechnol 2014;32:466-73. doi:10.1016/J.TIBTECH.2014.05.001.

[11] Alayash AI. Blood substitutes: Why haven't we been more successful? Trends Biotechnol 2014;32:177-85. doi:10.1016/j.tibtech.2014.02.006.

[12] Severinghaus JW. Blood gas calculator. J Appl Physiol 1966;21:1108-16. doi:10.1152/jappl.1966.21.3.1108.

[13] Umbreit J. Methemoglobin - It's not just blue: A concise review. Am J Hematol 2007;82:134-44. doi:10.1002/ajh.20738.

[14] Gu J, Chang TMS. Extraction of erythrocyte enzymes for the preparation of polyhemoglobin-catalase-superoxide dismutase. Artif Cells, Blood Substitutes, Biotechnol 2009;37:69-77. doi:10.1080/10731190902742240.

[15] Nagababu E, Chrest FJ, Rifkind JM. Hydrogen-peroxide-induced heme degradation in red blood cells: the protective roles of catalase and glutathione peroxidase. Biochim Biophys Acta 2003;1620:211-7. doi:10.1016/S0304-4165(02)00537-8.

[16] Rother RP, Bell L, Hillmen P, Gladwin MT. The clinical sequelae of intravascular hemolysis and extracellular plasma hemoglobin: A novel mechanism of human disease. J Am Med Assoc 2005;293:1653-62.

[17] Nagel RL, Gibson QH. The binding of hemoglobin to haptoglobin and its relation to subunit dissociation of hemoglobin. J Biol Chem 1971;246:69-73.

[18] Chen G, Duan Y, Liu J, Wang H, Yang C. Antioxidant effects of vitamin C on hemoglobin-based oxygen carriers derived from human cord blood. Artif Cells, 
Nanomedicine Biotechnol 2015;44:56-61. doi:10.3109/21691401.2015.1111239.

[19] Butt OI, Buehler PW, D’Agnillo F. Blood-brain barrier disruption and oxidative stress in guinea pig after systemic exposure to modified cell-free hemoglobin. Am J Pathol 2011;178:1316-28. doi:10.1016/j.ajpath.2010.12.006.

[20] Alayash AI. Oxygen therapeutics: Can we tame haemoglobin? Nat Rev Drug Discovery 2004;3:152-9. doi:10.1038/nrd1307.

[21] Buehler PW, D’Agnillo F, Schaer DJ. Hemoglobin-based oxygen carriers: From mechanisms of toxicity and clearance to rational drug design. Trends Mol Med 2010;16:447-57. doi:10.1016/j.molmed.2010.07.006.

[22] Smith A, McCulloh RJ. Hemopexin and haptoglobin: allies against heme toxicity from hemoglobin not contenders. Front Physiol 2015;6:187. doi:10.3389/fphys.2015.00187.

[23] Figueiredo RT, Fernandez PL, Mourao-Sa DS, Porto BN, Dutra FF, Alves LS, et al. Characterization of heme as activator of toll-like receptor 4 . J Biol Chem 2007;282:20221-9. doi:10.1074/jbc.M610737200.

[24] Belcher JD, Chen C, Nguyen J, Milbauer L, Abdulla F, Alayash AI, et al. Heme triggers TLR4 signaling leading to endothelial cell activation and vaso-occlusion in murine sickle cell disease. Blood 2014;123:377-90. doi:10.1182/blood-2013-04-495887.

[25] Cabrales P. Examining and mitigating acellular hemoglobin vasoactivity. Antioxid Redox Signaling 2013;18:2329-41. doi:10.1089/ars.2012.4922.

[26] Kim-Shapiro DB, Schechter AN, Gladwin MT. Unraveling the reactions of nitric oxide, nitrite, and hemoglobin in physiology and therapeutics. Arterioscler, Thromb, Vasc Biol 2006;26:697-705. doi:10.1161/01.ATV.0000204350.44226.9a.

[27] Olson JS, Foley EW, Rogge C, Tsai A-L, Doyle MP, Lemon DD. NO scavenging and the 
hypertensive effect of hemoglobin-based blood substitutes. Free Radical Biol Med 2004;36:685-97. doi:10.1016/j.freeradbiomed.2003.11.030.

[28] Napolitano LM. Hemoglobin-based oxygen carriers: First, second or third Generation? human or bovine? where are we now? Crit Care Clin 2009;25:279-301. doi:10.1016/j.ccc.2009.01.003.

[29] Buehler PW, Alayash AI. All hemoglobin-based oxygen carriers are not created equally. Biochim Biophys Acta, Proteins Proteomics 2008;1784:1378-81. doi:10.1016/j.bbapap.2007.12.009.

[30] Squires JE. Artificial blood. Science 2002;295:1002-5. doi:10.1126/science.1068443.

[31] Sloan EP, Koenigsberg MD, Philbin NB, Gao W. Diaspirin cross-linked hemoglobin infusion did not influence base deficit and lactic acid levels in two clinical trials of traumatic hemorrhagic shock patient resuscitation. J Trauma: Inj, Infect, Crit Care 2010;68:1158-71. doi:10.1097/TA.0b013e3181bbfaac.

[32] Jahr JS, Moallempour M, Lim JC. HBOC-201, hemoglobin glutamer-250 (bovine), Hemopure ® (Biopure Corporation). Expert Opin Biol Ther 2008;8:1425-33. doi:10.1517/14712598.8.9.1425.

[33] Gould SA, Moore EE, Hoyt DB, Burch JM, Haenel JB, Garcia J, et al. The first randomized trial of human polymerized hemoglobin as a blood substitute in acute trauma and emergent surgery. J Am Coll Surg 1998;187:113-20. doi:10.1016/S10727515(98)00095-7.

[34] Cheng DCH, Mazer CD, Martineau R, Ralph-Edwards A, Karski J, Robblee J, et al. A phase II dose-response study of hemoglobin raffimer (Hemolink) in elective coronary artery bypass surgery. J Thorac Cardiovasc Surg 2004;127:79-86. 
doi:10.1016/j.jtcvs.2003.08.024.

[35] Winslow RM. Blood substitutes. Adv Drug Delivery Rev 2000;40:131-42. doi:10.1016/S0169-409X(99)00045-9.

[36] Natanson C, Kern SJ, Lurie P, Banks SM, Wolfe SM. Cell-free hemoglobin-based blood substitutes and risk of myocardial infarction and death: A meta-analysis. J Am Med Assoc 2008;299:2304-12. doi:10.1001/jama.299.19.jrv80007.

[37] Taguchi K, Yamasaki K, Maruyama T, Otagiri M. Comparison of the pharmacokinetic properties of hemoglobin-based oxygen carriers. J Funct Biomater 2017;8:11. doi:10.3390/jfb8010011.

[38] Chang TMS. Blood replacement with nanobiotechnologically engineered hemoglobin and hemoglobin nanocapsules. Wiley Interdiscip Rev: Nanomed Nanobiotechnol 2010;2:41830. doi:10.1002/wnan.95.

[39] Moore EE, Moore FA, Fabian TC, Bernard AC, Fulda GJ, Hoyt DB, et al. Human polymerized hemoglobin for the treatment of hemorrhagic shock when blood is unavailable: The USA multicenter trial. J Am Coll Surg 2009;208:1-13. doi:10.1016/j.jamcollsurg.2008.09.023.

[40] Chen JY, Scerbo M, Kramer G. A review of blood substitutes: examining the history, clinical trial results, and ethics of hemoglobin-based oxygen carriers. Clinics 2009;64:803-13. doi:10.1590/S1807-59322009000800016.

[41] Mozzarelli A, Ronda L, Faggiano S, Bettati S, Bruno S. Haemoglobin-based oxygen carriers: Research and reality towards an alternative to blood transfusions. Blood Transfus 2010;8:59-68. doi:10.2450/2010.010S.

[42] Winslow RM. MP4, a new nonvasoactive polyethylene glycol-hemoglobin conjugate. 
Artif Organs 2004;28:800-6. doi:10.1111/j.1525-1594.2004.07392.x.

[43] Vandegriff KD, Winslow RM. Hemospan: Design principles for a new class of oxygen therapeutic. Artif Organs 2009;33:133-8. doi:10.1111/j.1525-1594.2008.00697.x.

[44] Bonneaux F, Dellacherie E. Fixation of various aldehydic dextrans onto human hemoglobin: Study of conjugate stability. J Protein Chem 1995;14:1-5. doi:10.1007/BF01902838.

[45] Jia Y, Wood F, Menu P, Faivre B, Caron A, Alayash AI. Oxygen binding and oxidation reactions of human hemoglobin conjugated to carboxylate dextran. Biochim Biophys Acta, Gen Subj 2004;1672:164-73. doi:10.1016/j.bbagen.2004.03.009.

[46] Chauvierre C, Manchanda R, Labarre D, Vauthier C, Marden MC, Leclerc L. Artificial oxygen carrier based on polysaccharides-poly(alkylcyanoacrylates) nanoparticle templates. Biomaterials 2010;31:6069-74. doi:10.1016/j.biomaterials.2010.04.039.

[47] Wang Y, Zhang S, Zhang J, Yu WL, Gao DW, Wang Q, et al. Structural, functional and physiochemical properties of dextran-bovine hemoglobin conjugate as a hemoglobinbased oxygen carrier. Process Biochem 2017;60:67-73. doi:10.1016/j.procbio.2017.05.021.

[48] Wang Q, Sun L, Ji S, Zhao D, Liu J, Su Z, et al. Reversible protection of Cys-93( $\beta$ ) by PEG alters the structural and functional properties of the PEGylated hemoglobin. Biochim Biophys Acta, Proteins Proteomics 2014;1844:1201-7. doi:10.1016/j.bbapap.2014.04.005.

[49] Baek JH, Zhou Y, Harris DR, Schaer DJ, Palmer AF, Buehler PW. Down selection of polymerized bovine hemoglobins for use as oxygen releasing therapeutics in a guinea pig model. Toxicol Sci 2012;127:567-81. doi:10.1093/toxsci/kfs109.

[50] Cheng Y, Shen T-J, Simplaceanu V, Ho C. Ligand binding properties and structural 
studies of recombinant and chemically modified hemoglobins altered at $\beta 93$ cysteine $\uparrow$. Biochemistry 2002;41:11901-13. doi:10.1021/bi0202880.

[51] Li D, Hu T, Manjula BN, Acharya SA. Extension arm facilitated pegylation of $\alpha \alpha-$ hemoglobin with modifications targeted exclusively to amino groups: Functional and structural advantages of free cys-93( $\beta$ ) in the PEG-Hb adduct. Bioconjugate Chem 2009;20:2062-70. doi:10.1021/bc900170e.

[52] Wei X, Xiong H, He S, Wang Y, Zhou D, Jing X, et al. A facile way to prepare functionalized dextran nanogels for conjugation of hemoglobin. Colloids Surf, B 2017;155:440-8. doi:10.1016/J.COLSURFB.2017.04.047.

[53] Neamtu I, Rusu AG, Diaconu A, Nita LE, Chiriac AP. Basic concepts and recent advances in nanogels as carriers for medical applications. Drug Deliv 2017;24:539-57. doi:10.1080/10717544.2016.1276232.

[54] Xiong Y, Liu ZZ, Georgieva R, Smuda K, Steffen A, Sendeski M, et al. Nonvasoconstrictive hemoglobin particles as oxygen carriers. ACS Nano 2013;7:7454-61. doi:10.1021/nn402073n.

[55] Cummings C, Murata H, Koepsel R, Russell AJ. Dramatically increased pH and temperature stability of chymotrypsin using dual block polymer-based protein engineering. Biomacromolecules 2014;15:763-71. doi:10.1021/bm401575k.

[56] Lam CN, Olsen BD. Phase transitions in concentrated solution self-assembly of globular protein-polymer block copolymers. Soft Matter 2013;9:2393-402. doi:10.1039/c2sm27459k.

[57] Wang S, Yuan F, Chen G, Tu K, Wang H, Wang L-Q. Dextran-based thermo-responsive hemoglobin-polymer conjugates with oxygen-carrying capacity. RSC Adv 2014;4:52940- 
8. doi:10.1039/C4RA06397J.

[58] Chen P, Chen J, Cao Y. Self-assembly behavior of thermo- and pH-responsive diblock copolymer of poly( $\mathrm{N}$-isopropylacrylamide)- block- poly(acrylic acid) synthesized via reversible addition-fragmentation chain transfer polymerization. J Macromol Sci, Part A: Pure ApplChem 2013;50:478-86. doi:10.1080/10601325.2013.780947.

[59] Bu H, Xu X, Chen J, Cui Y, Wang L-Q. Synthesis of a hemoglobin-conjugated triblock copolymer for oxygen carrying and specific recognition of cancer cells. RSC Adv 2017;7:48166-75. doi:10.1039/C7RA09747F.

[60] Olofsson C, Nygårds EB, Ponzer S, Fagrell B, Przybelski R, Keipert PE, et al. A randomized, single-blind, increasing dose safety trial of an oxygen-carrying plasma expander $\left(H_{e m o s p a n}{ }^{\circledR}\right)$ administered to orthopaedic surgery patients with spinal anaesthesia. Transfus Med 2008;18:28-39. doi:10.1111/j.1365-3148.2007.00811.x.

[61] Silverman TA, Weiskopf RB. Hemoglobin-based oxygen carriers: Current status and future directions. Transfusion 2009;49:2495-515. doi:10.1111/j.1537-2995.2009.02356.x.

[62] Elmer J, Alam HB, Wilcox SR. Hemoglobin-based oxygen carriers for hemorrhagic shock. Resuscitation 2012;83:285-92. doi:10.1016/j.resuscitation.2011.09.020.

[63] D'Agnillo F, Chang TMS. Polyhemoglobin-superoxide dismutase-catalase as a blood substitute with antioxidant properties. Nat Biotechnol 1998;16:667-71. doi:10.1038/nbt0798-667.

[64] Chang TMS. Blood replacement with nanobiotechnologically engineered hemoglobin and hemoglobin nanocapsules. Wiley Interdiscip Rev: Nanomed Nanobiotechnol 2010;2:41830. doi:10.1002/wnan.95.

[65] D'Agnillo F, Chang TMS. Polyhemoglobin-superoxide dismutase catalase as a blood 
substitute with antioxidant properties. Nat Biotechnol 1998;16:667-71. doi:10.1038/nbt0798-667.

[66] Powanda DD, Chang TMS. Cross-linked polyhemoglobin-superoxide dismutase-catalase supplies oxygen without causing blood-brain barrier disruption or brain edema in a rat model of transient global brain ischemia-reperfusion. Artif Cells Blood Substitutes, Immobilization Biotechnol 2002;30:23-37. doi:10.1081/BIO-120002725.

[67] Bian Y, Chang TMS. A novel nanobiotherapeutic poly-[hemoglobin-superoxide dismutase-catalase-carbonic anhydrase] with no cardiac toxicity for the resuscitation of a rat model with 90 minutes of sustained severe hemorrhagic shock with loss of 2/3 blood volume. Artif Cells, Nanomedicine Biotechnol 2015;43:1-9. doi:10.3109/21691401.2014.964554.

[68] Kim HW, Greenburg AG. Hemoglobin-based oxygen carriers as red cell substitutes and oxygen therapeutics. Springer-Verlag Berlin Heidelberg; 2013. doi:10.1007/978-3-64240717-8.

[69] Tronstad C, Pischke SE, Holhjem L, Tønnessen TI, Martinsen ØG, Grimnes S. Early detection of cardiac ischemia using a conductometric $\mathrm{pCO}_{2}$ sensor: Real-time drift correction and parameterization. Physiol Meas 2010;31:1241-55. doi:10.1088/0967$3334 / 31 / 9 / 013$.

[70] Sims C, Seigne P, Menconi M, Monarca J, Barlow C, Pettit J, et al. Skeletal muscle acidosis correlates with the severity of blood volume loss during shock and resuscitation. $\mathbf{J}$ Trauma Inj Infect Crit Care 2001;51:1137-45. doi:10.1097/00005373-200112000-00020.

[71] Hathazi D, Mot AC, Vaida A, Scurtu F, Lupan I, Fischer-Fodor E, et al. Oxidative protection of hemoglobin and hemerythrin by cross-linking with a nonheme iron 
peroxidase: Potentially improved oxygen carriers for use in blood substitutes. Biomacromolecules 2014;15:1920-7. doi:10.1021/bm5004256.

[72] Simoni J, Simoni G, Moeller JF, Feola M, Wesson DE. Artificial oxygen carrier with pharmacologic actions of adenosine-5'-triphosphate, adenosine, and reduced glutathione formulated to treat an array of medical conditions. Artif Organs 2014;38:684-90. doi:10.1111/aor.12337.

[73] Simoni J, Simoni G, Wesson DE, Feola M. ATP-adenosine-glutathione cross-linked hemoglobin as clinically useful oxygen carrier. Curr Drug Discovery Technol 2012;9:173-87.

[74] Tomita D, Kimura T, Hosaka H, Daijima Y, Haruki R, Ludwig K, et al. Covalent coreshell architecture of hemoglobin and human serum albumin as an artificial $\mathrm{O}_{2}$ carrier. Biomacromolecules 2013;14:1816-25. doi:10.1021/bm400204y.

[75] Michel CC. Transport of macromolecules through microvascular walls. Cardiovasc Res 1996;32:644-53. doi:10.1016/0008-6363(96)00064-8.

[76] Hosaka H, Haruki R, Yamada K, Böttcher CB, Komatsu T. Hemoglobin-albumin cluster incorporating a PT nanoparticle: Artificial $\mathrm{O}_{2}$ carrier with antioxidant activities. PLoS One 2014;9:e110541. doi:10.1371/journal.pone.0110541.

[77] Haruki R, Kimura T, Iwasaki H, Yamada K, Kamiyama I, Kohno M, et al. Safety evaluation of hemoglobin-albumin cluster "HemoAct" as a red blood cell substitute. Sci Rep 2015;5:12778.

[78] Yamada K, Yokomaku K, Kureishi M, Akiyama M, Kihira K, Komatsu T. Artificial blood for dogs. Sci Rep 2016;6:36782. doi:10.1038/srep36782.

[79] Yokomaku K, Akiyama M, Morita Y, Kihira K, Komatsu T. Core-shell protein clusters 
comprising haemoglobin and recombinant feline serum albumin as an artificial $\mathrm{O}_{2}$ carrier for cats. J Mater Chem B 2018;6:2417-25. doi:10.1039/c8tb00211h.

[80] Sen Gupta A. Role of particle size, shape, and stiffness in design of intravascular drug delivery systems: insights from computations, experiments, and nature. Wiley Interdiscip Rev: Nanomed Nanobiotechnol 2015;8:255-70. doi:10.1002/wnan.1362.

[81] Geng Y, Dalhaimer P, Cai S, Tsai R, Tewari M, Minko T, et al. Shape effects of filaments versus spherical particles in flow and drug delivery. Nat Nanotechnol 2007;2:249-55. doi:10.1038/nnano.2007.70.

[82] Muro S, Garnacho C, Champion JA, Leferovich J, Gajewski C, Schuchman EH, et al. Control of endothelial targeting and intracellular delivery of therapeutic enzymes by modulating the size and shape of ICAM-1-targeted carriers. Mol Ther J Am Soc Gene Ther 2008;16:1450-8. doi:10.1038/mt.2008.127.

[83] Merkel TJ, Jones SW, Herlihy KP, Kersey FR, Shields AR, Napier M, et al. Using mechanobiological mimicry of red blood cells to extend circulation times of hydrogel microparticles. PNAS 2011;108:586-91. doi:10.1073/pnas.1010013108.

[84] Doshi N, Zahr AS, Bhaskar S, Lahann J, Mitragotri S. Red blood cell-mimicking synthetic biomaterial particles. PNAS 2009;106:21495-9. doi:10.1073/pnas.0907127106.

[85] Rudt S, Müller RH. In vitro phagocytosis assay of nano- and microparticles by chemiluminescence. III. Uptake of differently sized surface-modified particles, and its correlation to particle properties and in vivo distribution. Eur J Pharm Sci 1993;1:31-9. doi:10.1016/0928-0987(93)90015-3.

[86] Champion JA, Walker A, Mitragotri S. Role of particle size in phagocytosis of polymeric microspheres. Pharm Res 2008;25:1815-21. doi:10.1007/s11095-008-9562-y. 
[87] Gholipourmalekabadi M, Zhao S, Harrison BS, Mozafari M, Seifalian AM. Oxygengenerating biomaterials: A new, viable paradigm for tissue engineering? Trends Biotechnol 2016;34:1010-21. doi:10.1016/j.tibtech.2016.05.012.

[88] Farris AL, Rindone AN, Grayson WL. Oxygen delivering biomaterials for tissue engineering. J Mater Chem B 2016;4:3422-32. doi:10.1039/C5TB02635K.

[89] Colton CK. Oxygen supply to encapsulated therapeutic cells. Adv Drug Delivery Rev 2014;67-68:93-110. doi:10.1016/j.addr.2014.02.007.

[90] Wijekoon A, Fountas-Davis N, Leipzig ND. Fluorinated methacrylamide chitosan hydrogel systems as adaptable oxygen carriers for wound healing. Acta Biomater 2013;9:5653-64. doi:10.1016/j.actbio.2012.10.034.

[91] Paciello A, Amalfitano G, Garziano A, Urciuolo F, Netti PA. Hemoglobin-conjugated gelatin microsphere as a smart oxygen releasing biomaterial. Adv Healthcare Mater 2016;5:2655-66. doi:10.1002/adhm.201600559.

[92] Goddard JM, Hotchkiss JH. Polymer surface modification for the attachment of bioactive compounds. Prog Polym Sci 2007;32:698-725. doi:10.1016/j.progpolymsci.2007.04.002.

[93] Müller R, Abke J, Schnell E, Macionczyk F, Gbureck U, Mehrl R, et al. Surface engineering of stainless steel materials by covalent collagen immobilization to improve implant biocompatibility. Biomaterials 2005;26:6962-72. doi:10.1016/j.biomaterials.2005.05.013.

[94] Diamanti S, Arifuzzaman S, Elsen A, Genzer J, Vaia RA. Reactive patterning via postfunctionalization of polymer brushes utilizing disuccinimidyl carbonate activation to couple primary amines. Polymer 2008;49:3770-9. doi:10.1016/j.polymer.2008.06.020.

[95] Grabarek Z, Gergely J. Zero-length crosslinking procedure with the use of active esters. 
Anal Biochem 1990;185:131-5. doi:10.1016/0003-2697(90)90267-D.

[96] López-Alonso JP, Diez-García F, Font J, Ribó M, Vilanova M, Scholtz JM, et al. Carbodiimide EDC induces cross-links that stabilize RNase a C-dimer against dissociation: EDC adducts can affect protein net charge, conformation, and activity. Bioconjugate Chem 2009;20:1459-73. doi:10.1021/bc9001486.

[97] Harrington JP, Wollocko H. Molecular design properties of OxyVita hemoglobin, a new generation therapeutic oxygen carrier: A review. J Funct Biomater 2011;2:414-24. doi:10.3390/jfb2040414.

[98] Jenkins JD, Musayev FN, Danso-Danquah R, Abraham DJ, Safo MK. Structure of relaxed-state human hemoglobin: Insight into ligand uptake, transport and release. Acta Crystallogr, Sect D: Biol Crystallogr 2009;65:41-8. doi:10.1107/S0907444908037256.

[99] Eaton WA, Henry ER, Hofrichter J, Mozzarelli A. Is cooperative oxygen binding by hemoglobin really understood? Nat Struct Biol 1999;6:351.

[100] Guaccio A, Borselli C, Oliviero O, Netti PA. Oxygen consumption of chondrocytes in agarose and collagen gels: A comparative analysis. Biomaterials 2008;29:1484-93. doi:10.1016/j.biomaterials.2007.12.020.

[101] Knirsch MC, Dell'Anno F, Chicoma D, Stephano MA, Bou-Chacra NA, Palombo D, et al. Preparation and characterization of a microencapsulated polyethylene glycol cross-linked polyhemoglobin. Bioprocess Biosyst Eng 2015;38:2263-9. doi:10.1007/s00449-015$1463-\mathrm{y}$

[102] Knirsch MC, Dell'Anno F, Salerno M, Larosa C, Polakiewicz B, Eggenhöffner R, et al. Combined characterization of bovine polyhemoglobin microcapsules by $\mathrm{UV}-\mathrm{Vis}$ absorption spectroscopy and cyclic voltammetry. Bioprocess Biosyst Eng 2017;40:431-8. 
doi:10.1007/s00449-016-1711-9.

[103] Jia Y, Duan L, Li J. Hemoglobin-based nanoarchitectonic assemblies as oxygen carriers. Adv Mater 2016;28:1312-8. doi:10.1002/adma.201502581.

[104] Yu WP, Chang TMS. Submicron polymer membrane hemoglobin nanocapsules as potential blood substitutes: Preparation and characterization. Artif Cells Blood Substitutes, Immobilization Biotechnol 2009;24:169-83. doi:10.3109/10731199609117433.

[105] Meng FT, Zhang WZ, Ma GH, Su ZG. The preparation and characterization of monomethoxypoly(ethylene glycol)-b-poly-DL-lactide microcapsules containing bovine hemoglobin. Artif Cells Blood Substitutes, Immobilization Biotechnol 2003;31:279-92. doi:10.1081/BIO-120023158.

[106] Rameez S, Alosta H, Palmer AF. Biocompatible and biodegradable polymersome encapsulated hemoglobin: A potential oxygen carrier. Bioconjugate Chem 2008;19:102532. doi: $10.1021 / \mathrm{bc} 700465 \mathrm{v}$.

[107] Sheng Y, Yuan Y, Liu C, Tao X, Shan X, Xu F. In vitro macrophage uptake and in vivo biodistribution of PLA-PEG nanoparticles loaded with hemoglobin as blood substitutes: Effect of PEG content. J Mater Sci: Mater Med 2009;20:1881-91. doi:10.1007/s10856009-3746-9.

[108] Zhao J, Liu CS, Yuan Y, Tao XY, Shan XQ, Sheng Y, et al. Preparation of hemoglobinloaded nano-sized particles with porous structure as oxygen carriers. Biomaterials 2007;28:1414-22. doi:10.1016/j.biomaterials.2006.10.012.

[109] Xu F, Yuan Y, Shan X, Liu C, Tao X, Sheng Y, et al. Long-circulation of hemoglobinloaded polymeric nanoparticles as oxygen carriers with modulated surface charges. Int $\mathbf{J}$ Pharm 2009;377:199-206. doi:10.1016/j.ijpharm.2009.05.015. 
[110] Liu G-Y, Chen C-J, Ji J. Biocompatible and biodegradable polymersomes as delivery vehicles in biomedical applications. Soft Matter 2012;8:8811-21. doi:10.1039/c2sm25721a.

[111] Zhang X, Zhang P. Polymersomes in nanomedicine - A review. Curr Nanosci 2017;13:124-9. doi:10.2174/1573413712666161018144519.

[112] Lu M, Zhao C, Wang Q, You G, Wang Y, Deng H, et al. Preparation, characterization and in vivo investigation of blood-compatible hemoglobin-loaded nanoparticles as oxygen carriers. Colloids Surf, B 2016;139:171-9. doi:10.1016/j.colsurfb.2015.12.012.

[113] Lai P, Daear W, Löbenberg R, Prenner EJ. Overview of the preparation of organic polymeric nanoparticles for drug delivery based on gelatine, chitosan, poly(D,L-lactideco-glycolic acid) and polyalkylcyanoacrylate. Colloids Surf, B 2014;118:154-63. doi:10.1016/j.colsurfb.2014.03.017.

[114] Li B, Qi Y, He S, Wang Y, Xie Z, Jing X, et al. Asymmetric copolymer vesicles to serve as a hemoglobin vector for ischemia therapy. Biomater Sci 2014;2:1254-61. doi:10.1039/C4BM00123K.

[115] Li B, He S, Qi Y, Xie Z, Chen X, Jing X, et al. Insight into the fabrication of polymeric particle based oxygen carriers. Int J Pharm 2014;468:75-82. doi:10.1016/j.ijpharm.2014.04.004.

[116] Chang BS, Yeung B. Physical stability of protein pharmaceuticals. In: Jameel F, Hershenson S, editors. ormulation Process Dev. Strategies Manuf. Biopharm., John Wiley \& Sons, Inc.; 2010, p. 69-104. doi:10.1002/9780470595886.ch3.

[117] Wang Q, Zhang R, Lu M, You G, Wang Y, Chen G, et al. Bioinspired polydopaminecoated hemoglobin as potential oxygen carrier with antioxidant properties. 
Biomacromolecules 2017;18:1333-41. doi:10.1021/acs.biomac.7b00077.

[118] Liu Y, Ai K, Lu L. Polydopamine and its derivative materials: Synthesis and promising applications in energy, environmental, and biomedical fields. Chem Rev 2014;114:5057115. doi:10.1021/cr400407a.

[119] Liebscher J, Mrówczyński R, Scheidt HA, Filip C, Hădade ND, Turcu R, et al. Structure of polydopamine: A never-ending story? Langmuir 2013;29:10539-48. doi:10.1021/la4020288.

[120] Dreyer DR, Miller DJ, Freeman BD, Paul DR, Bielawski CW. Elucidating the structure of poly(dopamine). Langmuir 2012;28:6428-35. doi:10.1021/la204831b.

[121] Liu X, Cao J, Li H, Li J, Jin Q, Ren K, et al. Mussel-inspired polydopamine: A biocompatible and ultrastable coating for nanoparticles in vivo. ACS Nano 2013;7:938495. doi:10.1021/nn404117j.

[122] Ku SH, Ryu J, Hong SK, Lee H, Park CB. General functionalization route for cell adhesion on non-wetting surfaces. Biomaterials 2010;31:2535-41. doi:10.1016/j.biomaterials.2009.12.020.

[123] Ku SH, Park CB. Human endothelial cell growth on mussel-inspired nanofiber scaffold for vascular tissue engineering. Biomaterials 2010;31:9431-7. doi:10.1016/j.biomaterials.2010.08.071.

[124] Wang Q, Zhang R, You G, Hu J, Li P, Wang Y, et al. Influence of polydopaminemediated surface modification on oxygen-release capacity of haemoglobin-based oxygen carriers. Artif Cells, Nanomedicine, Biotechnol 2018:1-9. doi:10.1080/21691401.2018.1459636.

[125] Ariga K, Yamauchi Y, Rydzek G, Ji Q, Yonamine Y, Wu KC-W, et al. Layer-by-layer 
Nanoarchitectonics: Invention, Innovation, and Evolution. Chem Lett 2014;43:36-68. doi:10.1246/cl.130987.

[126] Ariga K, Lvov YM, Kawakami K, Ji Q, Hill JP. Layer-by-layer self-assembled shells for drug delivery. Adv Drug Delivery Rev 2011;63:762-71. doi:10.1016/j.addr.2011.03.016.

[127] Ariga K, Hill JP, Ji Q. Layer-by-layer assembly as a versatile bottom-up nanofabrication technique for exploratory research and realistic application. Phys Chem Chem Phys 2007;9:2319-40. doi:10.1039/b700410a.

[128] He Q, Cui Y, Li J. Molecular assembly and application of biomimetic microcapsules. Chem Soc Rev 2009;38:2292-303. doi:10.1039/b816475b.

[129] Chen B, Jia Y, Zhao J, Li H, Dong W, Li J. Assembled hemoglobin and catalase nanotubes for the treatment of oxidative stress. J Phys Chem C 2013;117:19751-8. doi:10.1021/jp407164q.

[130] Kameta N, Minamikawa H, Masuda M. Supramolecular organic nanotubes: how to utilize the inner nanospace and the outer space. Soft Matter 2011;7:4539-61. doi:10.1039/c0sm01559h.

[131] Komatsu T, Qu X, Ihara H, Fujihara M, Azuma H, Ikeda H. Virus trap in human serum albumin nanotube. J Am Chem Soc 2011;133:3246-8. doi:10.1021/ja1096122.

[132] Richards MP, Dettmann MA. Comparative analysis of different hemoglobins: Autoxidation, reaction with peroxide, and lipid oxidation. J Agric Food Chem 2003;51:3886-91. doi:10.1021/jf0212082.

[133] Djordjevich L, Miller IF. Synthetic erythrocytes from lipid encapsulated hemoglobin. Exp Hematol 1980;8:584-92.

[134] Hunt CA, Burnette RR, Macgregor RD, Strubbe AE, Lau DT, Taylor N, et al. Synthesis 
and evaluation of a prototypal artificial red cell. Science 1985;230:1165-8. doi:10.1126/science.4071041.

[135] Farmer MC, Johnson SA, Beissinger RL, Gossage JL, Lynn AB, Carter KA. Liposomeencapsulated hemoglobin: a synthetic red cell. In: Gaber BP, Schnur JM, Chapman D, editors. Biotechnol. Appl. Lipid Microstruct. Adv. Exp. Med. Biol., United States: Springer, Boston, MA; 1988, p. 161-70. doi:10.1007/978-1-4684-7908-9_13.

[136] Sakai H, Sou K, Horinouchi H, Kobayashi K, Tsuchida E. Hemoglobin-vesicle, a cellular artificial oxygen carrier that fulfils the physiological roles of the red blood cell structure. In: Takahashi E, Bruley D, editors. Oxyg. Transp. to Tissue XXXI, vol. 662, Springer, Boston, MA; 2010, p. 433-8. doi:10.1007/978-1-4419-1241-1_62.

[137] Tsuchida E, Sakai H, Horinouchi H, Kobayashi K. Hemoglobin-vesicles as a transfusion alternative. Artif Cells, Blood Substitutes, Biotechnol 2006;34:581-8. doi:10.1080/10731190600973907.

[138] Rudolph AS, Klipper RW, Goins B, Phillips WT. In vivo biodistribution of a radiolabeled blood substitute: 99mTc-labeled liposome-encapsulated hemoglobin in an anesthetized rabbit. PNAS 1991;88:10976-80. doi:10.1073/pnas.88.23.10976.

[139] Tsuchida E, Sou K, Nakagawa A, Sakai H, Komatsu T, Kobayashi K. Artificial oxygen carriers, hemoglobin vesicles and albumin-hemes, based on bioconjugate chemistry. Bioconjugate Chem 2009;20:1419-40. doi:10.1021/bc800431d.

[140] Taguchi K, Watanabe H, Sakai H, Horinouchi H, Kobayashi K, Maruyama T, et al. A fourteen-day observation and pharmacokinetic evaluation after a massive intravenous infusion of hemoglobin-vesicles (artificial oxygen carriers) in cynomolgus monkeys. J Drug Metab Toxicol 2012;3. doi:10.4172/2157-7609.1000128. 
[141] Kaneda S, Ishizuka T, Goto H, Kimura T, Inaba K, Kasukawa H. Liposome-encapsulated hemoglobin, TRM-645: Current status of the development and important issues for clinical application. Artif Organs 2009;33:146-52. doi:10.1111/j.15251594.2008.00699.x.

[142] Rameez S, Guzman N, Banerjee U, Fontes J, Paulaitis ME, Palmer AF, et al. Encapsulation of hemoglobin inside liposomes surface conjugated with poly(ethylene glycol) attenuates their reactions with gaseous ligands and regulates nitric oxide dependent vasodilation. Biotechnol Prog 2012;28:636-45. doi:10.1002/btpr.1532.

[143] Nag OK, Awasthi V. Surface engineering of liposomes for stealth behavior. Pharmaceutics 2013;5:542-69. doi:10.3390/pharmaceutics5040542.

[144] Sakai H, Takeoka S, Park SI, Kose T, Nishide H, Izumi Y, et al. Surface modification of hemoglobin vesicles with poly(ethylene glycol) and effects on aggregation, viscosity, and blood flow during 90\% exchange transfusion in anesthetized rats. Bioconjugate Chem 1997;8:23-30. doi:10.1021/bc960069p.

[145] Taguchi K, Urata Y, Anraku M, Watanabe H, Kadowaki D, Sakai H, et al. Hemoglobin vesicles, polyethylene glycol (PEG)ylated liposomes developed as a red blood cell substitute, do not induce the accelerated blood clearance phenomenon in mice. Drug Metab Dispos 2009;37:2197-203. doi:10.1124/dmd.109.028852.

[146] Sakai H. Present situation of the development of cellular-type hemoglobin-based oxygen carrier (hemoglobin-vesicles). Curr Drug Discovery Technol 2012;9:188-93. doi:10.2174/157016312802650805.

[147] Yadav VR, Nag O, Awasthi V. Biological evaluation of liposome-encapsulated hemoglobin surface-modified with a novel pegylated nonphospholipid amphiphile. Artif 
Organs 2014;38:625-33. doi:10.1111/aor.12304.

[148] Yadav VR, Rao G, Houson H, Hedrick A, Awasthi S, Roberts PR, et al. Nanovesicular liposome-encapsulated hemoglobin (LEH) prevents multi-organ injuries in a rat model of hemorrhagic shock. Eur J Pharm Sci 2016;93:97-106. doi:10.1016/j.ejps.2016.08.010.

[149] Sou K, Tsuchida E. Electrostatic interactions and complement activation on the surface of phospholipid vesicle containing acidic lipids: Effect of the structure of acidic groups. Biochim Biophys Acta, Biomembr 2008;1778:1035-41. doi:10.1016/j.bbamem.2008.01.006.

[150] Nag OK, Yadav VR, Hedrick A, Awasthi V. Post-modification of preformed liposomes with novel non-phospholipid poly(ethylene glycol)-conjugated hexadecylcarbamoylmethyl hexadecanoic acid for enhanced circulation persistence in vivo. Int J Pharm 2013;446:119-29. doi:10.1016/j.ijpharm.2013.02.026.

[151] Agashe H, Awasthi V. Chapter 1 - Current perspectives in liposome-encapsulated hemoglobin as oxygen carrier. In: Leitmannova Liu A, Tien HT, editors. Adv. Planar Lipid Bilayers Liposomes, vol. 9, Academic Press; 2009, p. 1-28. doi:10.1016/S15544516(09)09001-2.

[152] Agashe H, Lagisetty P, Awasthi S, Awasthi V. Improved formulation of liposomeencapsulated hemoglobin with an anionic non-phospholipid. Colloids Surf, B 2010;75:573-83. doi:10.1016/j.colsurfb.2009.09.038.

[153] Yadav VR, Rao G, Houson H, Hedrick A, Awasthi S, Roberts PR, et al. Nanovesicular liposome-encapsulated hemoglobin (LEH) prevents multi-organ injuries in a rat model of hemorrhagic shock. Eur J Pharm Sci 2016;93:97-106. doi:10.1016/J.EJPS.2016.08.010.

[154] Yadav VR, Nag O, Awasthi V. Biological evaluation of liposome-encapsulated 
hemoglobin surface-modified with a novel PEGylated nonphospholipid amphiphile. Artif Organs 2014;38:625-33. doi:10.1111/aor.12304.

[155] Sakai H. Present situation of the development of cellular-type hemoglobin-based oxygen carrier (hemoglobin-vesicles). Curr Drug Discov Technol 2012;9:188-93. doi:10.2174/157016312802650805.

[156] Li T, Jing X, Huang Y. Polymer/hemoglobin assemblies: Biodegradable oxygen carriers for artificial red blood cells. Macromol Biosci 2011;11:865-75. doi:10.1002/mabi.201000469.

[157] Chang TMS, Poznansky MJ. Semipermeable microcapsules containing catalase for enzyme replacement in acatalasaemic mice. Nature 1968;218:243-5. doi:10.1038/218243a0.

[158] Chang TMS. Semipermeable microcapsules. Science 1964;146:524-5. doi:10.1126/science.146.3643.524.

[159] Chang TM. Biodegradable semipermeable microcapsules containing enzymes, hormones, vaccines, and other biologicals. J Bioeng 1976;1:25-32.

[160] Jia Y, Cui Y, Fei J, Du M, Dai L, Li J, et al. Construction and evaluation of hemoglobinbased capsules as blood substitutes. Adv Funct Mater 2012;22:1446-53. doi:10.1002/adfm.201102737.

[161] Jia Y, Li J. Molecular assembly of Schiff base interactions: Construction and application. Chem Rev 2015;115:1597-621. doi:10.1021/cr400559g.

[162] Tomaiuolo G. Biomechanical properties of red blood cells in health and disease towards microfluidics. Biomicrofluidics 2014;8:51501. doi:10.1063/1.4895755.

[163] Cui J, Björnmalm M, Liang K, Xu C, Best JP, Zhang X, et al. Super-soft hydrogel 
particles with tunable elasticity in a microfluidic blood capillary model. Adv Mater 2014;26:7295-9. doi:10.1002/adma.201402753.

[164] Wang X, Gao W, Peng W, Xie J, Li Y. Biorheological properties of reconstructed erythrocytes and its function of carrying-releasing oxygen. Artif Cells, Blood Substitutes, Biotechnol 2009;37:41-4. doi:10.1080/10731190802674477.

[165] Goldsmith HL, Marlow J. Flow behaviour of erythrocytes. I. Rotation and deformation in dilute suspensions. Proc R Soc B 1972;182:351-84. doi:10.1098/rspb.1972.0084.

[166] Charoenphol P, Mocherla S, Bouis D, Namdee K, Pinsky DJ, Eniola-Adefeso O. Targeting therapeutics to the vascular wall in atherosclerosis - Carrier size matters. Atherosclerosis 2011;217:364-70. doi:10.1016/j.atherosclerosis.2011.04.016.

[167] Best JP, Yan Y, Caruso F. The role of particle geometry and mechanics in the biological domain. Adv Healthcare Mater 2012;1:35-47. doi:10.1002/adhm.201100012.

[168] Yu C, Qian D, Huang X, Han F, Bao N, Gu H. Construction of biconcave hemoglobinbased microcapsules and electrochemical evaluation for its ability of oxygen carry. Sens Actuators, B 2018;256:217-25. doi:10.1016/j.snb.2017.09.166.

[169] Duan L, Du L, Jia Y, Liu W, Liu Z, Li J. High impact of uranyl ions on carrying-releasing oxygen capability of hemoglobin-based blood substitutes. Chem - Eur J 2015;21:520-5. doi:10.1002/chem.201405439.

[170] Vladisavljević GT, Williams RA. Recent developments in manufacturing emulsions and particulate products using membranes. Adv Colloid Interface Sci 2005;113:1-20. doi:10.1016/j.cis.2004.10.002.

[171] Chu L-Y, Xie R, Zhu J-H, Chen W-M, Yamaguchi T, Nakao S-I. Study of SPG membrane emulsification processes for the preparation of monodisperse core-shell microcapsules. $\mathbf{J}$ 
Colloid Interface Sci 2003;265:187-96. doi:10.1016/S0021-9797(03)00350-3.

[172] Lai YT, Sato M, Ohta S, Akamatsu K, Nakao S ichi, Sakai Y, et al. Preparation of uniform-sized hemoglobin-albumin microspheres as oxygen carriers by Shirasu porous glass membrane emulsification technique. Colloids Surf, B 2015;127:1-7. doi:10.1016/j.colsurfb.2015.01.018.

[173] Nakashima T, Shimizu M, Kukizaki M. Particle control of emulsion by membrane emulsification and its applications. Adv Drug Delivery Rev 2000;45:47-56. doi:10.1016/S0169-409X(00)00099-5.

[174] Sakai Y, Huang H, Hanada S, Niino T. Toward engineering of vascularized threedimensional liver tissue equivalents possessing a clinically significant mass. Biochem Eng J 2010;48:348-61. doi:10.1016/j.bej.2009.10.010.

[175] Lai YT, Ohta S, Akamatsu K, Nakao SI, Sakai Y, Ito T. Size-dependent interaction of cells and hemoglobin-albumin based oxygen carriers prepared using the SPG membrane emulsification technique. Biotechnol Prog 2015;31:1676-84. doi:10.1002/btpr.2170.

[176] Chen G, Palmer AF. Hemoglobin regulates the metabolic, synthetic, detoxification, and biotransformation functions of hepatoma cells cultured in a hollow fiber bioreactor. Tissue Eng, Part A 2010;16:3231-40. doi:10.1089/ten.tea.2010.0058.

[177] Naruto H, Huang H, Nishikawa M, Kojima N, Mizuno A, Ohta K, et al. Feasibility of direct oxygenation of primary-cultured rat hepatocytes using polyethylene glycoldecorated liposome-encapsulated hemoglobin (LEH). J Biosci Bioeng 2007;104:343-6. doi:10.1263/jbb.104.343.

[178] Montagne K, Huang H, Ohara K, Matsumoto K, Mizuno A, Ohta K, et al. Use of liposome encapsulated hemoglobin as an oxygen carrier for fetal and adult rat liver cell 
culture. J Biosci Bioeng 2011;112:485-90. doi:10.1016/j.jbiosc.2011.07.004.

[179] Kimura T, Kurosawa H, Goto H, Kora S, Ogata Y, Amano Y. Oxygen carrying capacity and oxygen supply rate of artificial oxygen carrier, Neo Red Cell (NRC). Artif Cells, Blood Substitutes, Immobilization Biotechnol 1998;26:455-64. doi:10.3109/10731199809117466.

[180] Nahmias Y, Kramvis Y, Barbe L, Casali M, Berthiaume F, Yarmush ML. A novel formulation of oxygen-carrying matrix enhances liver-specific function of cultured hepatocytes. FASEB J 2006;20:2531-3. doi:10.1096/fj.06-6192fje.

[181] Charoenphol P, Huang RB, Eniola-Adefeso O. Potential role of size and hemodynamics in the efficacy of vascular-targeted spherical drug carriers. Biomaterials 2010;31:1392-402. doi:10.1016/j.biomaterials.2009.11.007.

[182] Huang RB, Mocherla S, Heslinga MJ, Charoenphol P, Eniola-Adefeso O. Dynamic and cellular interactions of nanoparticles in vascular-targeted drug delivery (review). Mol Membr Biol 2010;27:190-205. doi:10.3109/09687688.2010.522117.

[183] Stadler AM, Digel I, Artmann GM, Embs JP, Zaccai G, Büldt G. Hemoglobin dynamics in red blood cells: Correlation to body temperature. Biophys J 2008;95:5449-61. doi:10.1529/biophysj.108.138040.

[184] McCarthy MR, Vandegriff KD, Winslow RM. The role of facilitated diffusion in oxygen transport by cell-free hemoglobins: implications for the design of hemoglobin-based oxygen carriers. Biophys Chem 2001;92:103-17. doi:https://doi.org/10.1016/S03014622(01)00194-6.

[185] Mackenzie CF, Moon-Massat PF, Shander A, Javidroozi M, Greenburg AG. When blood is not an option: Factors affecting survival after the use of a hemoglobin-based oxygen 
carrier in 54 patients with life-threatening anemia. Anesth Analg 2010;110:685-93.

[186] Page TC, Torres JO, Light WR. Method of forming a polymerized hemoglobin solution from stabilized hemoglobin. US7459535B2, 2008.

[187] Bian Y, Rong Z, Chang TMS. Polyhemoglobin-superoxide dismutase-catalase-carbonic anhydrase: A novel biotechnology-based blood substitute that transports both oxygen and carbon dioxide and also acts as an antioxidant. Artif Cells, Blood Substitutes, Biotechnol 2011;39:127-36. doi:10.3109/10731199.2011.582041.

[188] Guo C, Gynn M, Chang TMS. Extraction of superoxide dismutase, catalase, and carbonic anhydrase from stroma-free red blood cell hemolysate for the preparation of the nanobiotechnological complex of polyhemoglobin-superoxide dismutase-catalasecarbonic anhydrase. Artif Cells, Nanomedicine, Biotechnol 2015;43:157-62. doi:10.3109/21691401.2015.1035479.

[189] Simoni J, Simoni G, Moeller JF, Feola M, Wesson DE. Artificial oxygen carrier with pharmacologic actions of adenosine-5'-triphosphate, adenosine, and reduced glutathione formulated to treat an array of medical conditions. Artif Organs 2014;38:684-90. doi:10.1111/aor.12337.

[190] Yabuki A, Yamaji K, Ohki H, Iwashita Y. Characterization of a pyridoxalated hemoglobin-polyoxyethylene conjugate as a physiologic oxygen carrier. Transfusion 1990;30:516-20.

[191] Bjorkholm M, Fagrell B, Przybelski R, Winslow N, Young M, Winslow RM. A phase I single blind clinical trial of a new oxygen transport agent (MP4), human hemoglobin modified with maleimide-activated polyethylene glycol. Haematologica 2005;90:505-15.

[192] Tam SC, Blumenstein J, Wong JT. Blood replacement in dogs by dextran-hemoglobin. 
Can J Biochem 1978;56:981-4.

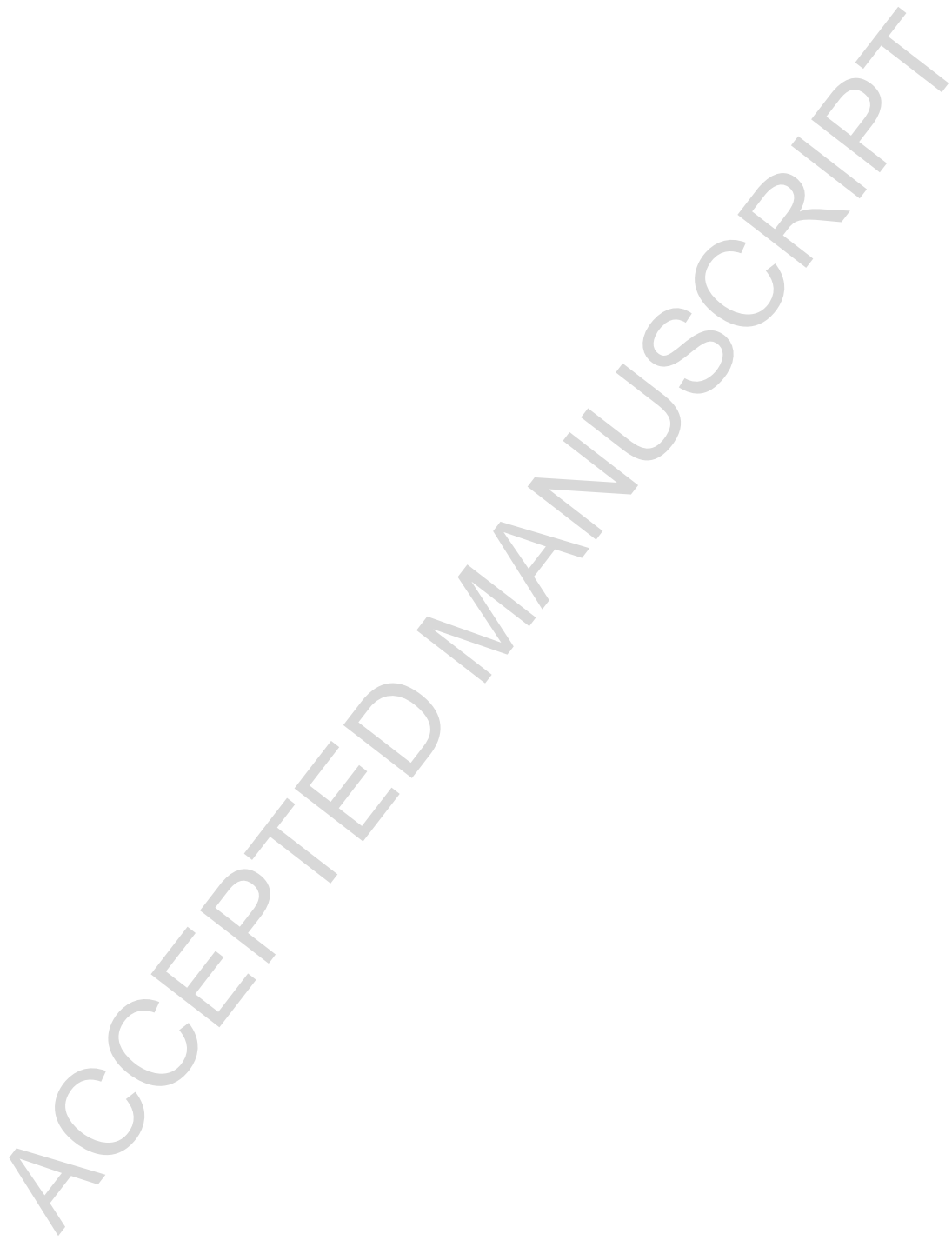


Table 1. Several research approaches for the creation of chemically modified hemoglobin-based oxygen carriers.

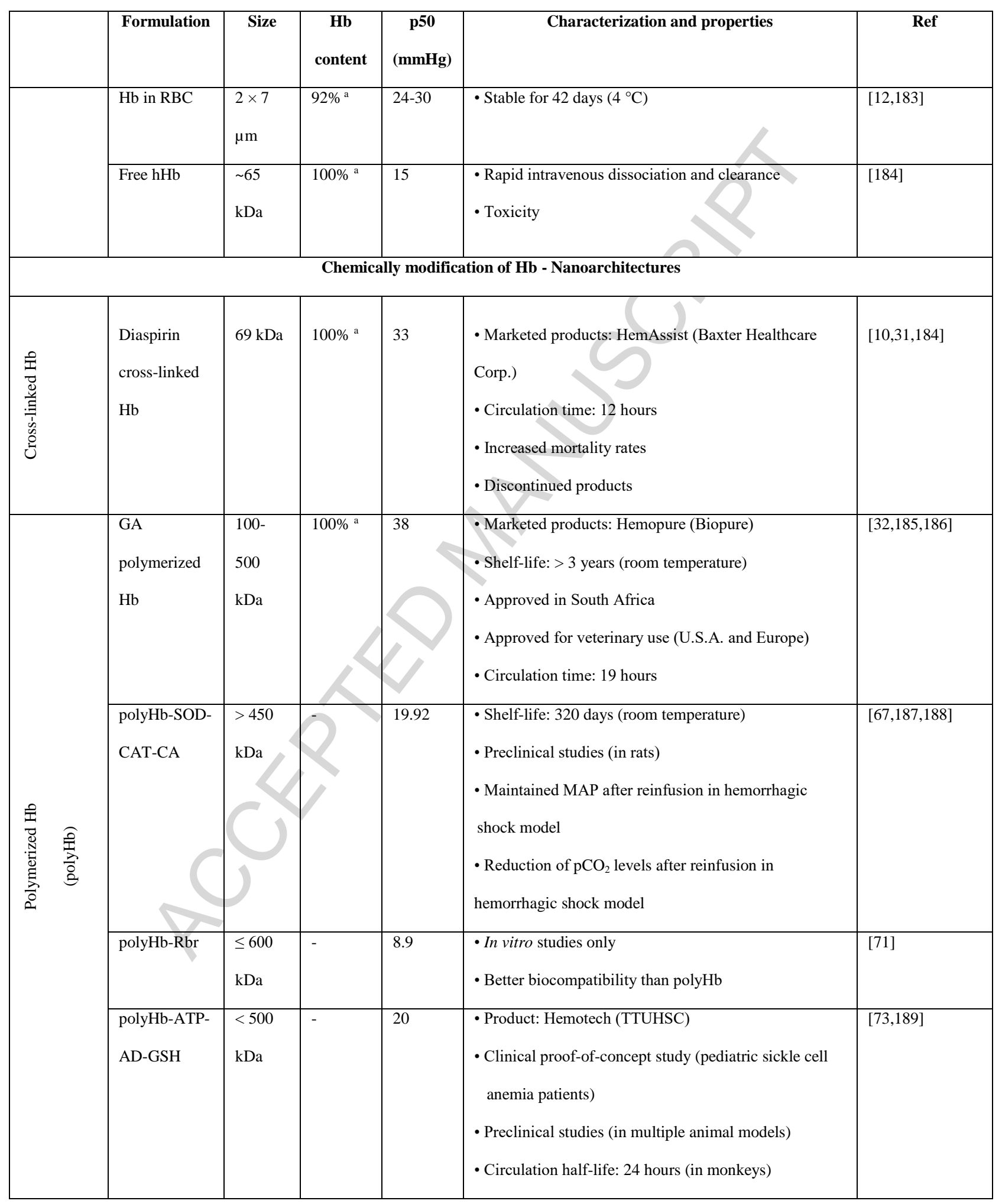




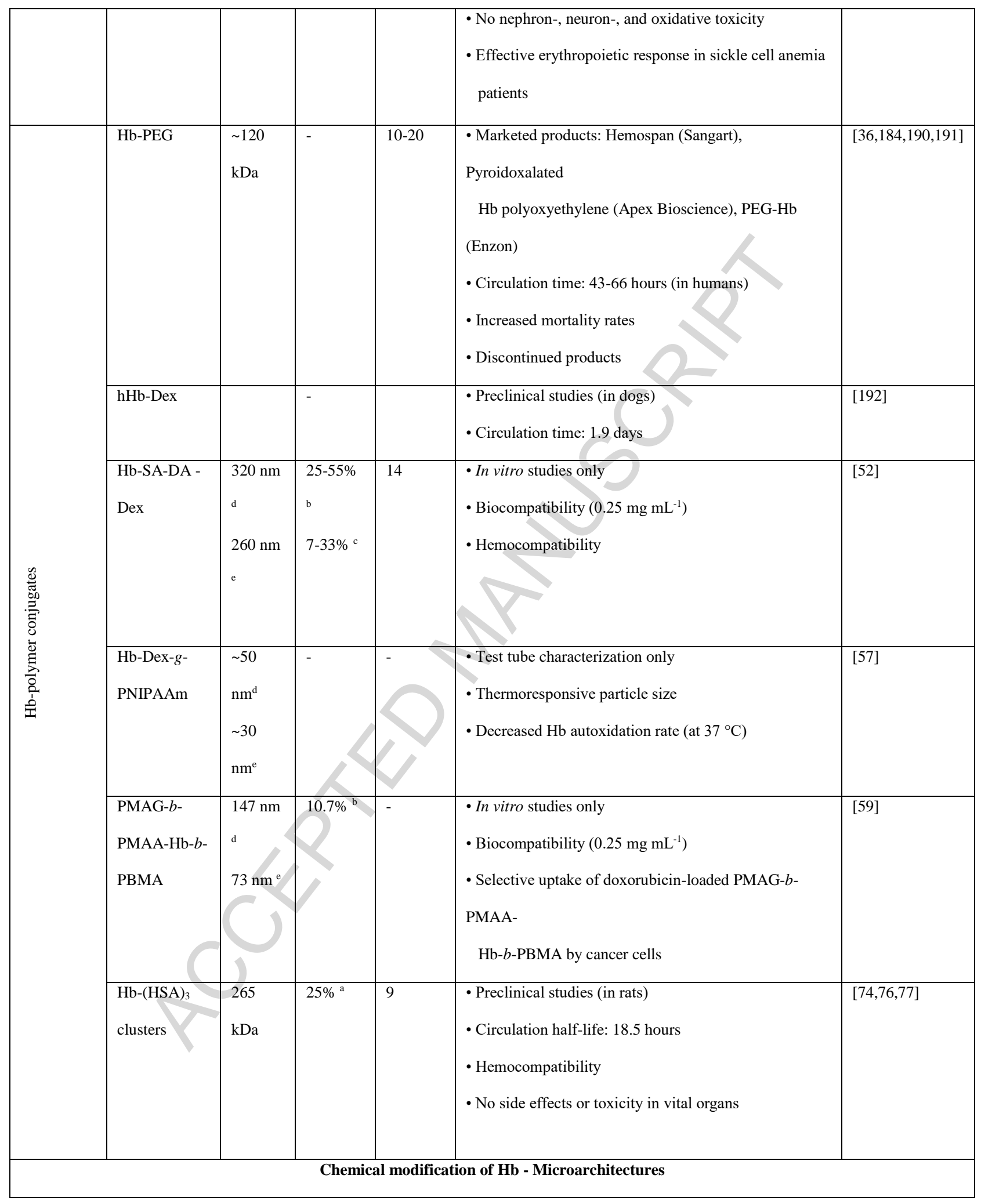




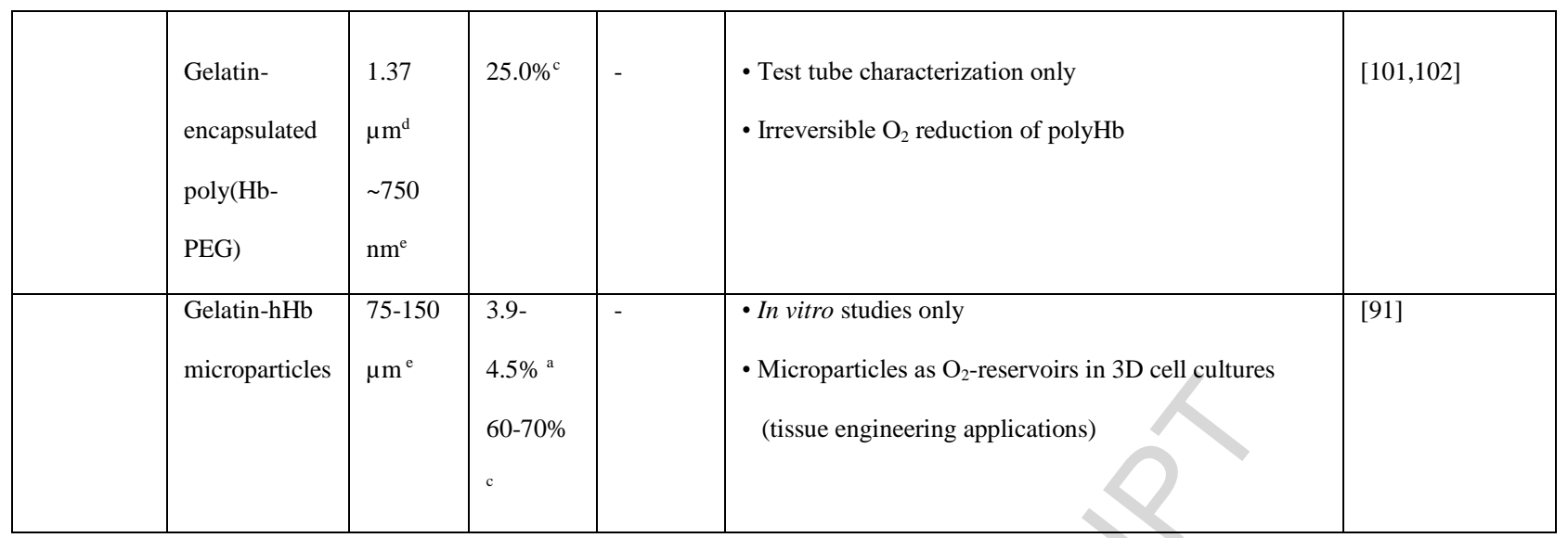

Hb: hemoglobin, hHb: human Hb, RBC: red blood cell, p50: partial pressure with 50\% oxygenated Hb, GA: glutaraldehyde, SOD: superoxide anhydrase, CAT: catalase, CA: carbonic anhydrase, MAP: mean arterial blood pressure, $\mathrm{pCO}_{2}$ : partial pressure of carbon dioxide, Rbr: ruberitrin, ATP: adenosine-5'-triphosphate, AD: adenosine, GSH: reduced glutathione, TTUHSC: Texas Tech Uni. Health Sc. Center, PEG: poly(ethylene glycol), Dex: dextran, SA: succinic anhydride, DA: dopamine, PNIPAAm: poly( $N$-isopropylacrylamide), PMAG- $b$-PMAA- $b$-PBMA: poly[2(methacrylamido) glucopyranose]-block-poly(methacrylicacid)-block-poly(butylmethacrylate), HSA: human serum albumin, $\mathrm{O}_{2}$ : oxygen. a) Weight content, b) Conjugation ratio: $\mathrm{C}_{\mathrm{Hb}} /\left(\mathrm{C}_{\mathrm{total}}-\mathrm{C}_{\mathrm{Hb}}\right) * 100 \%$, c) Encapsulation efficiency: (Hbtotal - Hbfree $) / \mathrm{Hb}$ total $\left.* 100 \%, \mathrm{~d}\right) \mathrm{Hydrodynamic}$ size, and e) size by electron microscopy. 
Table 2. Several encapsulation approaches for the creation of hemoglobin-based oxygen carriers.

\begin{tabular}{|c|c|c|c|c|c|c|}
\hline & Formulation & Size & $\begin{array}{c}\text { Hb } \\
\text { content }\end{array}$ & $\begin{array}{c}\text { p50 } \\
(\mathbf{m m H g})\end{array}$ & Characterization and properties & Ref \\
\hline \multicolumn{7}{|c|}{ Encapsulation strategies for $\mathrm{Hb}$ - Nanoarchitectures } \\
\hline \multirow{6}{*}{ 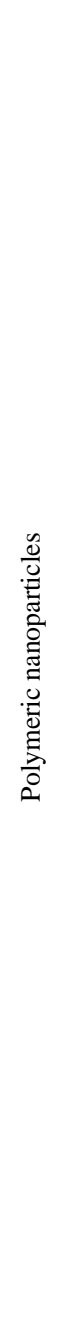 } & PLA-PEG & $100-200 \mathrm{~nm}$ & $71-88 \%{ }^{c}$ & - & $\begin{array}{l}\text { - Preclinical studies (in mice) } \\
\text { - Circulation time: } 34.3 \text { hours }\end{array}$ & [107] \\
\hline & PLGA-PEG & $200 \mathrm{~nm}^{\mathrm{d}}$ & $48 \%{ }^{\mathrm{c}}$ & 14.2 & $\begin{array}{l}\text { - Preclinical studies (in mice) } \\
\text { - Maintained MAP after reinfusion in } \\
\text { hemorrhagic } \\
\text { shock model } \\
\text { - Increased lactate concentrations in blood }\end{array}$ & [112] \\
\hline & PEG-PCL-PLA-PEG & $800 \mathrm{~nm}^{\mathrm{d}}$ & $>60 \%{ }^{\mathrm{a}}$ & 21.6 & $\begin{array}{l}\text { - Preclinical studies (in rats) } \\
\text { - Maintained MAP and heart rate after reinfusion } \\
\text { in } \\
\text { hemorrhagic shock model } \\
\text { - Reduced short-term mortality }\end{array}$ & [114] \\
\hline & $\begin{array}{l}\text { PEG-PAGE(MPA)- } \\
\text { PCL }\end{array}$ & $200-300 \mathrm{~nm}^{\mathrm{d}}$ & - & 20.4 & $\begin{array}{l}\text { - In vitro studies only } \\
\text { - Hemocompatibility }\end{array}$ & [115] \\
\hline & PDA-coated $\mathrm{Hb}$ & $6-8 \mathrm{~nm}^{\mathrm{d}}$ & 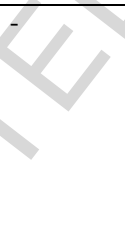 & 13.9 & $\begin{array}{l}\text { - In vitro studies only } \\
\text { - Biocompatibility }\left(1 \mathrm{mg} \mathrm{mL}^{-1}\right) \\
\text { - Hemocompatibility } \\
\text { - Antioxidant activity }\end{array}$ & {$[117,124]$} \\
\hline & $\begin{array}{l}\text { Hb-catalase } \\
\text { nanotubes }\end{array}$ & $\begin{array}{l}300-420 \mathrm{~nm} \times \\
10 \mu \mathrm{m}\end{array}$ & - & - & $\begin{array}{l}\text { - In vitro studies only } \\
\text { - Biocompatibility }\left(0.3 \mathrm{mg} \mathrm{mL}^{-1}\right) \\
\text { - Antioxidant activity }\end{array}$ & [129] \\
\hline \multirow[b]{2}{*}{ 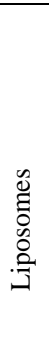 } & $\begin{array}{l}\text { hHb, DPPC, Chol, } \\
\text { DHSG, DSPE- } \\
\text { PEG }_{5 \mathrm{~K}}\end{array}$ & $250-280 \mathrm{~nm}$ & $10 \mathrm{~g} \mathrm{dL}^{-1}$ & 20.2 & $\begin{array}{l}\text { - Shelf-life: 2-3 years (under } \mathrm{N}_{2} \text { ) } \\
\text { - Preclinical studies (in multiple animal models) } \\
\text { - Circulation time: } 47-72 \text { hours (monkeys) }\end{array}$ & [140] \\
\hline & $\begin{array}{l}\text { hHb, DPPC, Chol, } \\
\text { VitE, HDAS, } \\
\text { HDAS-PEG }_{2 \mathrm{~K}}\end{array}$ & $215 \mathrm{~nm}^{\mathrm{d}}$ & $7.2 \mathrm{~g} \mathrm{dL}^{-1}$ & 31.9 & $\begin{array}{l}\text { - Preclinical studies (in rats) } \\
\text { - No inflammation or multi-organ injuries after } \\
\text { reinfusion in hemorrhagic shock model }\end{array}$ & {$[147,152,153]$} \\
\hline \multicolumn{7}{|c|}{\begin{tabular}{l|l|l} 
& & \\
Encapsulation strategies for $\mathbf{H b}$ - Microarchitectures
\end{tabular}} \\
\hline
\end{tabular}




\begin{tabular}{|c|c|c|c|c|c|c|}
\hline \multirow[t]{2}{*}{ 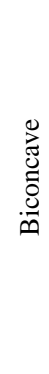 } & $\begin{array}{l}(\mathrm{hHb} / \mathrm{BSA})_{4} / \mathrm{hHb} \\
\text { capsules }\end{array}$ & & - & - & $\begin{array}{l}\text { - Test tube characterization only } \\
\text { - High deformability } \\
\text { (elastic modulus }=92.8 \pm 42 \mathrm{kPa} \text { ) } \\
\text { - } \mathrm{O}_{2} \text { carrying capacity similar to } \mathrm{RBCs}\end{array}$ & [84] \\
\hline & $\begin{array}{l}\mathrm{Ca}(\mathrm{OH})_{2}-\mathrm{Hb} \\
\text { particles }\end{array}$ & $6.5 \mu \mathrm{m}^{\mathrm{e}}$ & $\begin{array}{l}27 \%^{\mathrm{b}} \\
55.3 \%^{\mathrm{c}}\end{array}$ & - & $\begin{array}{l}- \text { Test tube characterization only } \\
\text { - Improved } \mathrm{O}_{2} \text { binding and release properties }\end{array}$ & [168] \\
\hline \multirow{3}{*}{ 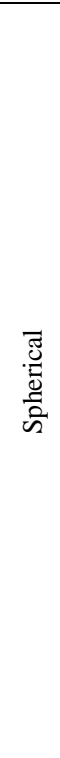 } & $(\mathrm{Hb} / \mathrm{DHP})_{5}$ capsules & $3.4 \mu \mathrm{m}^{\mathrm{d}}$ & - & - & $\begin{array}{l}\text { - In vitro studies only } \\
\text { - Biocompatibility }\left(0.11 \mathrm{mg} \mathrm{mL}^{-1}\right) \\
\text { - Low uptake by macrophages } \\
\text { - Hemocompatibility }\end{array}$ & [160] \\
\hline & $\begin{array}{l}\mathrm{CaCO}_{3} /(\mathrm{Hb} / \mathrm{PEG})_{5} \\
\text { microparticles }\end{array}$ & $>5 \mu \mathrm{m}^{\mathrm{e}}$ & - & - & $\begin{array}{l}\text { - Test tube characterization only } \\
\text { - Potential of } \mathrm{Hb} \text {-containing capsules for } \mathrm{UO}_{2}{ }^{2+} \\
\text { removal in radiation-contaminated blood }\end{array}$ & [169] \\
\hline & $\begin{array}{l}\text { Hb-albumin } \\
\text { microparticles }\end{array}$ & $4-5 \mu \mathrm{m}^{\mathrm{e}}$ & $30-70 \%{ }^{b}$ & $5-12$ & $\begin{array}{l}\text { - In vitro studies only } \\
\text { - Cytotoxic oxy-Hb containing microparticles ( } 20 \\
\left.\mathrm{mg} \mathrm{mL}^{-1}\right) \\
\text { - Increased size decreases uptake by macrophage }\end{array}$ & {$[172,175]$} \\
\hline
\end{tabular}

$\mathrm{Hb}$ : hemoglobin, hHb, human $\mathrm{Hb}$, p50: partial pressure with 50\% oxygenated $\mathrm{Hb}$, PLA: poly(lactic acid), PEG: poly(ethylene glycol), PLGA: poly(lactide-co-glycolide), PAGE(MPA): poly(allyl glycidyl ether) (functionalized with mercaptopropionic acid), MAP: mean arterial blood pressure, PCL: poly(e-caprolactone), DPPC: dipalmitoylphosphatidylcholine, Chol: cholesterol, DHSG: 1,5-O-dihexadecyl-N-succinyl-1glutamate, DSPE: 1, 2-distearoyl-sn-glycero-3-phosphatidyl-ethanolamine HDAS: hexadecylcarbamoylmethylhexadecanoate, VitE: vitamin E, BSA: bovine serum albumin, $\mathrm{O}_{2}$ : oxygen, $\mathrm{Ca}(\mathrm{OH})_{2}$ : calcium hydroxide, DHP: dialdehyde heparin, $\mathrm{CaCO}_{3}$ : calcium carbonate. a) Weight content, b) Conjugation ratio determined by means of $\mathrm{Hb}$ / (total weight) $* 100$ and c) Encapsulation efficiency: (Hbtotal - Hbfree) / Hbtotal *100\%, d) Hydrodynamic size, and e) size by electron microscopy. 


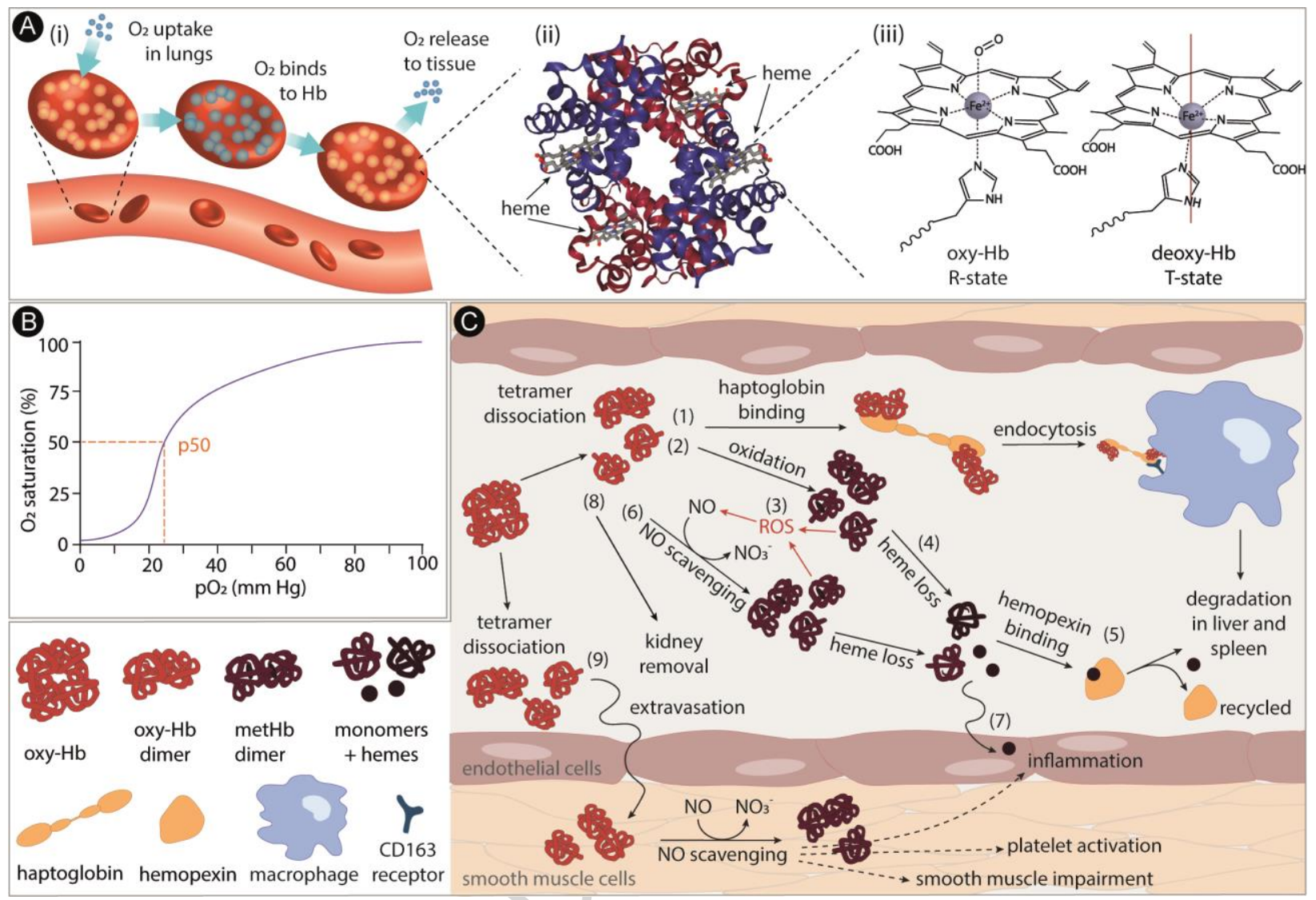

Scheme 1. Schematic representation of the red blood cells (RBCs) structure, oxygen $\left(\mathrm{O}_{2}\right)$ binding capacity and intravascular hemoglobin ( $\mathrm{Hb})$. A) $\mathrm{RBCs}$ intravenous $\mathrm{O}_{2}$ uptake and release (i), structure of the $\mathrm{Hb}$ tetramer (ii) and oxy-Hb or R-state (left) and deoxy-Hb or T-state (right) of the heme group (iii). B) The $\mathrm{O}_{2}$ dissociation curve of $\mathrm{Hb}$ with the p50 value (dotted line) at $26.5 \mathrm{mmHg} \mathrm{O}_{2}$ partial pressure $\left(\mathrm{pO}_{2}\right)$. C) Intravascular dissociation of $\mathrm{Hb}$. 1) $\mathrm{Oxy}-\mathrm{Hb}$ is dissociated into its dimers and monomers which bind to haptoglobin, followed by endocytosis via the CD163 receptor and degradation in liver and spleen. 2) Oxy-Hb dimers and monomers can also auto-oxidize into metHb products and the complementary reactive oxygen species (ROS) which results in nitric oxide (NO) depletion by converting it into nitrate $\left(\mathrm{NO}_{3}{ }^{-}\right)(3)$. Next, the oxy-Hb oxidation products (i.e., metHb and ferryl $\mathrm{Hb}$ ) promote the unfolding of the globin 
chains releasing the heme groups (4). The free heme groups bind to hemopexin to be released again and degraded by the macrophages while the hemopexin is recycled back (5). 6) When the plasma protein mechanisms are saturated, oxy-Hb will also scavenge NO resulting in metHb, $\mathrm{Hb}\left(\mathrm{Fe}^{4+}\right)$ and $\mathrm{NO}_{3}{ }^{-}$production. Unbound metHb products can penetrate through the endothelial cells membrane causing an inflammatory response (7). Additional intravenous oxy-Hb dimers and monomers are removed by kidney filtration (5). 9) Finally, oxy-Hb dimers and monomers can also extravasate in between the endothelial cells lining the blood vessels to scavenge the NO of the underlying smooth muscle cells which results in inflammation, smooth muscle impairment, and platelet activation. 


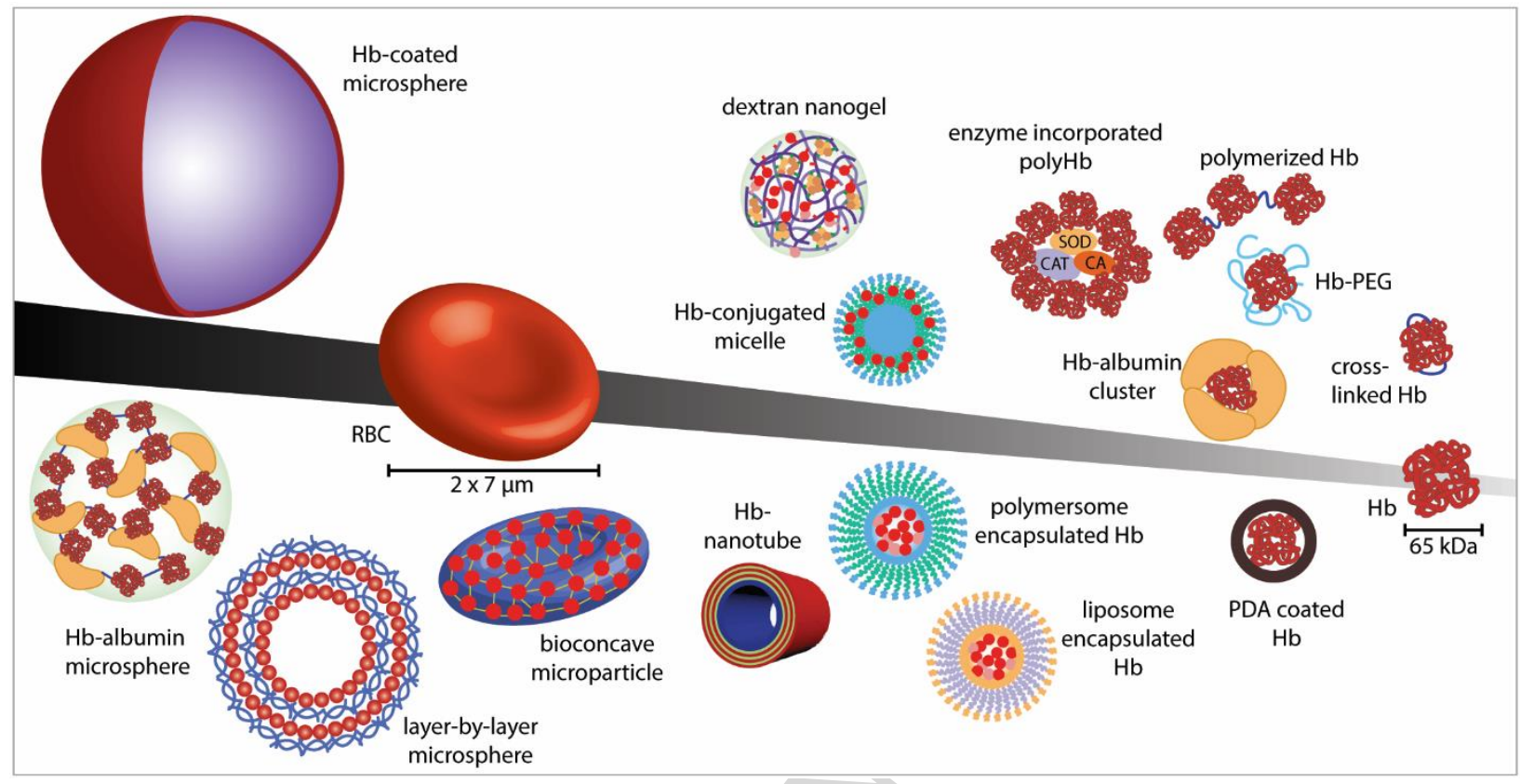

Scheme 2. Schematic representation of different hemoglobin ( $\mathrm{Hb}$ )-based oxygen carriers (HBOCs) discussed in the review. HBOCs are classified depending if $\mathrm{Hb}$ has been chemically modified to be attached to a carrier (top) or if it has been encapsulated (bottom). RBC: red blood cell, SOD: superoxide dismutase, CAT: catalase, CA: carbonic anhydrase, PEG: polyethylene glycol, PDA: polydopamine. 


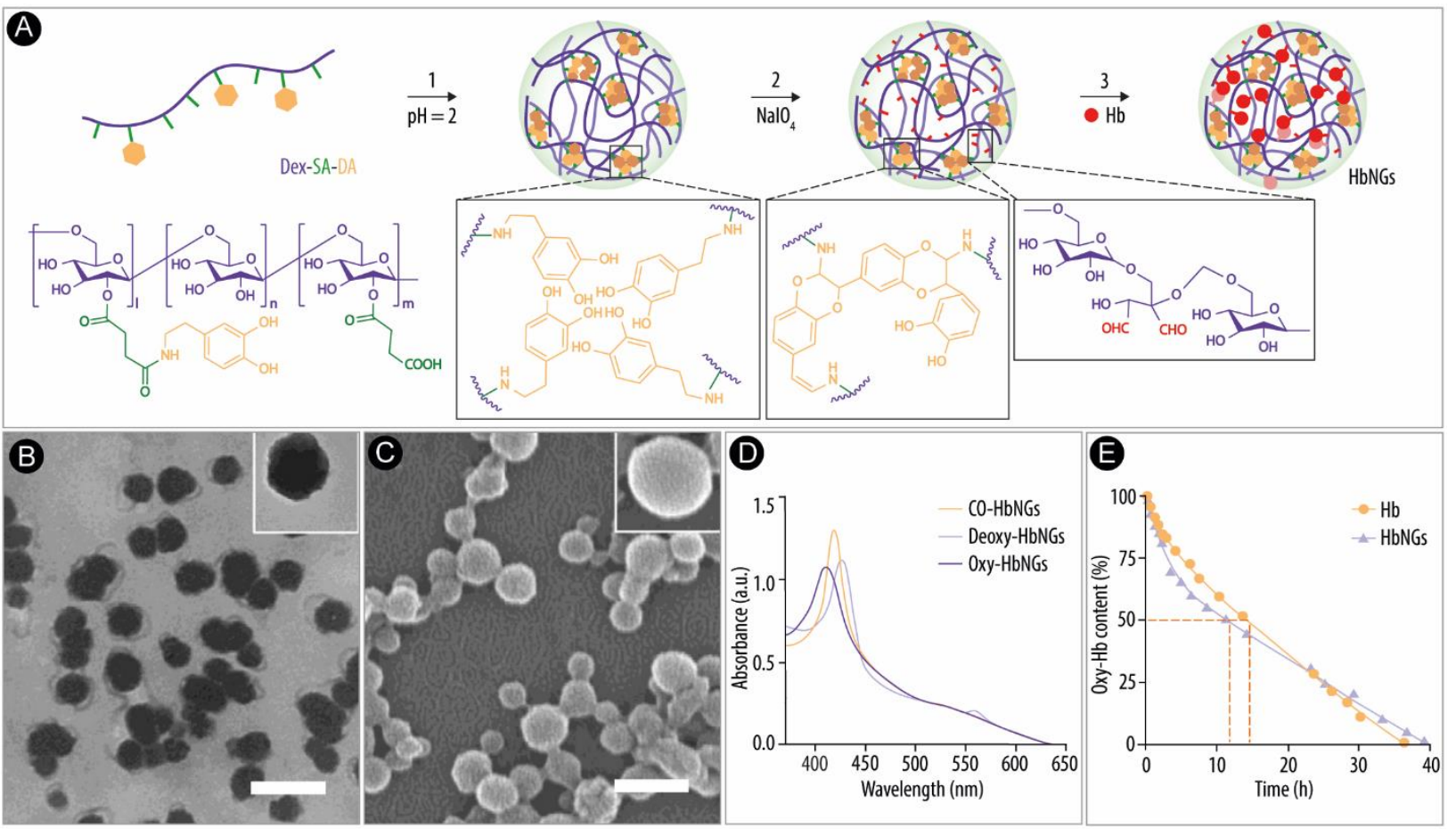

Figure 1. Hemoglobin-based nanogels (HbNGs) synthesis and characterization. A) The HbNGs assembly starts with the synthesis of a co-polymer consisting of dextran (Dex), succinic anhydride (SA) and dopamine (DA). The Dex-SA-DA co-polymer self-assembles into NGs at acidic $\mathrm{pH}$ (1). Next, the NGs are cross-linked by oxidizing the DA moieties with sodium periodate $\left(\mathrm{NaIO}_{4}\right)$ and functionalizing the Dex component with aldehyde groups (2). $\mathrm{Hb}$ is then incorporated through covalent bonding between the amino groups of $\mathrm{Hb}$ and the Dex's aldehyde groups (3). B) Transmission and scanning (C) electron microscopy images of the HbNGs. Scale bars of $500 \mathrm{~nm}$. D) UV-vis spectra of HbNGs exposed to carbon monoxide (CO-HbNGs), nitrogen (Deoxy-HbNGs) and oxygen (Oxy-HbNGs). E) Stability of $\mathrm{Hb}$ and $\mathrm{HbNGs}$ at $37{ }^{\circ} \mathrm{C}$ with the corresponding half-lives (dotted lines). Adapted from [52], with permission from Elsevier. 


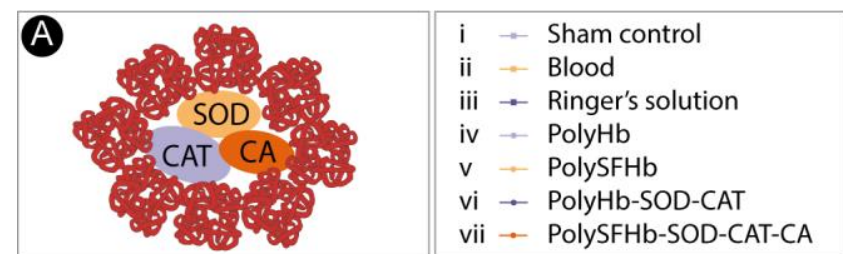

(B)
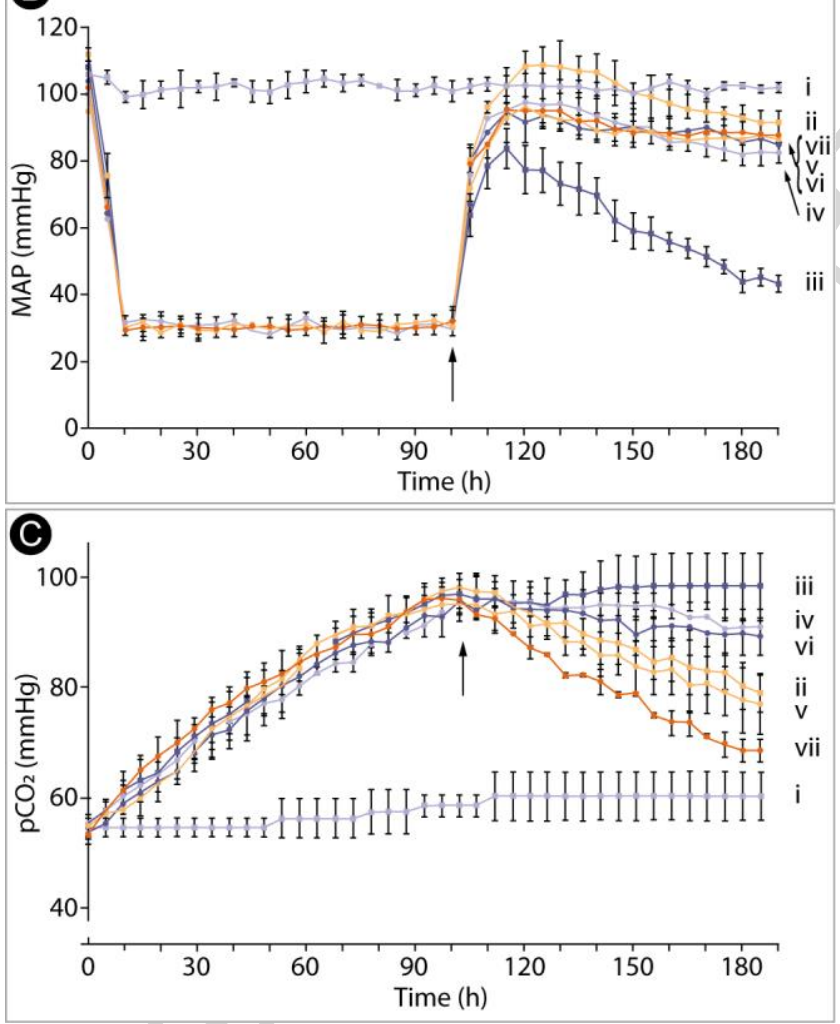

Figure 2. Hemorrhagic shock model for cross-linked hemoglobin $(\mathrm{Hb})$ or stroma-free hemolysate (SFHb) with superoxide dismutase (SOD), catalase (CAT), and carbonic anhydrase (CA). A) Schematic representation of the polyHb-SOD-CAT-CA. B) The mean arterial blood pressure (MAP) and tissue $\mathrm{CO}_{2}$ partial pressure $\left(\mathrm{pCO}_{2}\right)(\mathrm{C})$ were measured after reinfusion of different fluids (ii-vii) injected 90 min after inducing a hemorrhagic shock that had generated a MAP of $30 \mathrm{mmHg}$. i) Sham control without hemorrhagic shock. Adapted from [67], with permission from Informa Healthcare USA, Inc. 


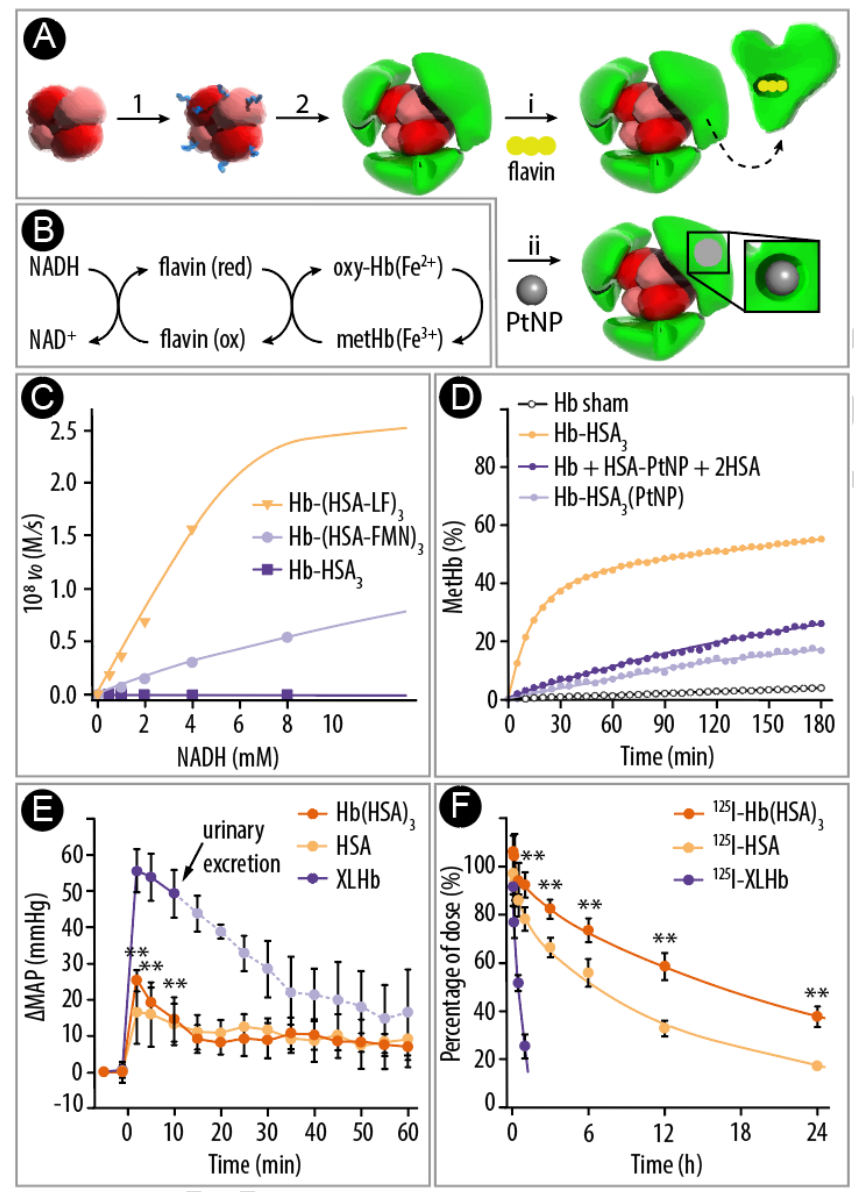

Figure 3. Hemoglobin (Hb)-albumin clusters assembly and metHb reduction. A) $\mathrm{Hb}$ was modified with the $N$-succinimidyl 4-(N-maleimidomethy) cyclohexane-1-carboxylate heterobifunctional cross-linker (1) after which human serum albumin (HSA) was attached to obtain $\mathrm{Hb}-(\mathrm{HSA})_{3}$ nanoclusters (2). Flavin derivatives could be bound to a subdomain of the HSA (i), or a platinum nanoparticle (PtNP) could be bound within the cleft of one HSA unit (ii). B) Diagram of metHb reduction by nicotinamide adenine dinucleotide (NADH) using flavin derivatives. C) Dependence of initial rate $\left(v_{0}\right)$ of metHb reduction on NADH concentration using the flavin derivatives lumiflavin (LF) or flavin mononucleotide (FMN) bound to the Hb-(HSA) 3 clusters. Reprinted with permission from [74]. Copyright 2013 ACS Publication. D) MetHb 
levels of $\mathrm{Hb}-(\mathrm{HSA})_{3}, \mathrm{Hb}-(\mathrm{HSA})_{3}(\mathrm{PtNP})$ clusters, and a mixture of the different components over time in a $20 \mu \mathrm{M}$ hydrogen peroxide solution. $\mathrm{Hb}$ sham without hydrogen peroxide. Adapted with permission from [76]. PLoS ONE open access. D) Difference in mean arterial pressure ( $\triangle \mathrm{MAP})$ after intravenous injection of $\mathrm{HSA}, \mathrm{Hb}-(\mathrm{HSA})_{3}$, and cross-linked $\mathrm{Hb}(\mathrm{XLHb})$ into rats. $* * \mathrm{p}<$ 0.01 vs. XLHb, stopped after 10 minutes due to urinary excretion. E) Relative blood plasma concentration of iodine-125 ( $\left.\mathrm{I}^{125}\right)$-labeled HSA, Hb-(HSA) $)_{3}$, and XLHb. ** $\mathrm{p}<0.01$ vs. $\mathrm{I}^{125}$ HSA. Reprinted with permission from [77]. Nature Scientific reports open access. 

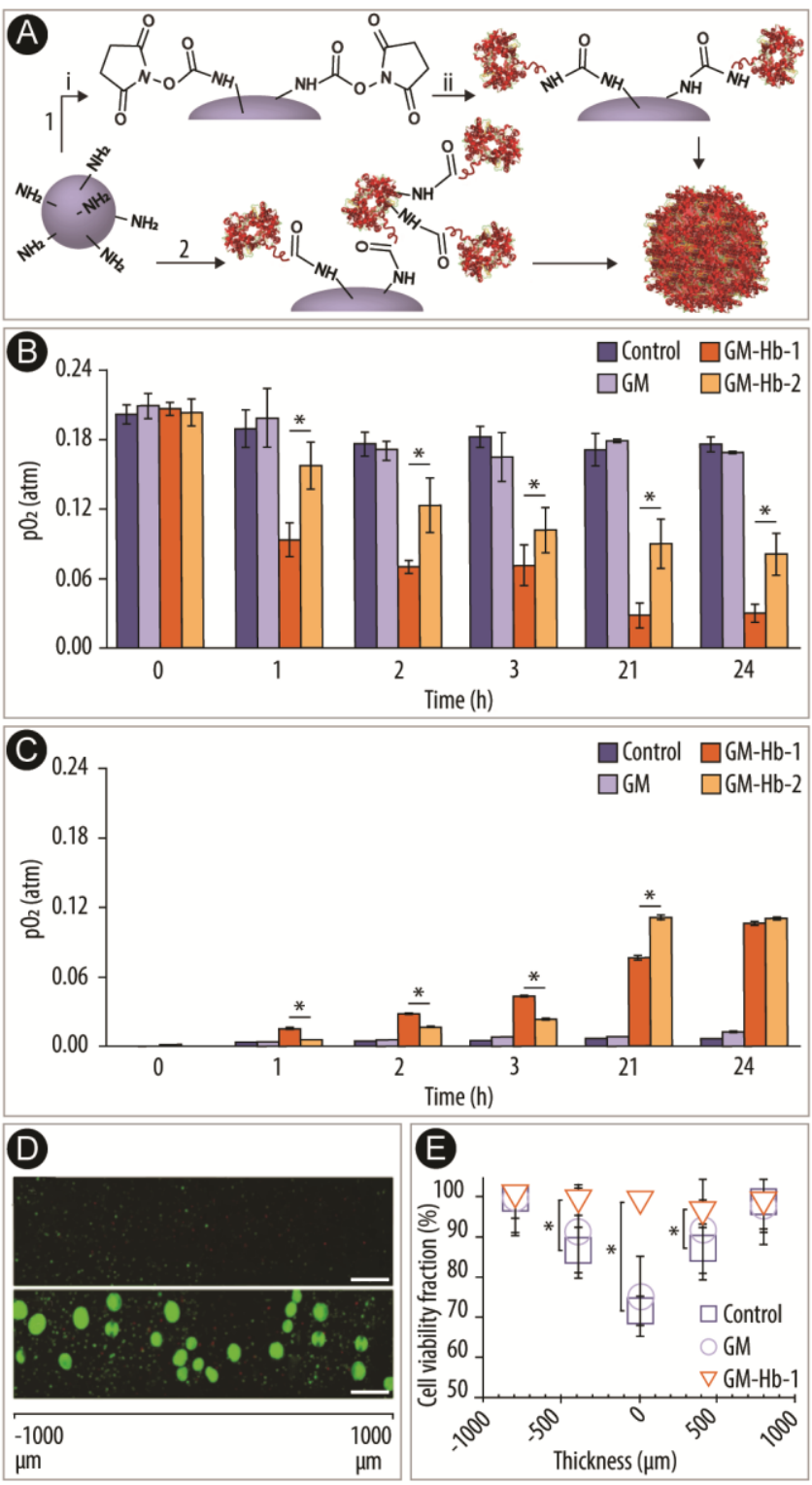

Figure 4. Synthesis and characterization of hemoglobin $(\mathrm{Hb})$ coated gelatin microparticles (GM), GM-Hb. A) Reaction scheme of GM where (1) the surface was activated with $N, N^{\prime}-$ disuccinimidyl carbonate (i) followed by $\mathrm{Hb}$ coupling (ii) using polyurethane linkage (GM-Hb1), and (2) where 1-ethyl-3-(3-dimethylaminopropyl)carbodiimide was employed to couple $\mathrm{Hb}$ to the GM using amide bond formation (GM-Hb-2). B) Oxygen uptake and release $(\mathrm{C})$ over time by measuring the partial oxygen pressure $\left(\mathrm{pO}_{2}\right)$ of cell medium without GM (control) with bare 
GM, GM-Hb-1 or GM-Hb-2. D) Fluorescence microscopy image of a 3D cell culture after $48 \mathrm{~h}$ of incubating cells only (top) and cells with embedded GM-Hb-1 (bottom). The green and red spots depict living and dead cells, respectively. GM-Hb-1 appear as big green circles. Scale bars of $100 \mu \mathrm{m}$. E) Cell viability fraction in the 3D cell culture after $48 \mathrm{~h}$ of incubating cells only, cells with bare GMs, and cells with GM-Hb-1. * $\mathrm{p}<0.01$. Adapted with permission from [91]. Copyright 2016 John Wiley and Sons. 

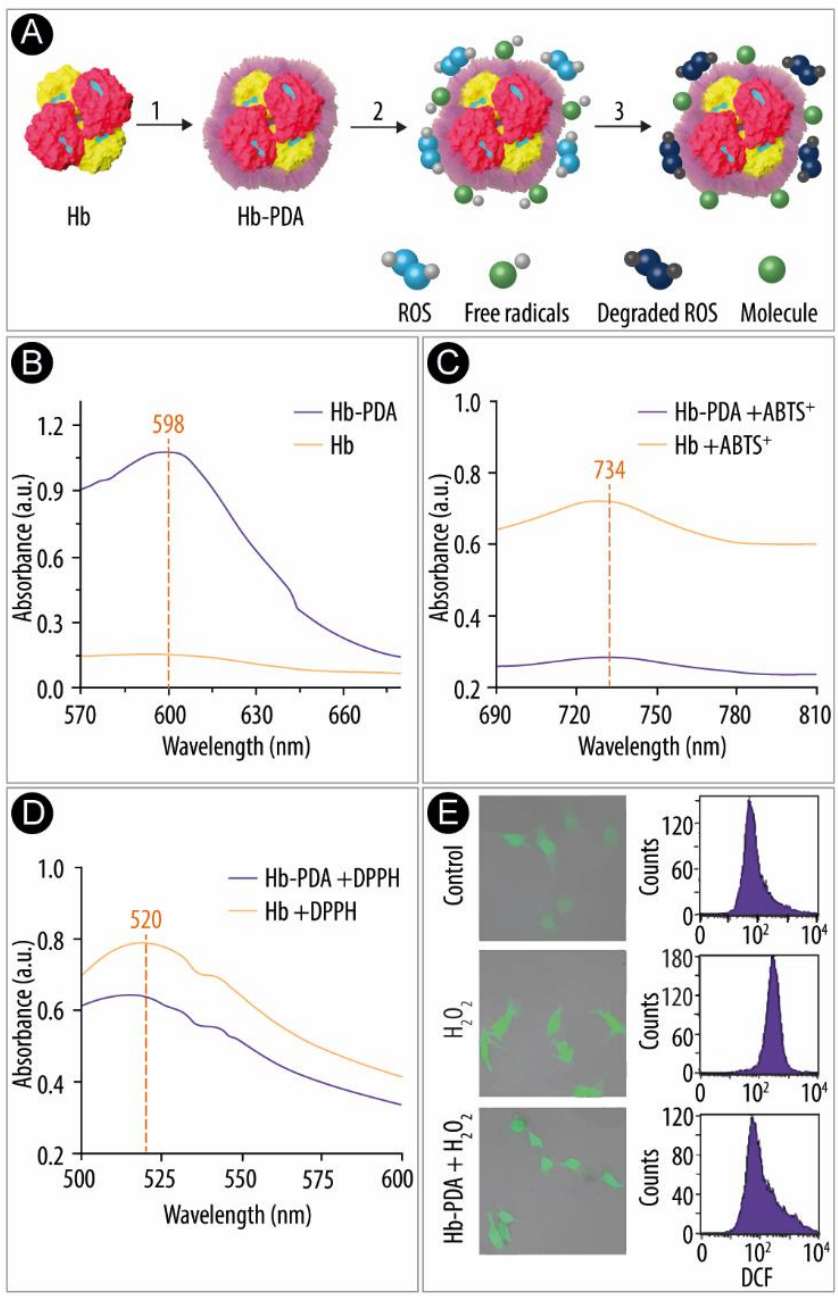

Figure 5. Oxidative protection of hemoglobin $(\mathrm{Hb})$ and reactive oxygen species (ROS) scavenging by a polydopamine (PDA) coating. A) Schematic illustration of Hb coated with PDA (1) which, upon being in contact with free radicals and ROS, (2) get reduced by the PDA coating thus preserving Hb's oxygen-carrying capacity (3). B) UV-vis absorption spectra of 2,4,6tripyridyl-s-triazine (TPTZ) incubated with $\mathrm{Hb}-\mathrm{PDA}$ and $\mathrm{Hb}$ only. The peak at $598 \mathrm{~nm}$ corresponds to ferrous-TPTZ. C) A 2,2-azio-bis(3-ethylbenzthiazoline-6-sulfonic acid) (ABTS ${ }^{+}$) solution, with a characteristic peak at $734 \mathrm{~nm}$, incubated with Hb-PDA and Hb only. D) A 2,2- 
diphenyl-1-picrylhydrazyl (DPPH) solution, with a characteristic peak at $520 \mathrm{~nm}$, incubated with $\mathrm{Hb}-\mathrm{PDA}$ and with $\mathrm{Hb}$ only. E) Intracellular ROS scavenging activity of $\mathrm{Hb}-\mathrm{PDA}$ in $\mathrm{H}_{2} \mathrm{O}_{2}-$ induced damaged cells employing dichlorofluorescein-diacetate (DCF) as fluorescent probe for ROS activity. Overlay of bright field and fluorescence microscopy images (right panel) and the corresponding flow cytometry histograms (left panel) of cells only (control, top image), cells incubated with $\mathrm{H}_{2} \mathrm{O}_{2}$ (middle image) and cells incubated with both $\mathrm{H}_{2} \mathrm{O}_{2}$ and Hb-PDA (bottom image). Adapted with permission from [117]. Copyright 2017 American Chemical Society. 


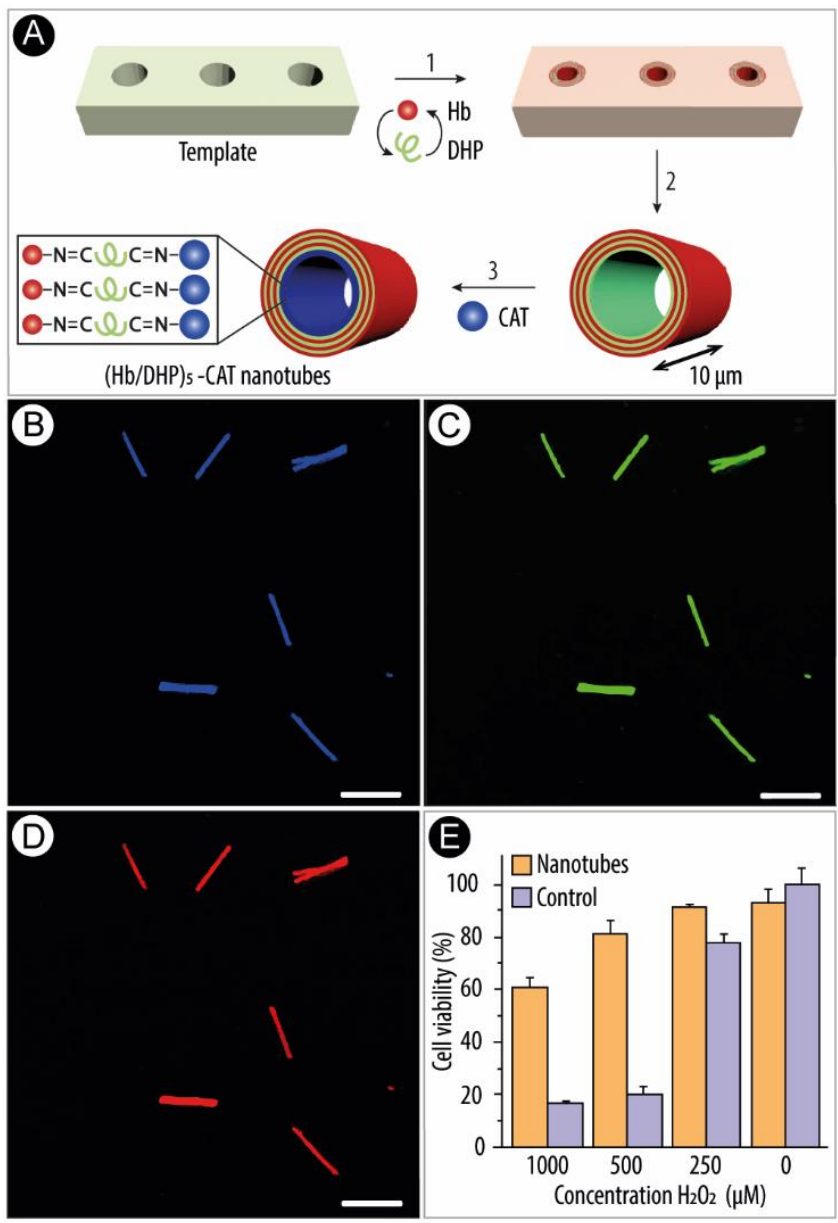

Figure 6. Hemoglobin (Hb)-based nanotubes for oxidative stress treatment. A) The nanotube fabrication starts with a sacrificial template containing $400 \mathrm{~nm}$-sized pores through which $\mathrm{Hb}$ and dialdehyde heparin (DHP) are deposited in alternating layers (1). The assembly is then followed by plasma cleaning and dissolution of the template (2) to obtain nanotubes which are then coated with catalase (CAT) on the inner wall (3). Confocal laser scanning fluorescence images of the as-prepared Hb-based nanotubes excited at 405 and $488 \mathrm{~nm}$ and read at 460-490 $\mathrm{nm}(\mathrm{B}), 510-540 \mathrm{~nm}(\mathrm{C})$ and $570-600 \mathrm{~nm}(\mathrm{D})$. Scale bars of $10 \mu \mathrm{m}$. E) Cell viability readings of HepG-2 cells incubated with decreasing amounts of oxygen peroxide $\left(\mathrm{H}_{2} \mathrm{O}_{2}\right)$ in the presence or 
absence of the CAT-loaded Hb-based nanotubes. Adapted with permission from [129]. Copyright 2013 American Chemical Society. 

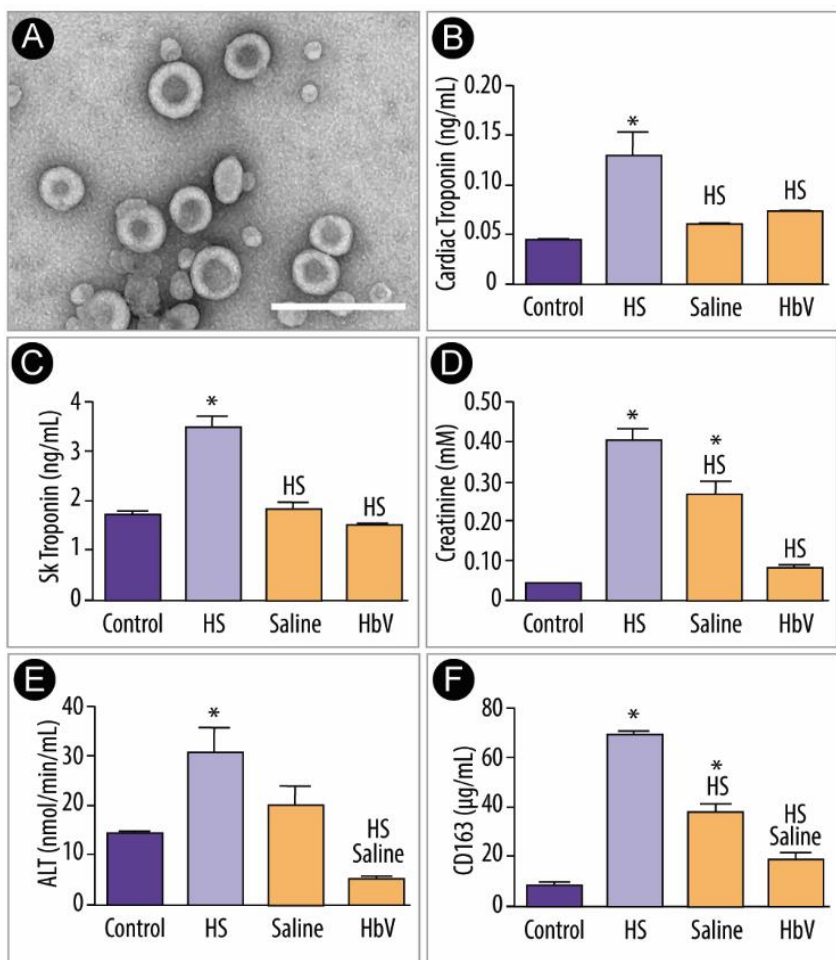

Figure 7. Hemoglobin (Hb)-loaded vesicles (HbVs) in a hemorrhagic shock model. A) Electron microscopy image of HbVs. Scale bar of $500 \mathrm{~nm}$. The effect of HbVs resuscitation on tissue toxicity measured by plasma levels of cardiac troponin (B), skeletal muscle troponin (C), creatinine (D), alanine transaminase (ALT) $(\mathrm{E})$, and CD163 receptor $(\mathrm{F})$. Plasma levels were recorded at baseline (control), after 6 hours of induction of the hemorrhagic shock (HS) and after saline or $\mathrm{HbVs}$ resuscitation. $\mathrm{p}<0.05$ vs. control ${ }^{*}$, HS and saline. Adapted with permission from [153]. Copyright 2016 Elsevier B.V. 


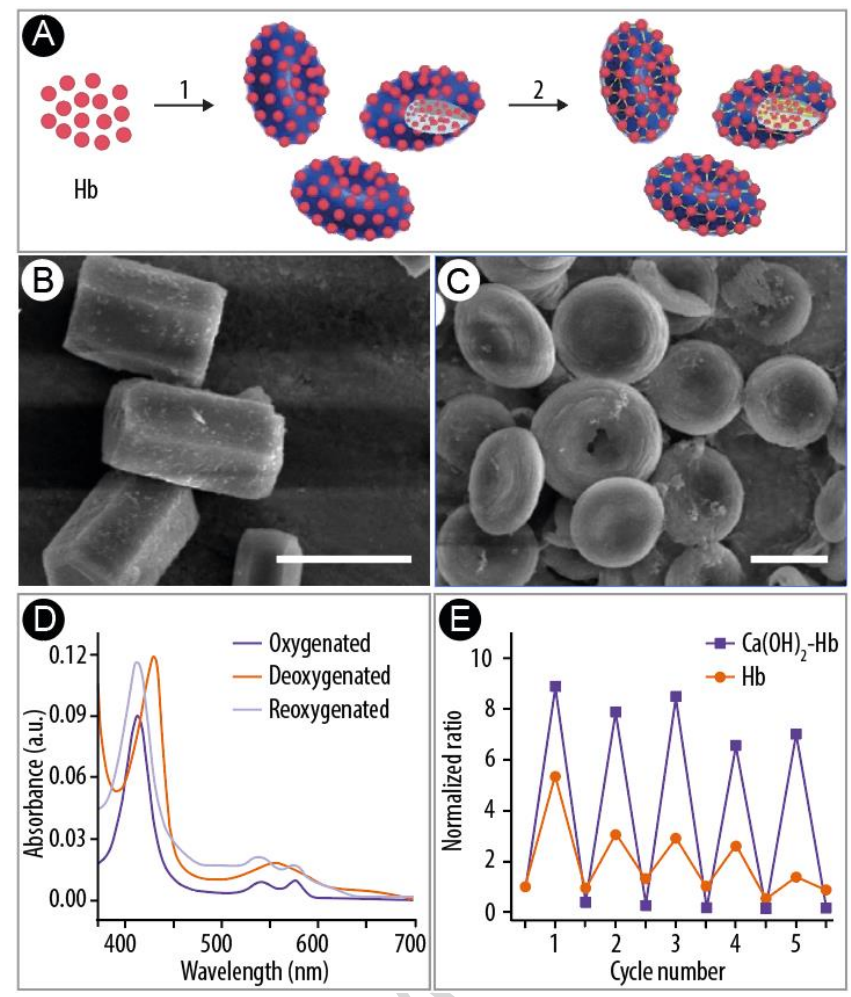

Figure 8. Biconcave hemoglobin (Hb)-based microparticles. A) Schematic illustration showing $\mathrm{Hb}$ co-precipitation with dextran and calcium chloride (1) to form calcium hydroxide $\left(\mathrm{Ca}(\mathrm{OH})_{2}\right)$ $\mathrm{Hb}$ microparticles, which are then cross-linked with glutaraldehyde (2). Scanning electron microscopy images of pure $\mathrm{Ca}(\mathrm{OH})_{2}(\mathrm{~B})$ and $\mathrm{Ca}(\mathrm{OH})_{2}-\mathrm{Hb}$ microparticles $(\mathrm{C})$. Scale bars of 5 $\mu \mathrm{m}$. D) UV-vis absorbance spectra of oxygenated, deoxygenated, and reoxygenated $\mathrm{Ca}(\mathrm{OH})_{2}-\mathrm{Hb}$ microparticles. E) Normalized ratio of differential pulse voltammetry peak currents of $\mathrm{Ca}(\mathrm{OH})_{2}$ $\mathrm{Hb}$ microparticles and free $\mathrm{Hb}$ to several cycles of oxygen and nitrogen treatment. Adapted with permission from [168]. Copyright 2017 Elsevier B.V. 


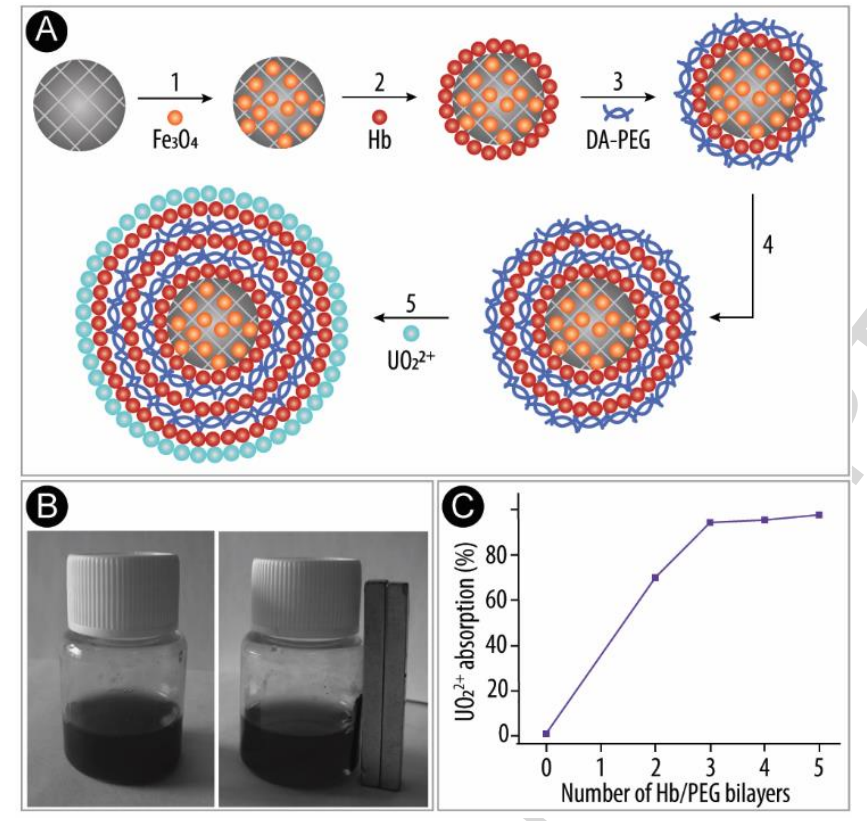

Figure 9. Magnetic hemoglobin $(\mathrm{Hb})$-based microparticles for the removal of radioactive uranyl ion $\left(\mathrm{UO}_{2}{ }^{2+}\right)$. A) Schematic illustration of the microparticles assembly. The Hb-based microparticles are fabricated by encapsulating iron oxide $\left(\mathrm{Fe}_{3} \mathrm{O}_{4}\right)$ nanoparticles into porous calcium carbonate particles (1) followed by the alternating deposition of $\mathrm{Hb}(2)$ and dialdehyde poly(ethylene glycol) (DA-PEG) layers (3). Upon addition of the desired number of bilayers (4) the microparticles are used to deplete $\mathrm{UO}_{2}{ }^{2+}(5)$. B) Images showing the $\mathrm{Fe}_{3} \mathrm{O}_{4}$-loaded $(\mathrm{Hb} / \mathrm{PEG})_{5}$ microparticles in $\mathrm{UO}_{2}{ }^{2+}$-contaminated blood (left), and the magnetically assisted separation process (right). C) Percentage of $\mathrm{UO}_{2}{ }^{2+}$ absorption by the $\mathrm{Fe}_{3} \mathrm{O}_{4}$-loaded (Hb/PEG) microparticles depending on the number of deposited Hb/PEG bilayers. Reprinted with permission from [169]. Copyright 2014 John Wiley and Sons. 


\section{Highlights}

- Overview of the recent achievements for the creation of artificial red blood cells

- Artificial red blood cells are crucial due to the short lifetime of donor blood

- Artificial red blood cells assembled by encapsulating or conjugating hemoglobin 